US Army Corps of Engineers ${ }_{\circledast}$ Engineer Research and Development Center

\title{
Engineering With Nature Website User Guide
}

Michael A. Clement

March 2022
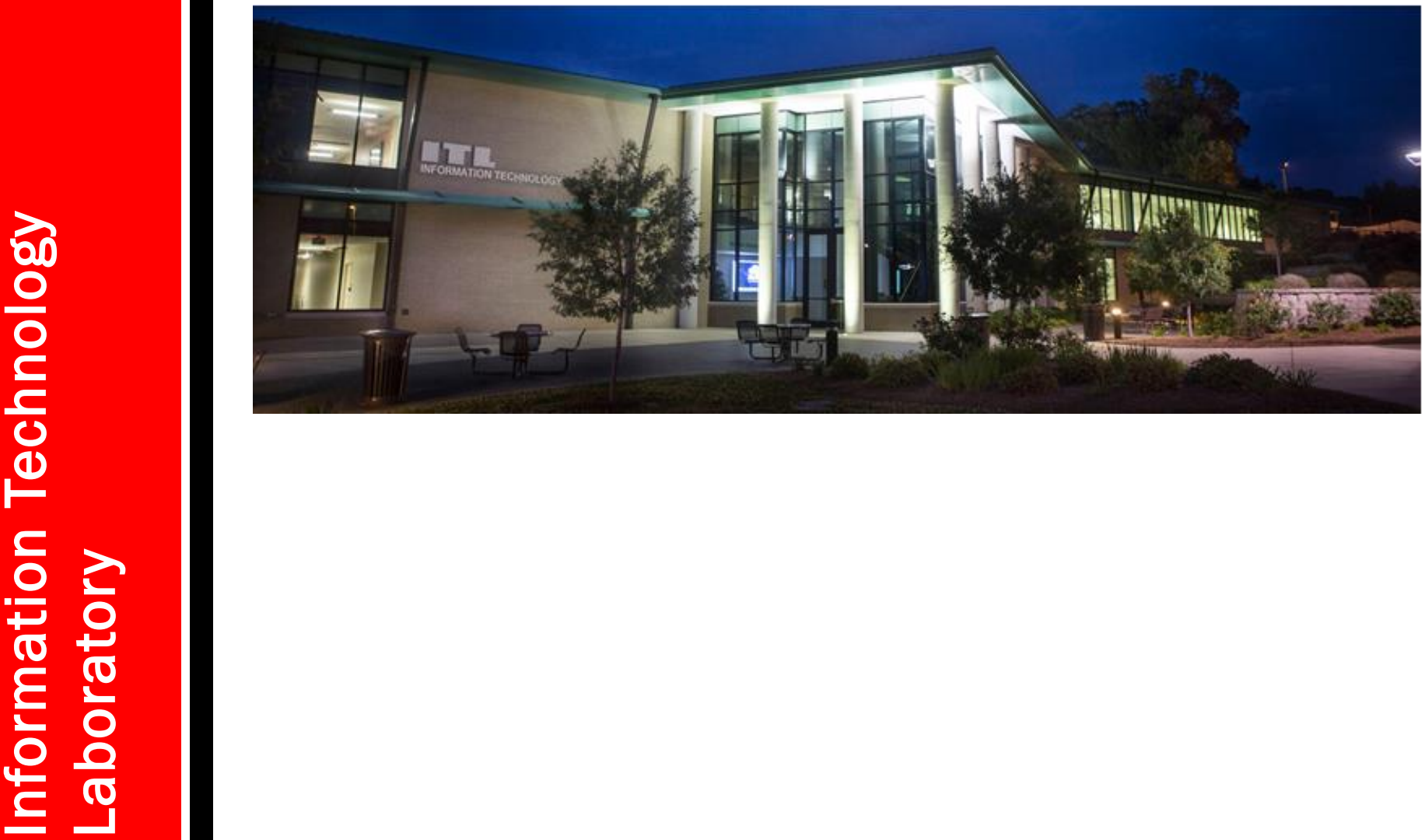
The U.S. Army Engineer Research and Development Center (ERDC) solves the nation's toughest engineering and environmental challenges. ERDC develops innovative solutions in civil and military engineering, geospatial sciences, water resources, and environmental sciences for the Army, the Department of Defense, civilian agencies, and our nation's public good. Find out more at www.erdc.usace.army.mil.

To search for other technical reports published by ERDC, visit the ERDC online library at https://erdclibrary.on.worldcat.org/discovery. 
ERDC/ITL SR-22-2

March 2022

\title{
Engineering With Nature Website User Guide
}

\author{
Michael A. Clement \\ Information Technology Laboratory \\ U.S. Army Engineer Research and Development Center \\ 3909 Halls Ferry Road \\ Vicksburg, MS 39180
}

Final Report

Approved for public release; distribution is unlimited.

$\begin{aligned} \text { Prepared for } & \text { ERDC Environmental Laboratory } \\ & \text { 3909 Halls Ferry Road } \\ & \text { Building } 3270 \\ & \text { Vicksburg MS } 39180 \\ \text { Under } & \text { Project 495371, "Engineering With Nature" }\end{aligned}$ 


\section{Abstract}

The Engineering With Nature (EWN) program is a high-profile effort that aims to deliver cost-effective, broadly beneficial solutions to natural resource and sustainability challenges across the nation. A portion of this is accomplished through the use of the EWN website, which features news, podcasts, articles, and more. The content on the EWN website serves to educate and inform hundreds of visitors monthly. This content is generated and managed by EWN team members with web development experience, as it requires manually editing the website HTML and staging changes on a development server. With the EWN website 2.0, a new website framework (WordPress) has been implemented that will save content managers time and effort by providing a front-end user interface (UI) to enable the uploading, staging, and approval of new content for the website, along with a visual refresh to herald the impending release of season 2 of the EWN Podcast. This document's purpose is to demonstrate the functionality of the new EWN website and provide instructional material for those managing content via the new EWN website.

DISCLAIMER: The contents of this report are not to be used for advertising, publication, or promotional purposes. Citation of trade names does not constitute an official endorsement or approval of the use of such commercial products. All product names and trademarks cited are the property of their respective owners. The findings of this report are not to be construed as an official Department of the Army position unless so designated by other authorized documents.

DESTROY THIS REPORT WHEN NO LONGER NEEDED. DO NOT RETURN IT TO THE ORIGINATOR. 


\section{Contents}

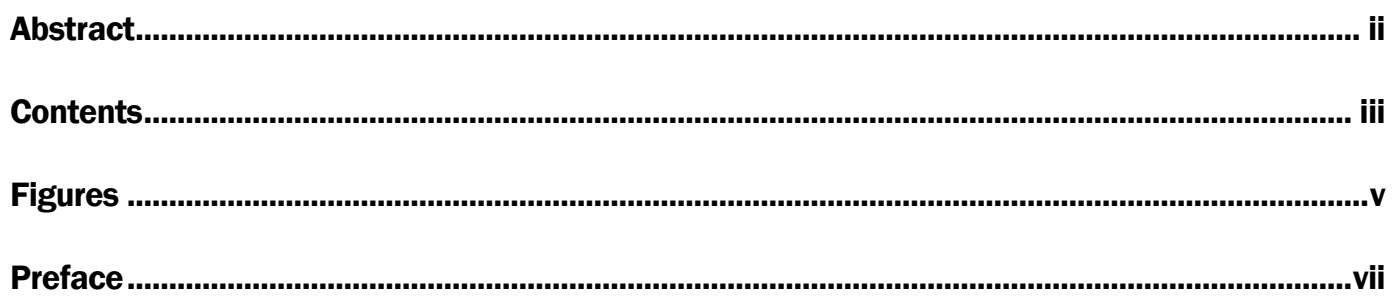

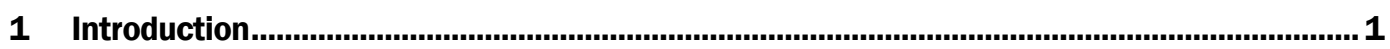

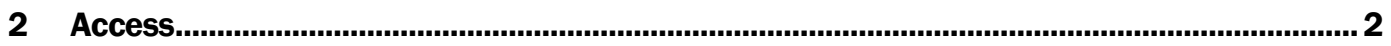

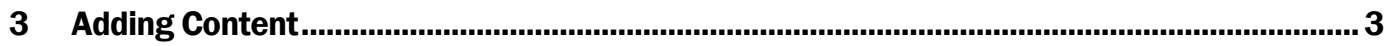

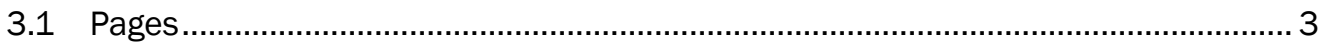

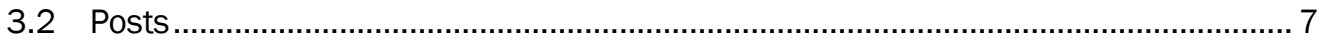

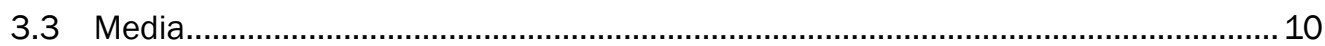

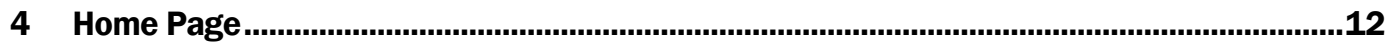

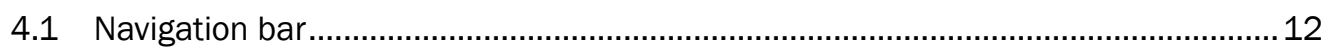

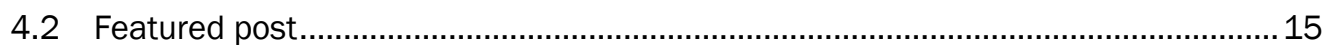

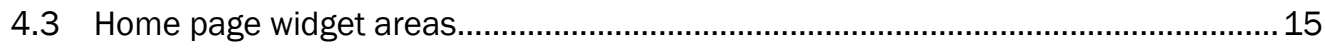

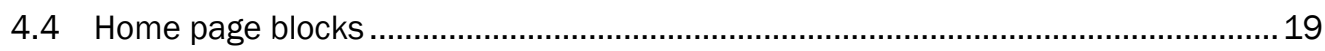

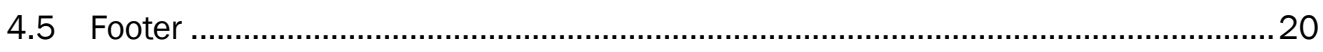

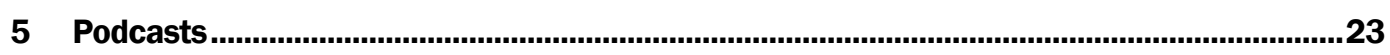

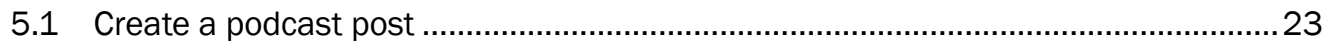

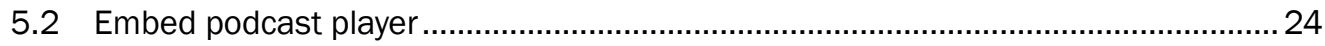

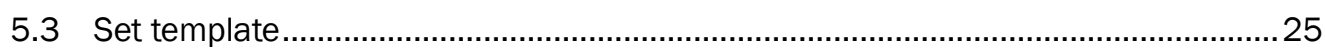

5.4 Set podcast featured image and excerpt .............................................................2 26

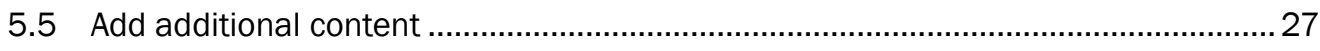

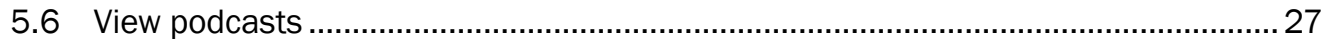

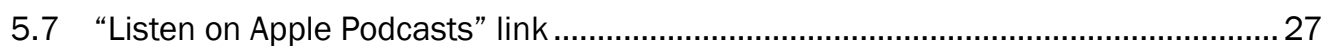

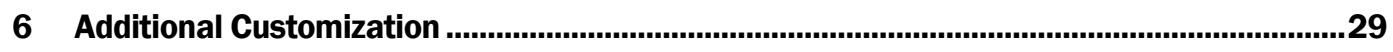

6.1 Setting custom button text on home page blocks and podcasts...............................29

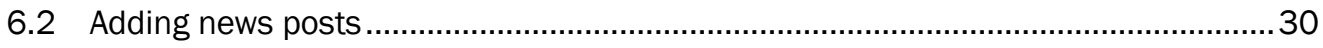

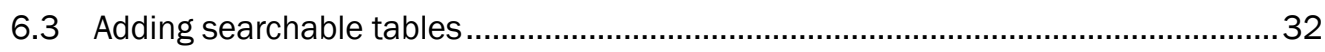

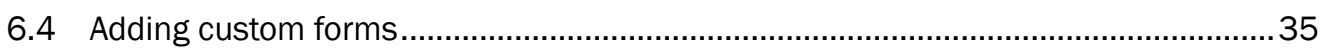

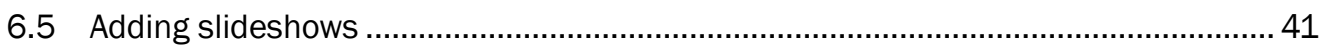

6.6 Configuring SMTP for email notifications (WP Mail SMTP plugin) ….......................44

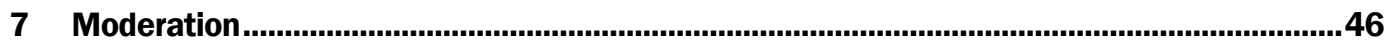

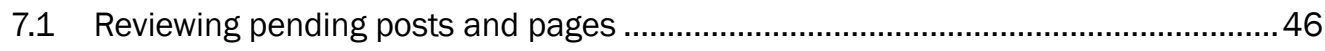

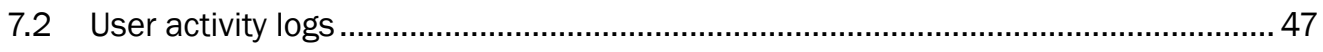

7.3 Comment moderation ............................................................................... 47 


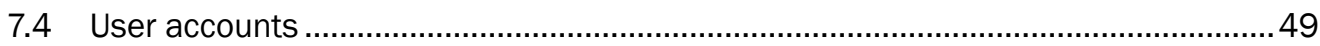

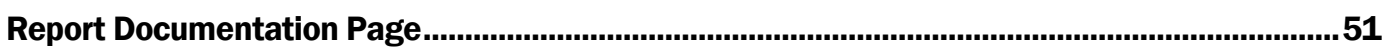




\section{Figures}

\section{Figures}

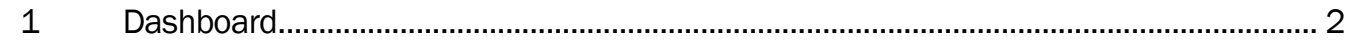

$2 \quad$ Add page

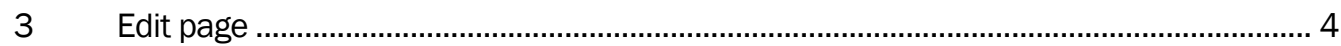

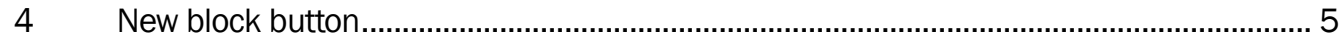

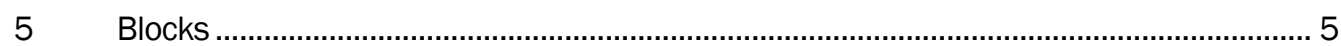

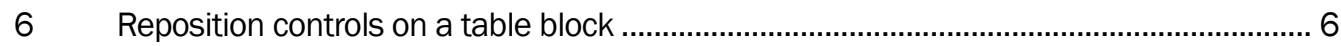

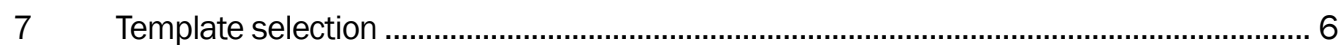

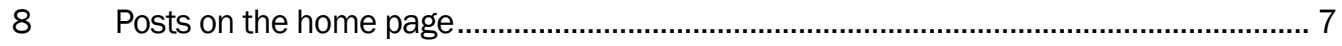

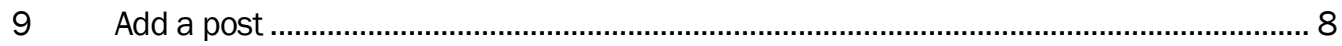

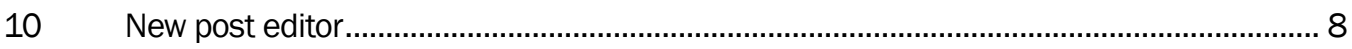

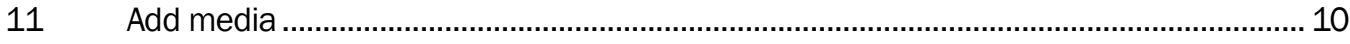

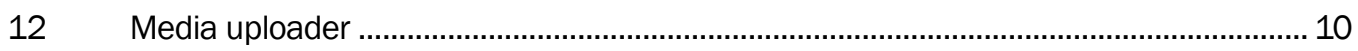

13 Media library .................................................................................................................. 11

14 EWN home page (logged-in view) ……………...................................................... 12

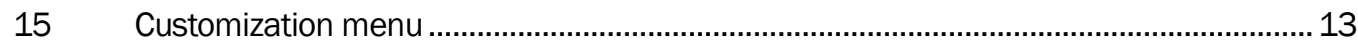

16 Primary navigation.................................................................................................. 13

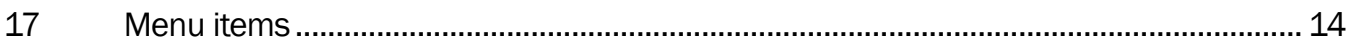

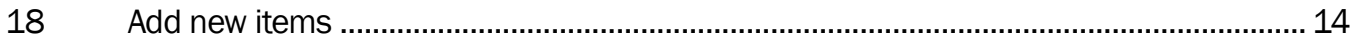

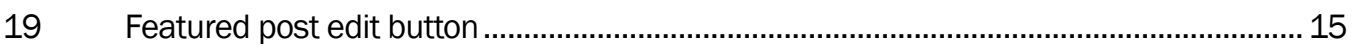

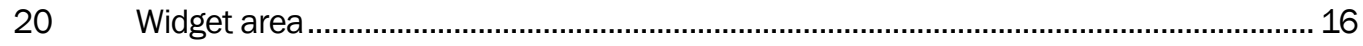

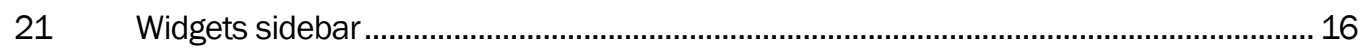

$22 \quad$ Widget selection .......................................................................................... 17

$23 \quad$ Gallery widget setup - name the gallery …………................................................. 17

$24 \quad$ Gallery widget setup-select images ........................................................................... 18

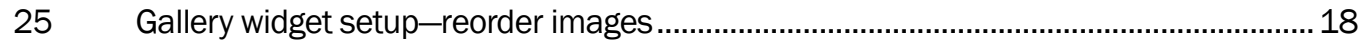

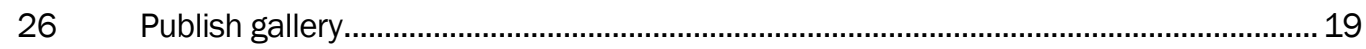

$27 \quad$ New gallery widget on home page ......................................................................... 19

$28 \quad$ Home page blocks.................................................................................................. 20

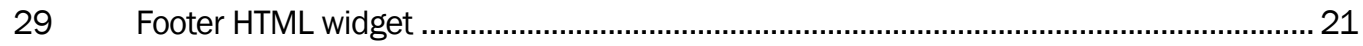

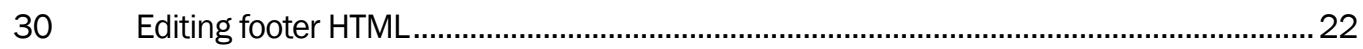

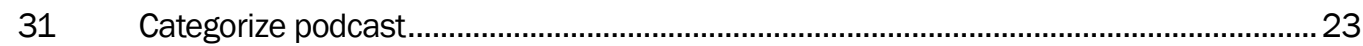

32 Add podcast season category ................................................................................. 24

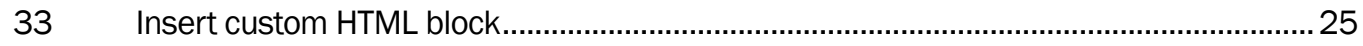

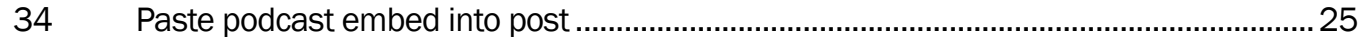

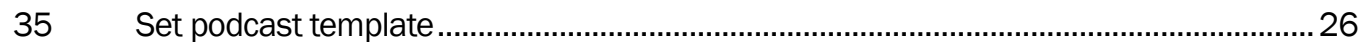

36 Podcast featured image and excerpt.................................................................................26 


\begin{tabular}{|c|c|}
\hline 7 & odcast listing........ \\
\hline 8 & pdating the Apple podcast embed HTML. \\
\hline & 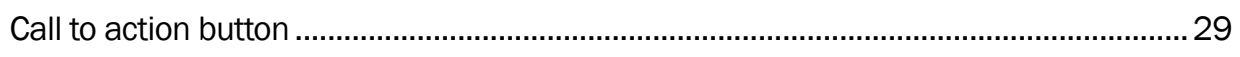 \\
\hline & Customize text and URL of call-to-action button..... \\
\hline & News section on home page ........ \\
\hline & 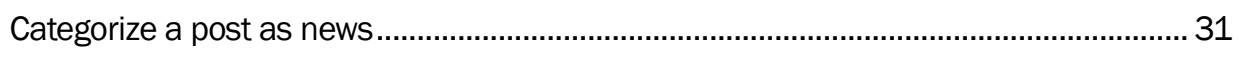 \\
\hline & Table example: "Workshops \& Presentations".. \\
\hline & All tables .................... \\
\hline & Create new table...... \\
\hline & Edit a table .... \\
\hline 47 & Embed table shortcode in a post or page...... \\
\hline 48 & Example: Atlas Order Form ............ \\
\hline 49 & Registration Magic tool.. \\
\hline 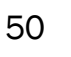 & Create a new form ......... \\
\hline 51 & Name a new form ......... \\
\hline 2 & Configure form fields..... \\
\hline 53 & Adding fields to $a$ form ............ \\
\hline 54 & Form field customization ........... \\
\hline 55 & 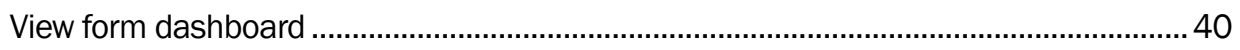 \\
\hline 56 & Form dashboard .............. \\
\hline 57 & Add form shortcode to page.......... \\
\hline 58 & Create new slideshow ... \\
\hline 59 & Add to slideshow......... \\
\hline 60 & Add slides to slideshow...... \\
\hline 61 & Save slideshow .......................... \\
\hline 62 & Copy slideshow shortcode...... \\
\hline 63 & Slideshow in a post ..... \\
\hline 64 & Configure SMTP mail settings .. \\
\hline 65 & Mark post or page as pending review \\
\hline 66 & View pending posts .. \\
\hline 6 & Activity log........... \\
\hline 68 & 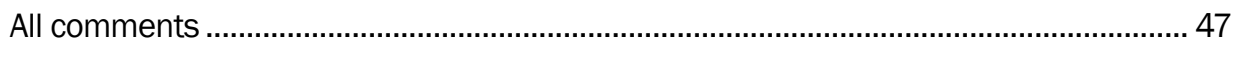 \\
\hline 69 & Comment settings ... \\
\hline & t moderation blacklist. \\
\hline & View all users \\
\hline
\end{tabular}




\section{Preface}

This study was conducted for the Engineer Research and Development Center-Environmental Laboratory under Project 495317, "Engineering With Nature," Civil Direct Funding Account Code U4376841.

The work was performed by the Scientific Software Branch (SSB) of the Computational Science and Engineering Division (CSED), U.S. Army Engineer Research and Development Center-Information Technology Laboratory (ERDC-ITL). At the time of publication, Mr. Timothy W. Dunaway was chief, SSB; Dr. Jeff Hensley was chief, CSED. The deputy director of ERDC-ITL was Ms. Patti S. Duett, and the director was Dr. David A. Horner.

COL Teresa Schlosser was the commander of ERDC, and Dr. David Pittman was the director. 


\section{Introduction}

The Engineering With Nature (EWN) website serves as a key distribution point for critical information surrounding the EWN family of endeavors. Through the EWN website, hundreds of people are able to get the latest information about what's happening in the EWN world.

This guide will provide an overview of the content management features of the Engineering With Nature WordPress site, along with detailed information about what functionality is contained in this web application.

Throughout this document, the reader will become more familiar with the various types of content that are hosted on the Engineering With Nature site, including podcasts, pages, posts, and more.

Note: This web application requires the use of Google Chrome, Mozilla Firefox, or a similar modern browser in order to function properly. These browsers can be obtained from their respective sources:

\section{Chrome:}

https://www.google.com/chrome

\section{Firefox:}




\section{Access}

This section gives details regarding accessing the Engineering With Nature site $(\mathrm{EWN})$ and a high-level overview of the components contained within.

For users with administrator accounts, the user must navigate to https://ewn.erdc.dren.mil/wp-admin using a modern web browser to begin adding and managing content on EWN. Upon doing so, the user will be presented with a login prompt. After entering the login information, the user will be taken to the EWN 2.0 Dashboard (Figure 1).

Figure 1. Dashboard.

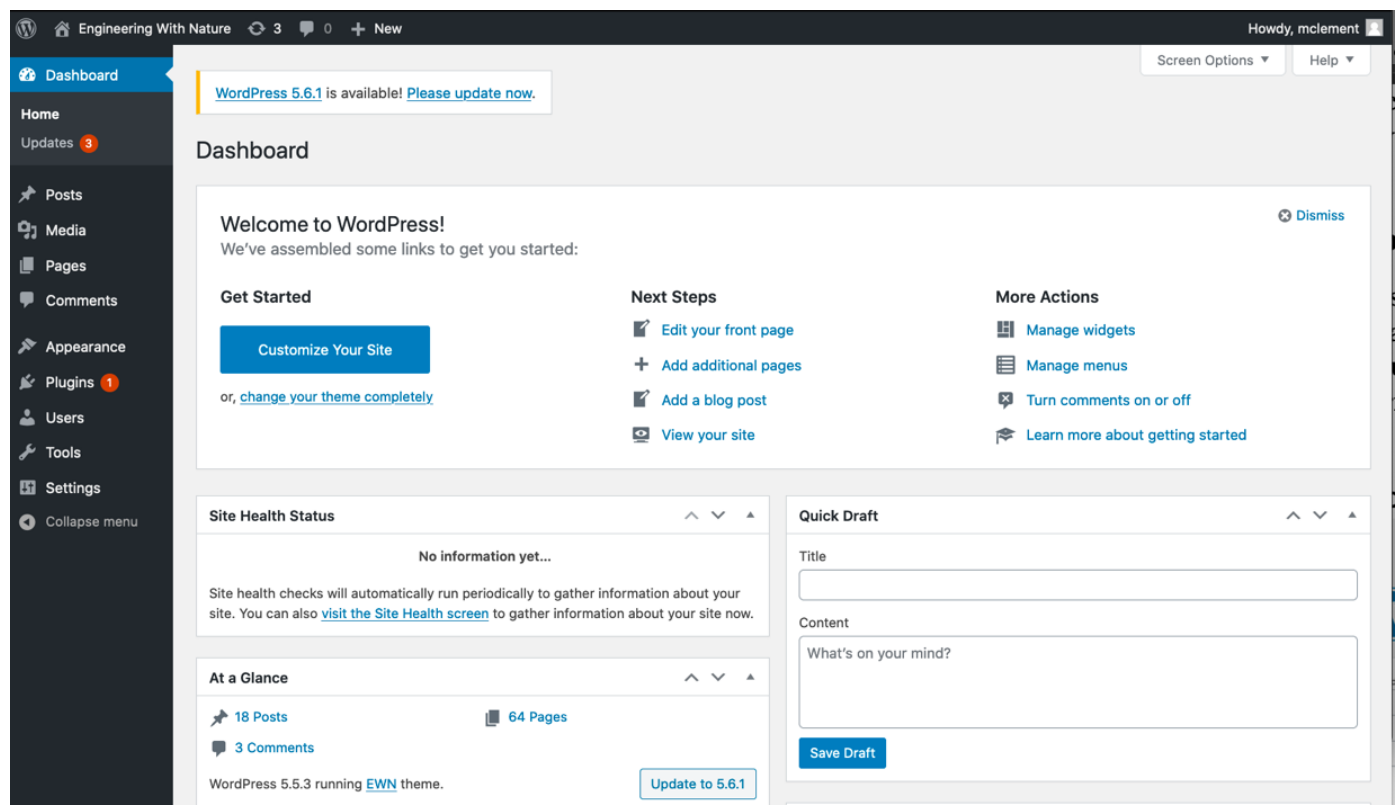

Users without administrator accounts should navigate to https://ewn.erdc.dren.mil/wp-login.php and login using their username and password. 


\section{Adding Content}

EWN has multiple types of content that can be created or uploaded to the site. The most significant types of content are Pages, Posts, and Media. Over the course of this section, these types will be elaborated on, and brief descriptions of how to add and manage content will be explained.

\subsection{Pages}

A page is a new page on the website. It can contain text and multimedia content such as images and videos. Pages can be organized in a hierarchy so that a page can be a parent page with subpages below it, providing structure to the site.

To add a page, first log in by going to https://ewn.erdc.dren.mil/wp-login.php. Once there, a page can be added by clicking the + New button and selecting Page (Figure 2).

Figure 2. Add page.

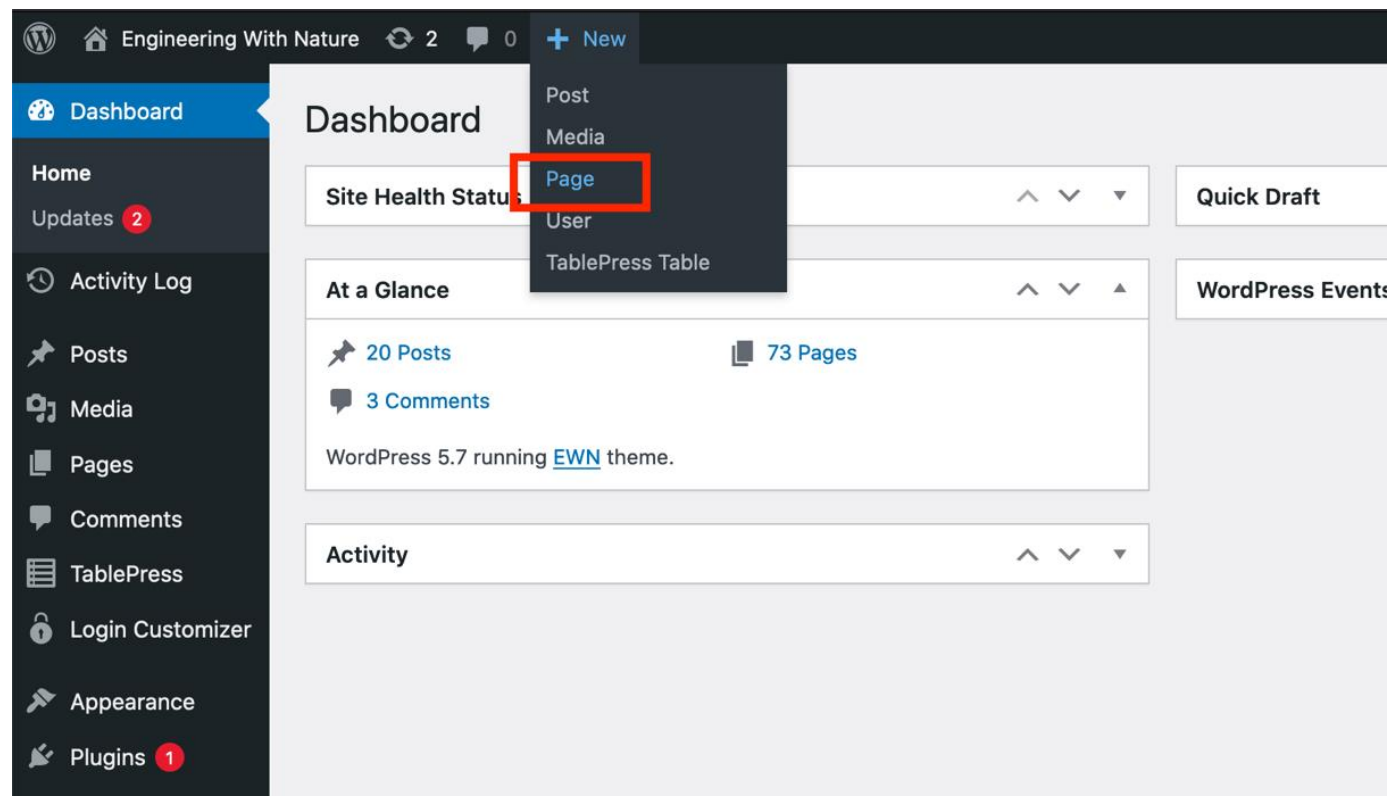

Clicking this will yield the page editor, where content and settings for the page can be configured (Figure 3). 
Figure 3. Edit page.

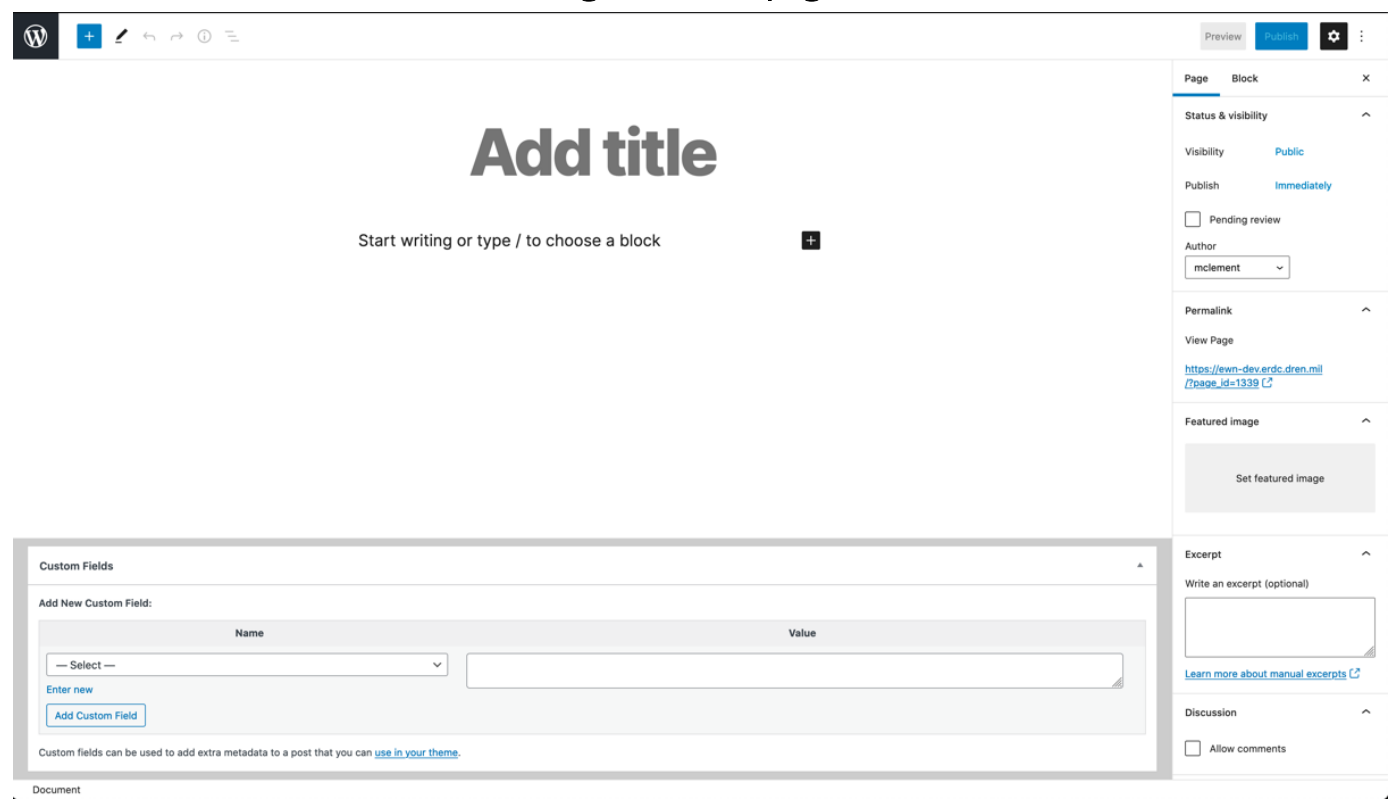

This screen has several areas of interest. In the center of the screen is the page content. To add text to the page, simply begin typing in the title or body area.

On the right side of the screen are advanced controls for the page that handle items like the page's featured image (thumbnail), whether user comments are permitted, which visual style template to use for the page, and more.

At the bottom of the page are Custom Fields. These are used to provide additional functionality in specific instances. Custom Fields will be discussed in more detail in Section 6.1.

In addition to plain text, pages can hold Blocks. Blocks enable adding images and videos to pages as well as special functionality within the page, such as stylized quotations, tables, and even custom HTML. Blocks are how all nontext content is added to a page.

To add a block to the page, click the + in the top left, and select the desired block (Figure 4 and Figure 5). 
Figure 4. New block button.

(10)

\section{Add title}

Start writing or type / to choose a block

$+$

Figure 5. Blocks.

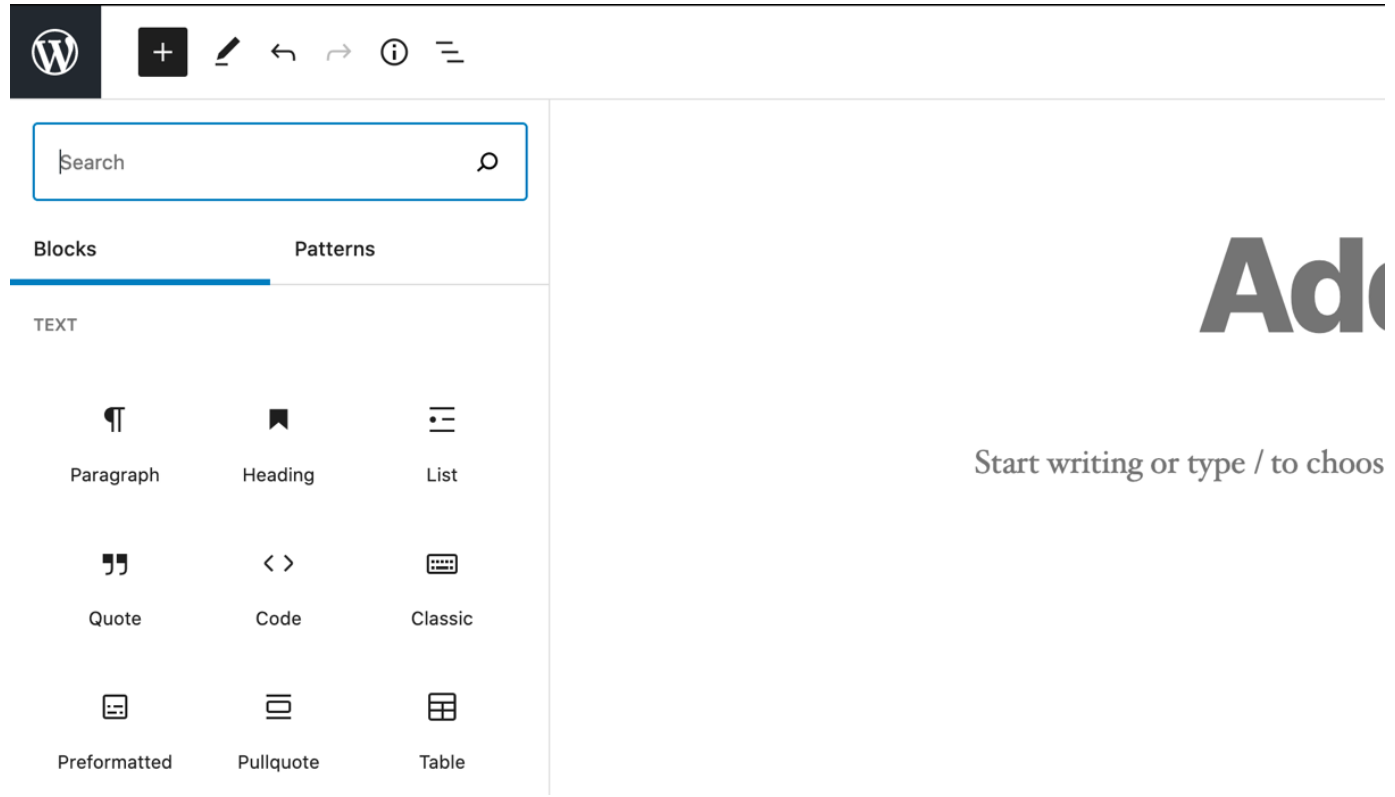

Clicking a block in this menu will automatically add it to the page, where it can be further customized. Blocks can also be moved up and down the page to reposition them as needed. To reposition a block, first add it to the page, then click the block. This will open the block's menu. With the block menu open, click the arrows on the left-hand side until it is positioned appropriately (Figure 6). 
Figure 6. Reposition controls on a table block.

(1) $\equiv$

\section{Demo Page}

This is a demo page.

\begin{tabular}{|c|c|c|c|c|c|c|c|c|c|}
\hline 田： & $\hat{\imath}$ & 트 & 田 & $\equiv$ & B & 1 & $\leftrightarrow$ & $\checkmark$ & : \\
\hline
\end{tabular}

Write caption...

$+$

There are blocks for adding images, videos, and more. The block menu is searchable, which makes it easy to find the necessary blocks for the task at hand.

In order to ensure consistent style across the website, all new pages should have the correct Template selected. The template can be selected in the sidebar on the right-hand side of the editor (Note: If the sidebar is collapsed, expand it by clicking the gear icon in the top-right corner of the editor). All basic pages on EWN should use the EWN Page Template (Figure 7).

Figure 7. Template selection.

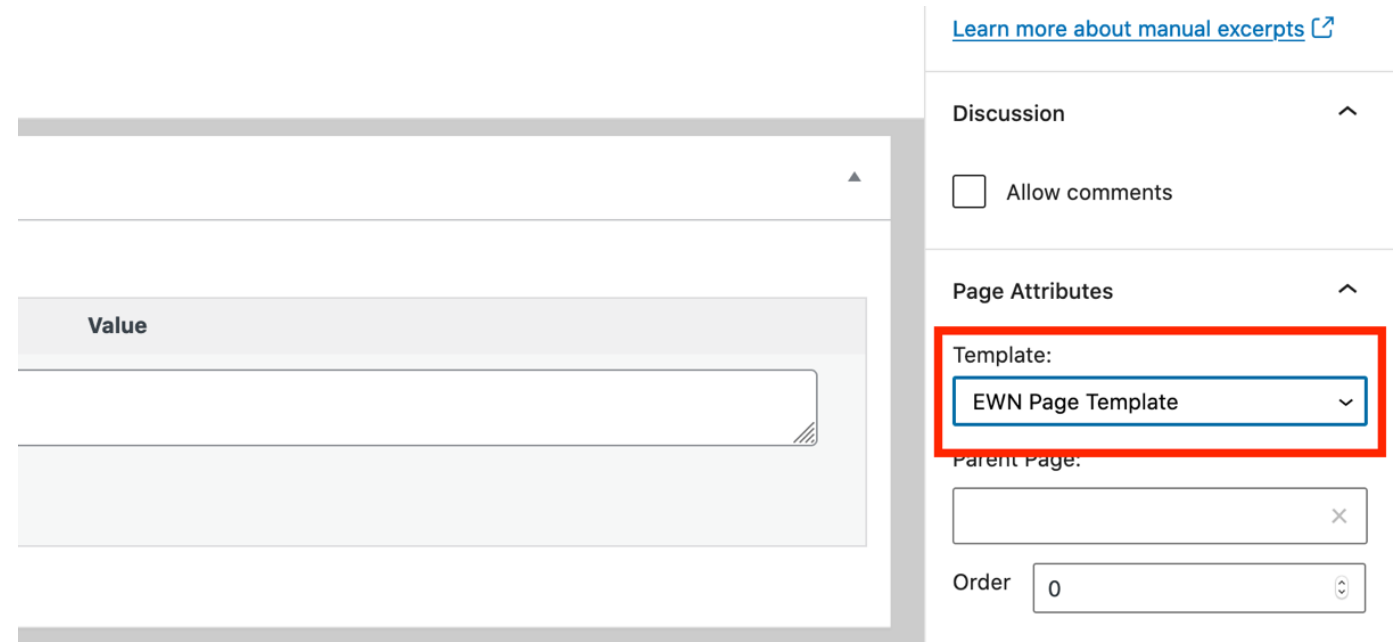


To save progress on a page while editing, click the Save Draft button in the top right of the editor. When a page is ready to be posted publicly, click the big, blue Publish button in the top right.

\subsection{Posts}

Posts are similar to pages. The main difference is in where they are displayed on the site. A page may contain multiple posts (like a blog), or a post may be the only item on a page.

EWN uses posts for special content types, such as the featured item and subsections on the home page, podcasts, and more. In Figure 8 below, two posts on the home page are highlighted in red:

Figure 8. Posts on the home page.

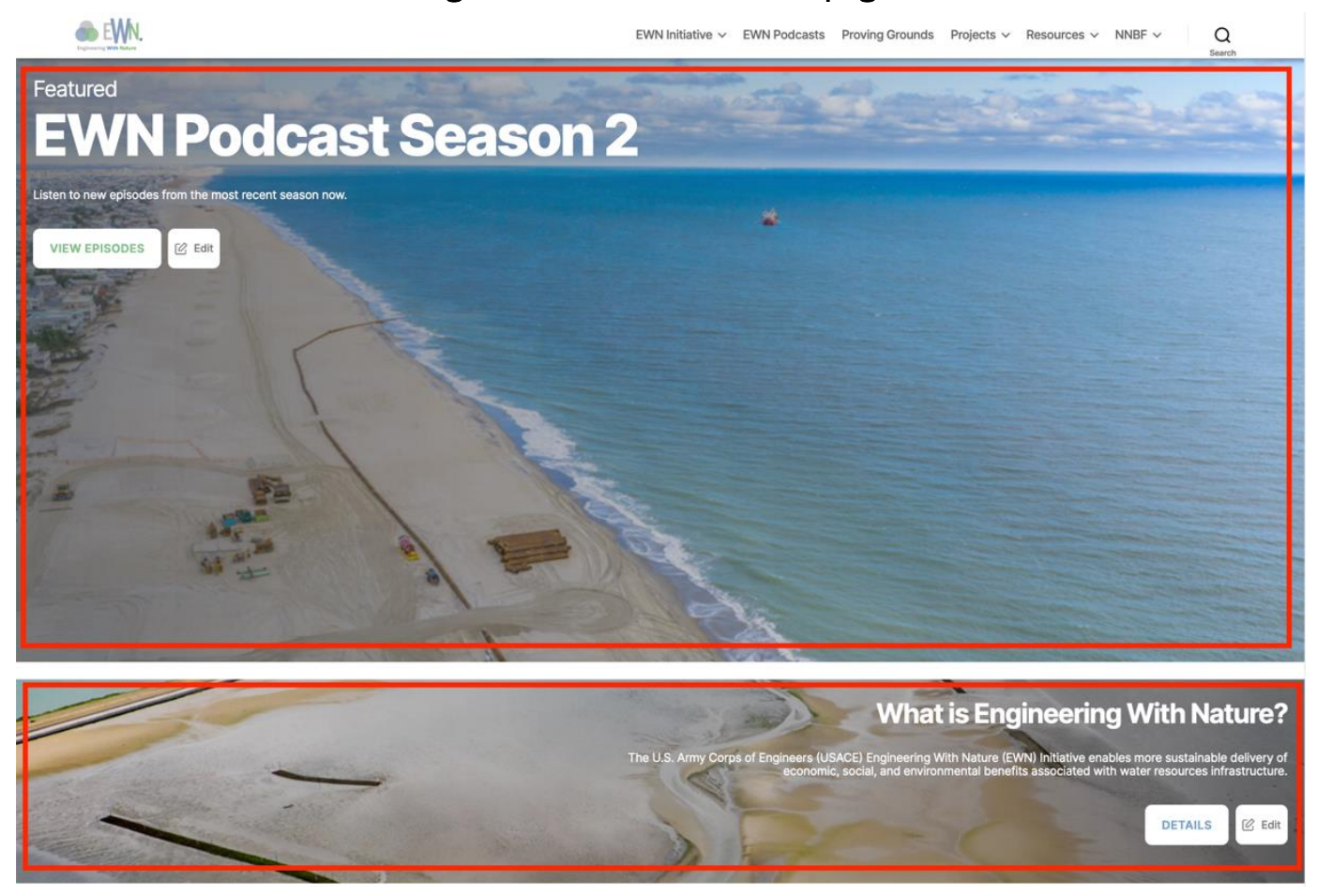

Posts are added and edited just like pages. From the admin interface (https://ewn.erdc.dren.mil/wp-admin), click the + New button and select post (Figure 9). 
Figure 9. Add a post.

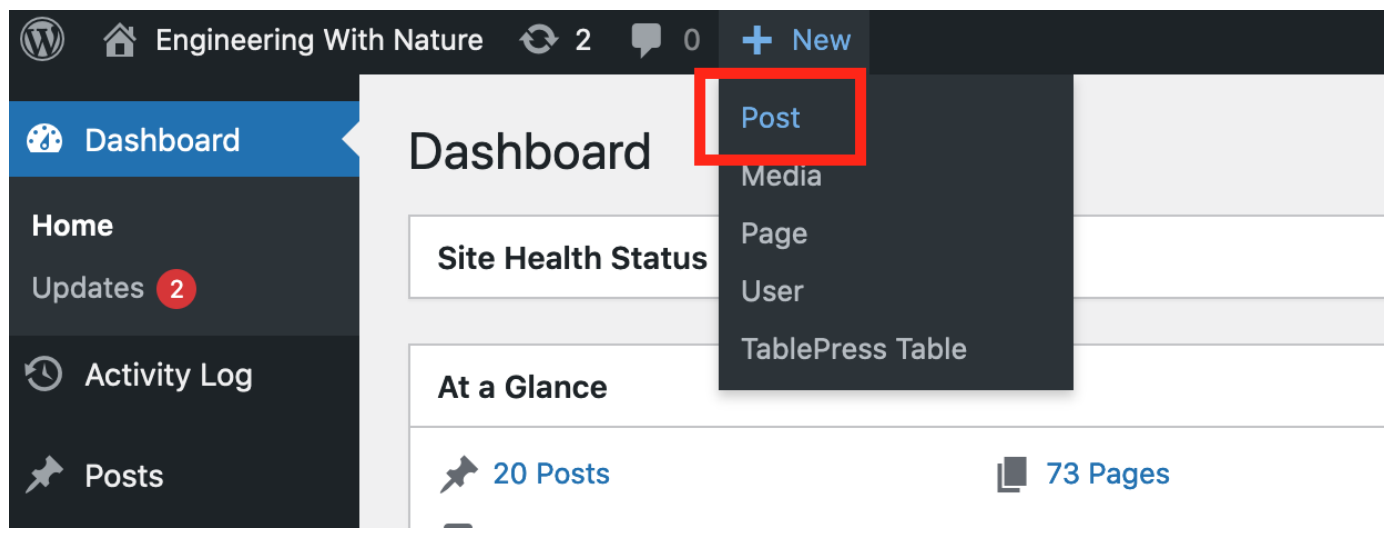

Upon doing so, you will be greeted by the new post editor screen (Figure 10).

(1)

Figure 10. New post editor.

\section{Add title}

Start writing or type / to choose a block

+

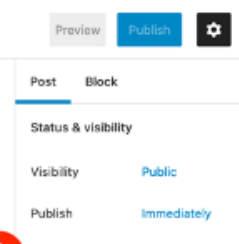

(1)

$\square$ Pending review

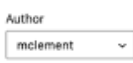

Permalink

View Post

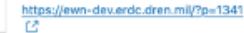

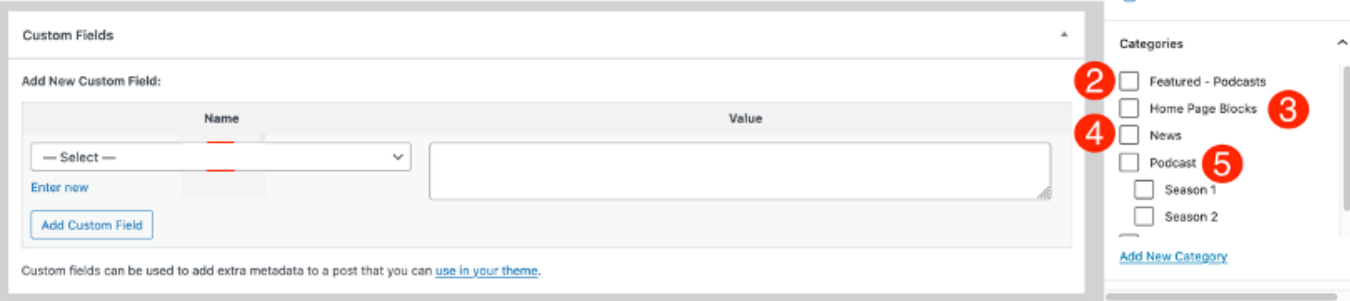

Editing a post works just like editing a page (see Section 3.1 for more details). Where posts differ from pages is in how they are configured and displayed.

There are five main post configurations used across the EWN site and shown in Figure 10 in red. They are

- Stick to the top of the blog": This checkbox (found in the right-hand sidebar of the post editor) designates a post as the main featured content 
at the top of the home page. When a post is configured this way, its Featured Image, Title, and Excerpt are displayed on the home page along with a button labeled "More" that links to the post. The button may be configured to have different text and a different link destination if desired (for more on configuring that button, see Section 6.1).

2. "Featured-Podcasts": Posts that have this category checked will be displayed in the main featured section of the Podcasts page. To configure a post to be featured on the Podcasts page, click the gear icon in the top right of the editor to open the post editor sidebar. From there, locate the Categories section and select Featured-Podcasts. (Note: If another post is already featured on the podcast screen you must first uncheck the featured box on that post to enable a new post to become featured).

3. "Home Page Blocks": Posts that have this category checked will be displayed on the home page below the main featured section. These posts are displayed in the same manner as the main featured item, meaning their Featured Image, Title, and Excerpt are displayed along with the More button that links to the full post. (Note: These posts are displayed on the home page in the order they were most recently edited. So, the last post to be edited will display at the top of the section, and on down the list. To reorder, simply edit the individual posts in the reverse order you want them to display).

4. "News": Posts that have this category checked will be displayed on the home page in the News section. These posts are shown with their Title and Excerpt only. Up to five posts tagged as News will be shown on the home page, with the rest being available on the news archive page. For more on the News Section, see Section 6.2.

5. "Podcast": Posts that have this category checked will be displayed on the podcasts page. Additionally, podcast posts must have a Season category selected to ensure proper grouping on the podcasts page. Posts that have the Podcast category must also use the "Podcast Episode Template" template. For more on adding podcasts, see Section 5 .

To save progress on a post while editing, click the Save Draft button in the top right of the editor. When a post is ready to be posted publicly, click the big, blue Publish button in the top right. 
If you do not want to publish immediately, click Save draft, located to the left of the Publish button. Drafts are found in the admin interface and can be edited or published at any time.

\subsection{Media}

Media refers to files of various types, such as images, videos, audio files, PDFs, and more. Media that is uploaded is available in the Media

Browser and can be used in any post or page.

To upload media, navigate to the administrative interface at https://ewn.erdc.dren.milwp-admin and click the + New button. Then select Media (Figure 11). This will open the media upload screen (Figure 12).

Figure 11. Add media.

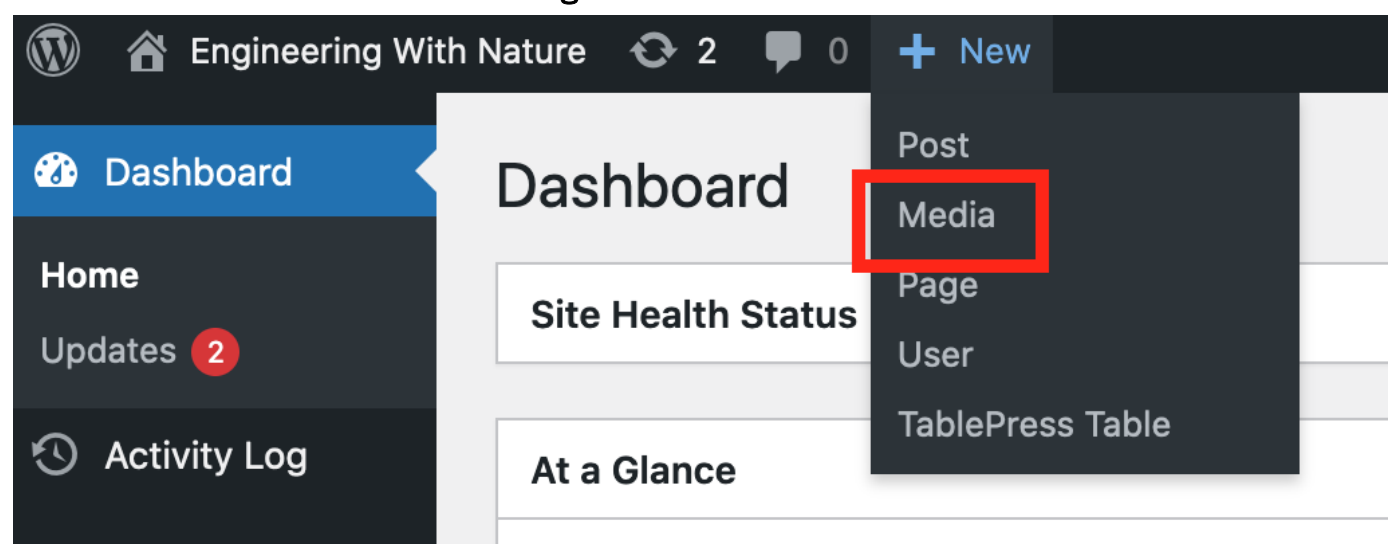

Figure 12. Media uploader.

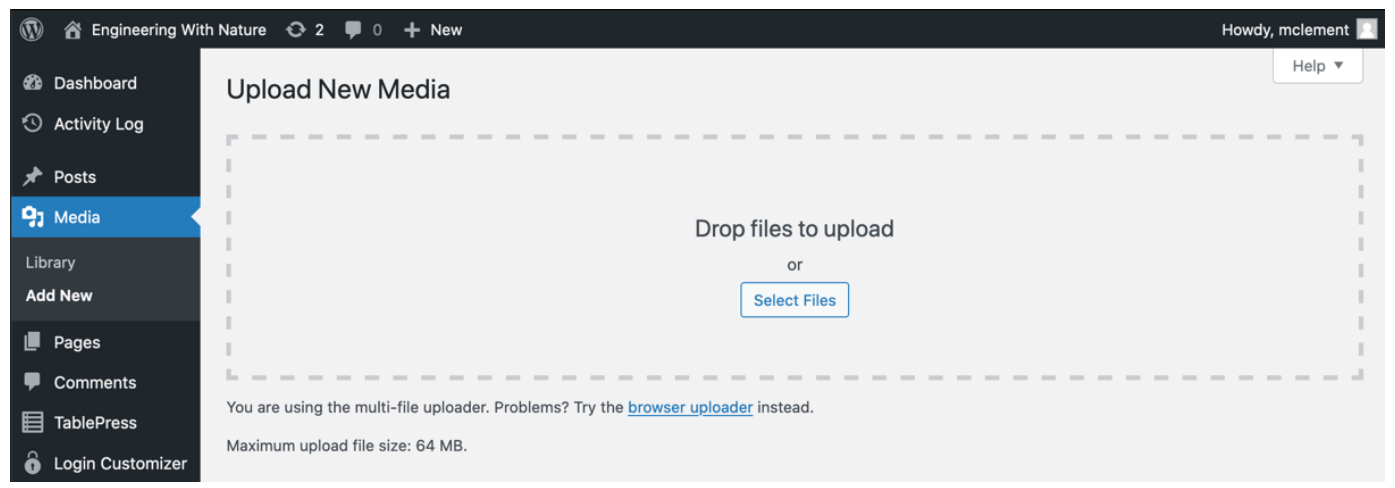

On this screen, media files can be dragged from the user's computer into this window or manually selected via the interface by clicking Select Files. 
Once media has been uploaded, it is viewable by clicking the Library button on the left-hand side of the screen. In the media library, all media are browsable, and metadata (such as image descriptions or captions) can be managed by clicking on individual media items (Figure 13).

Figure 13. Media library.

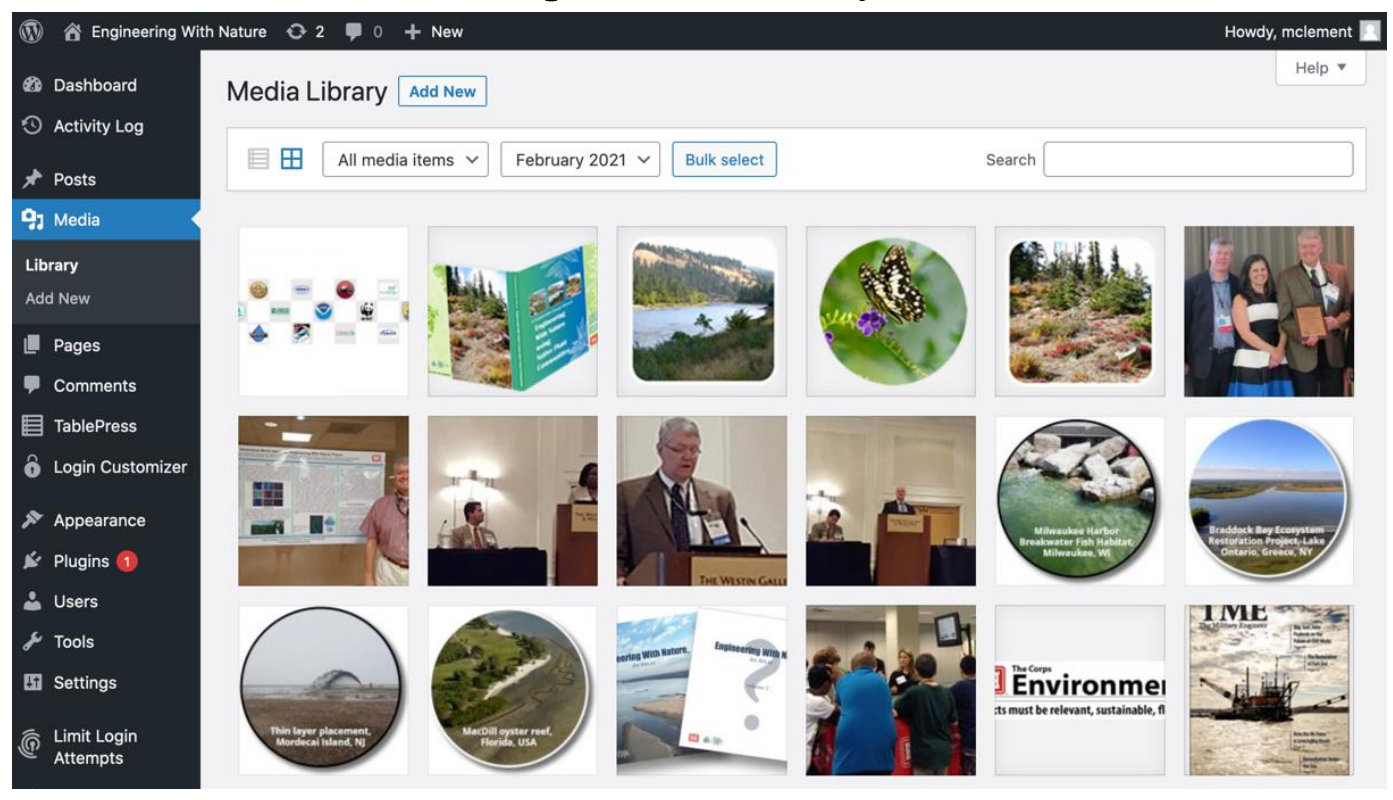




\section{Home Page}

This section will cover the home page's components (Figure 14), detailing how they can be customized and what is available to content editors.

Figure 14. EWN home page (logged-in view).

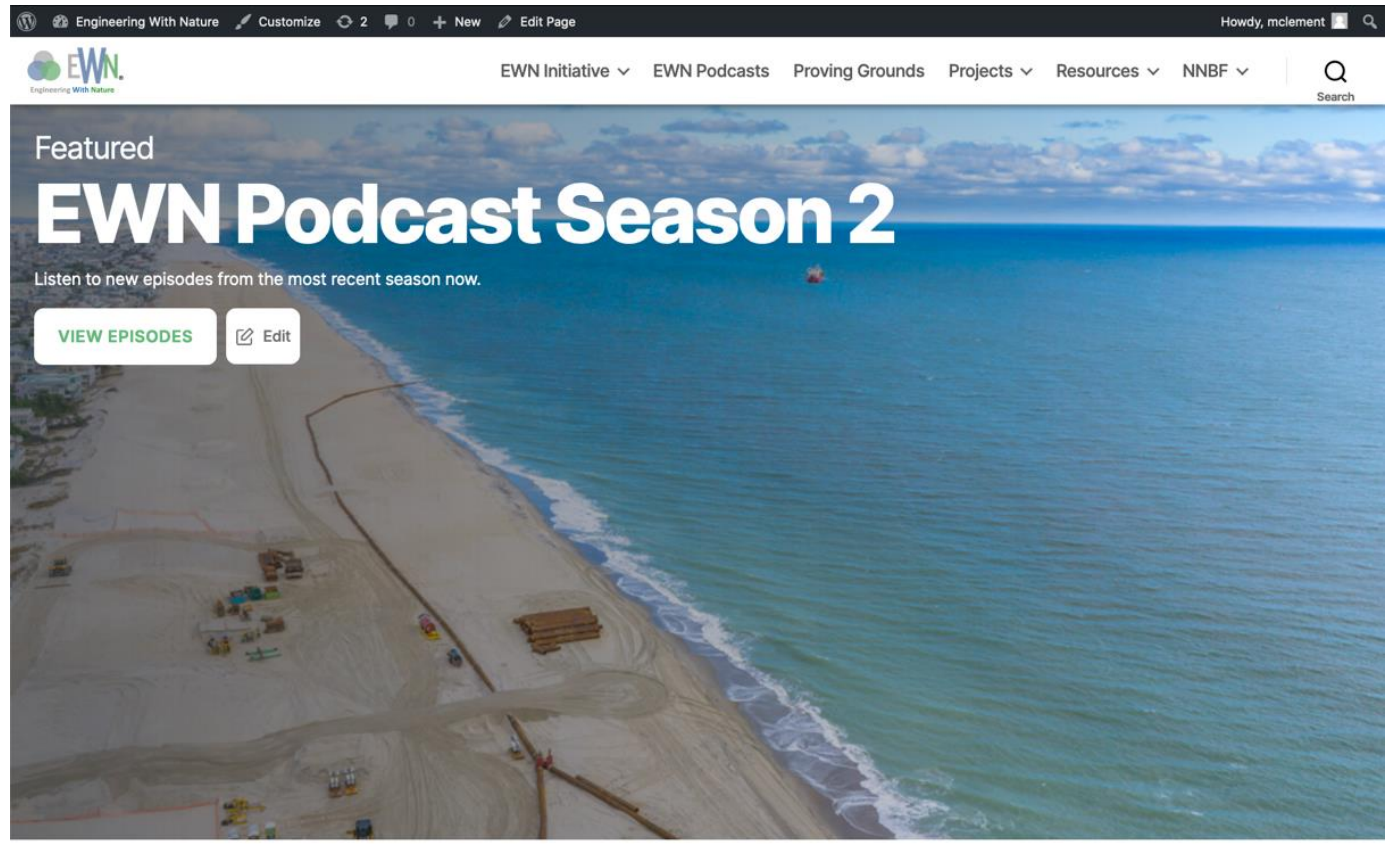

What ic Endihe

\subsection{Navigation bar}

The navigation bar is located at the very top of the page. It features the EWN logo and links to relevant pages as well as a search button that allows users to search for pages, posts, and media.

To customize the items displayed in the navigation bar, the user must login by going to https://ewn.erdc.dren.mil/wp-login.php. Once logged in, the user can return to the home page and click the Customize button in the administrative toolbar at the top of the page. This opens up a menu on the lefthand side of the page (Figure 15). 
Figure 15. Customization menu.

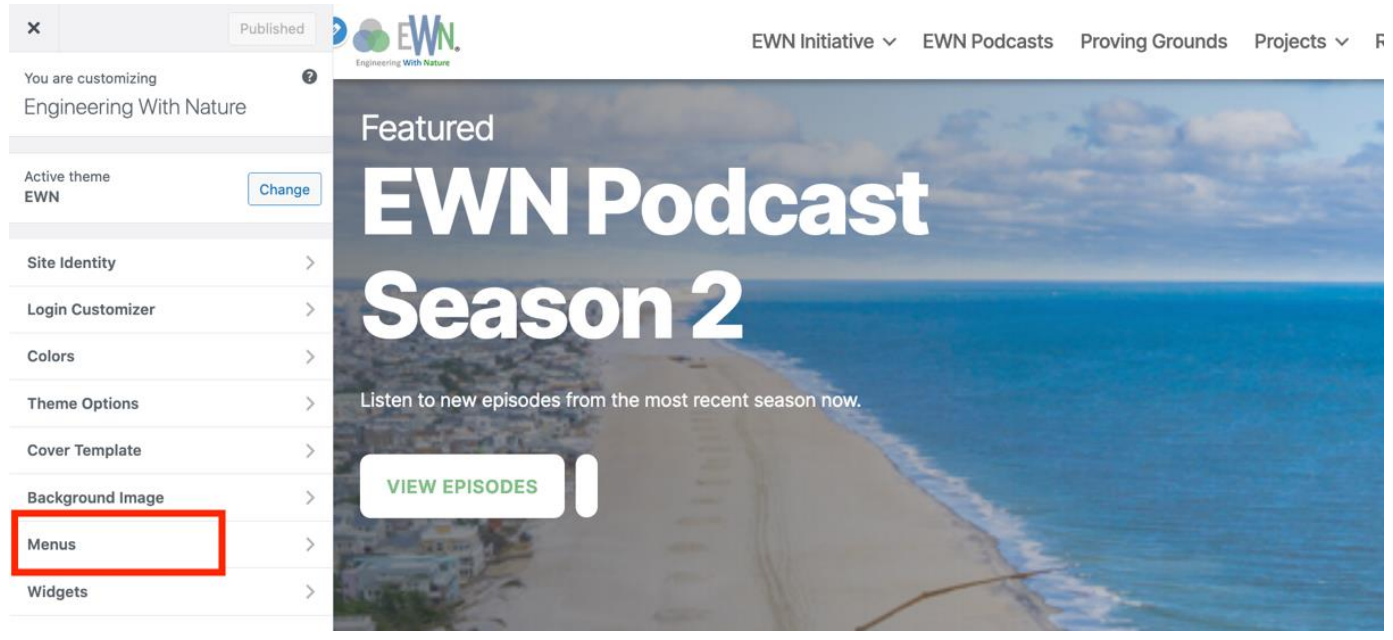

Clicking on the Menus option will open a second sidebar that allows the user to select which menu they want to customize. Select Primary (Figure 16).

Figure 16. Primary navigation.

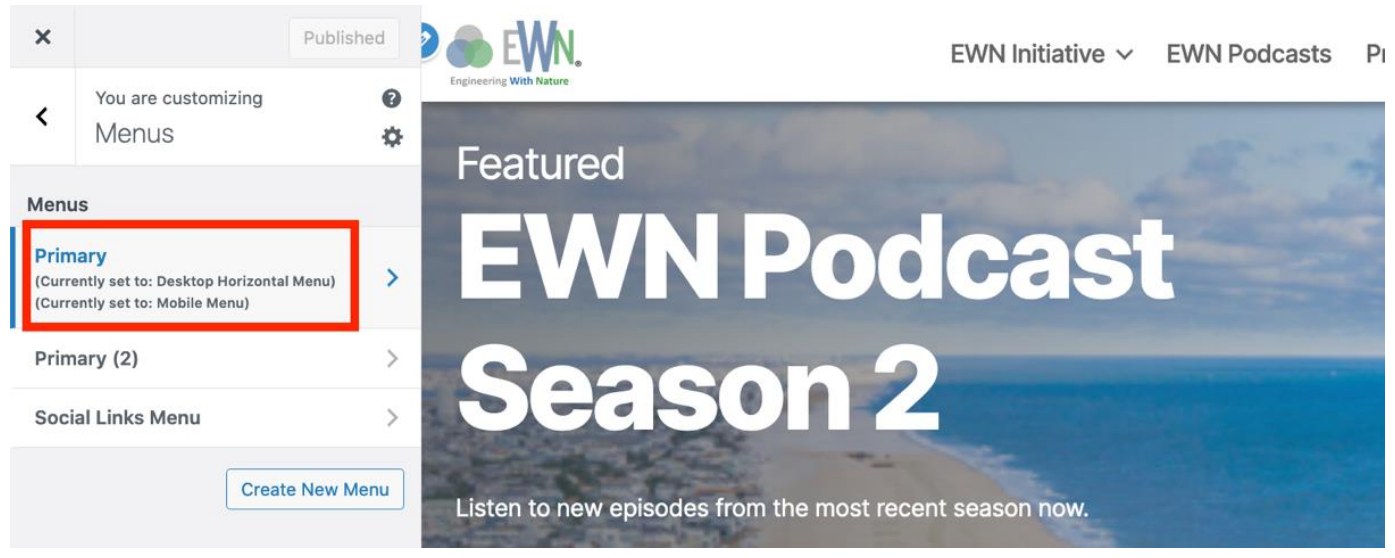

After selecting the primary menu, the user will be met with a display of all menu items. Items can be dragged and dropped to reorder them. Dragging a menu item below and to the right of another item will create nested menu items, which results in a dropdown in the navigation bar (Figure 17). 
Figure 17. Menu items.

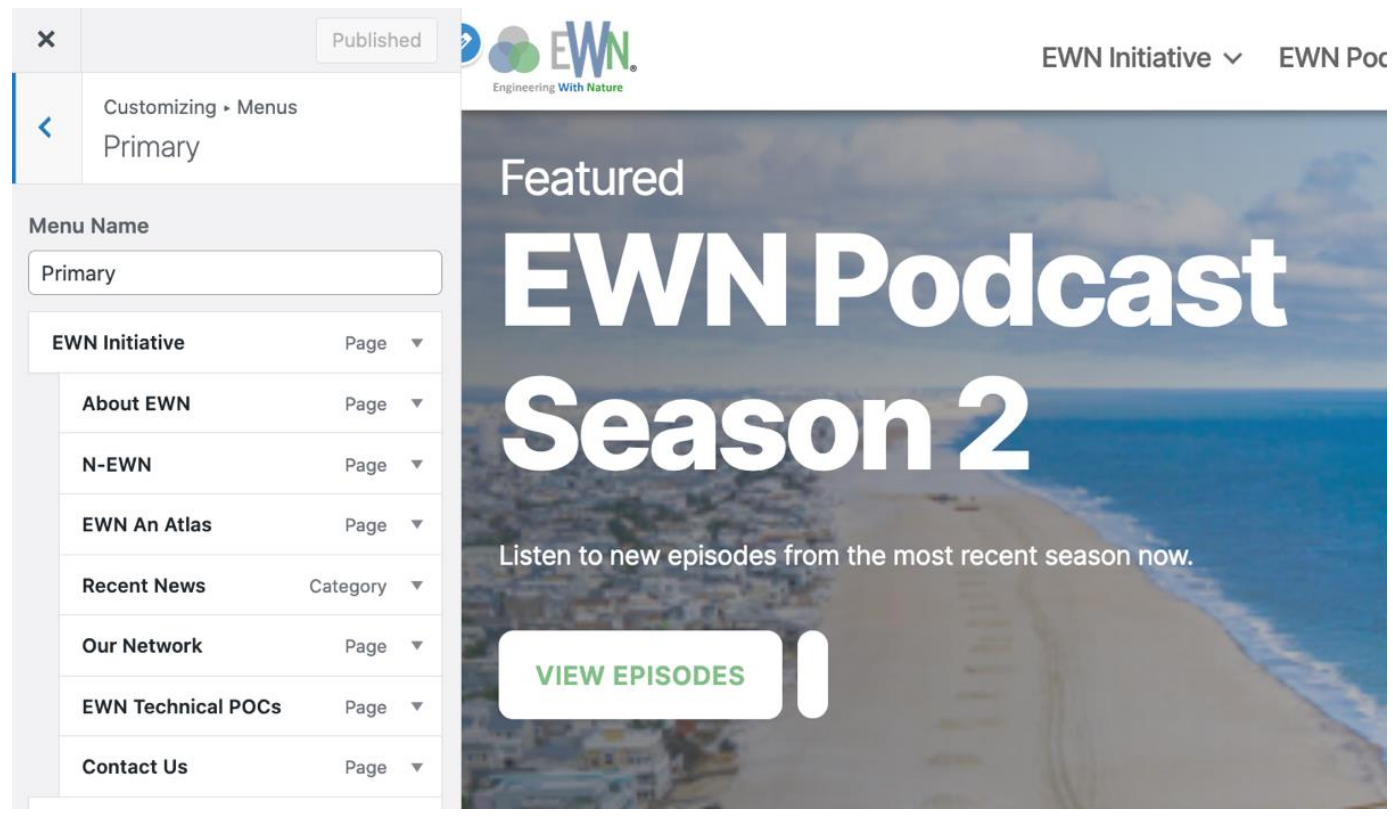

Clicking on the + Add Items button in the bottom of the sidebar will open a second sidebar that lets the user pick pages or posts to add to the navigation (Figure 18).

Figure 18. Add new items.

\begin{tabular}{|c|c|c|c|}
\hline$x$ & & \multicolumn{2}{|c|}{ Published } \\
\hline$<$ & $\begin{array}{l}\text { Customizing - Menus } \\
\text { Primary }\end{array}$ & & \\
\hline \multicolumn{4}{|c|}{ Menu Name } \\
\hline \multicolumn{4}{|c|}{ Primary } \\
\hline \multicolumn{2}{|c|}{ EWN Initiative } & Page & $x$ \\
\hline & About EWN & Page & $x$ \\
\hline & N-EWN & Page & $x$ \\
\hline & EWN An Atlas & Page & $x$ \\
\hline & Recent News & Category & $x$ \\
\hline & Our Network & Page & $x$ \\
\hline
\end{tabular}

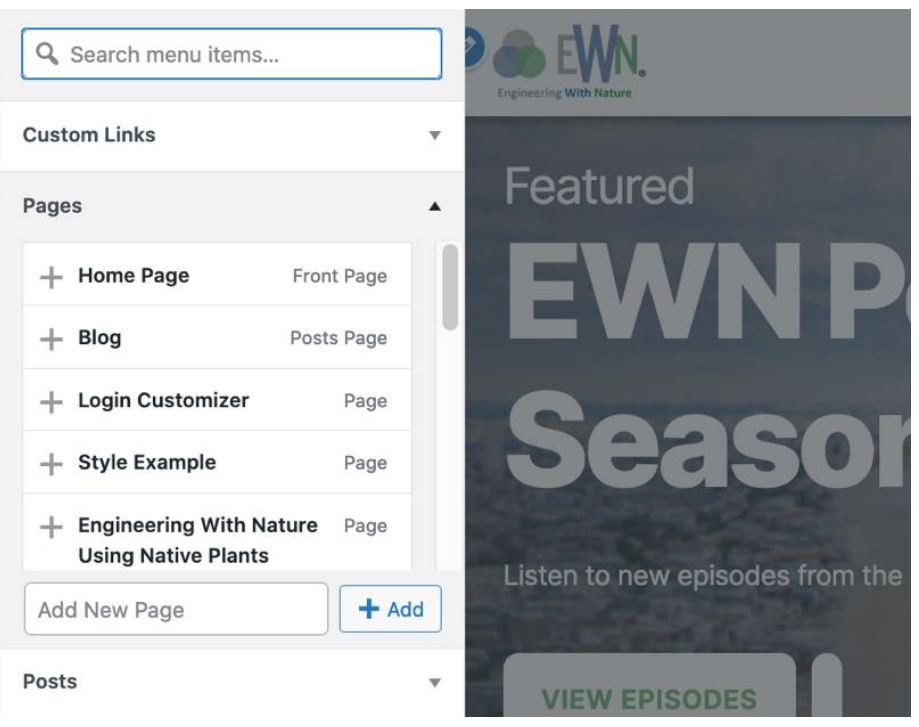

Once all changes are configured, click the big, blue Publish button at the top of the sidebar to save the changes. Then click the $\mathbf{X}$ in the top left to exit the customization screen. 


\subsection{Featured post}

The featured content section of the home page is located at the top of the page and is the largest item on the home page. The featured post is any Post that has been set as "Stick to the top of the blog" (see Section 3.2).

When an administrator or other privileged user is logged in, they will see an Edit button alongside the featured post's main button (Figure 19). Clicking that edit button will take the user to the post's edit page where they can make changes to the post content, update the featured image, or uncheck the "Stick to the top of the blog" option to revoke its featured status.

Figure 19. Featured post edit button.

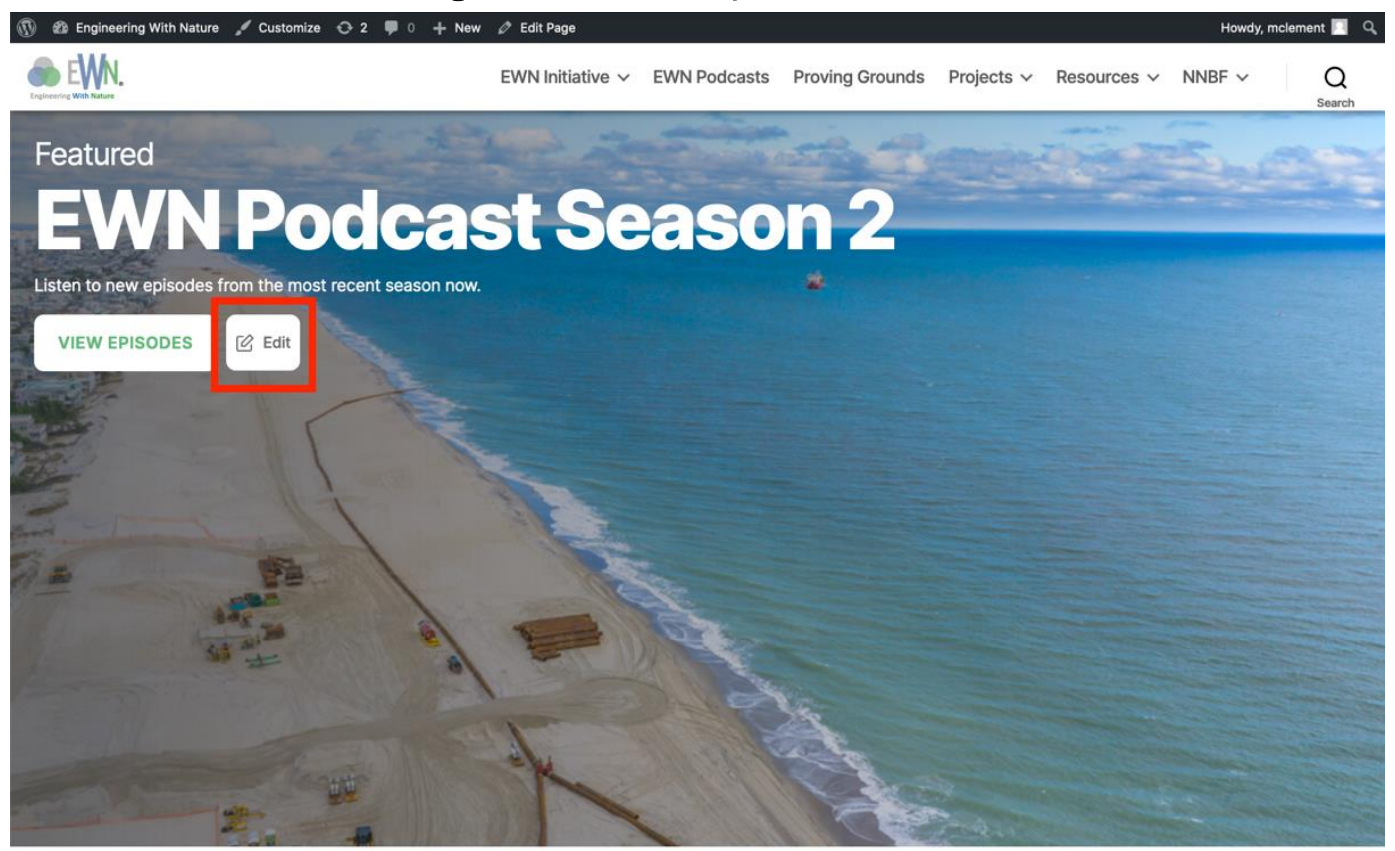

Whatic Enctioering With Nature?

\subsection{Home page widget areas}

Immediately below the featured post is a Widget Area (Figure 20). A widget area is a place where widgets (pieces of custom functionality, similar to a Block in a post or page) can be placed.

The home page has two widget areas, one directly below the featured post and one directly below the Home Page Blocks (Section 4.4). 
Figure 20. Widget area.

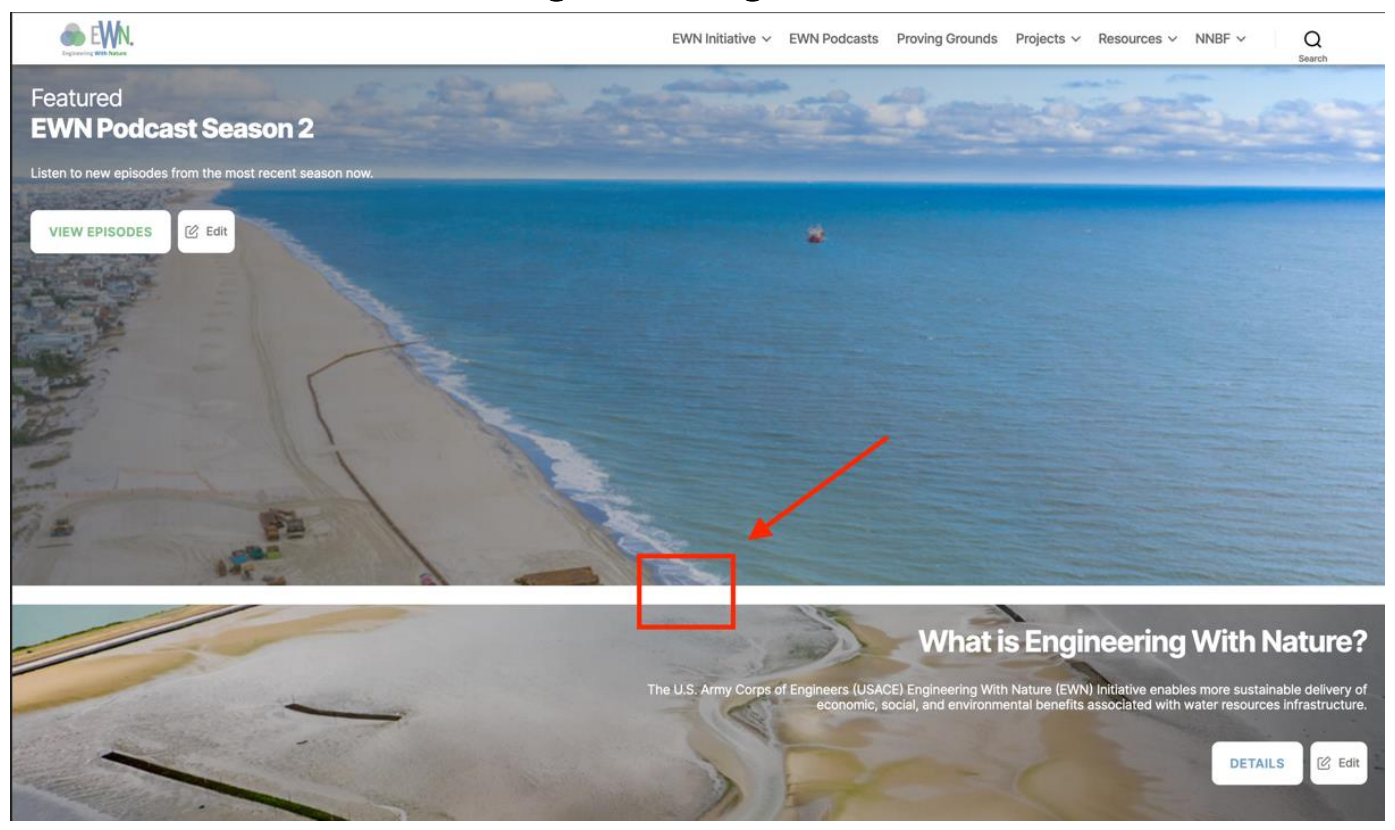

By default, there is nothing in this upper widget area. To add a widget (such as a photo gallery or a piece of custom HTML), log in and click the Customize button in the administrative toolbar at the top of the page.

This opens up a sidebar with several options. From the sidebar, select Widgets (Figure 21).

Figure 21. Widgets sidebar.

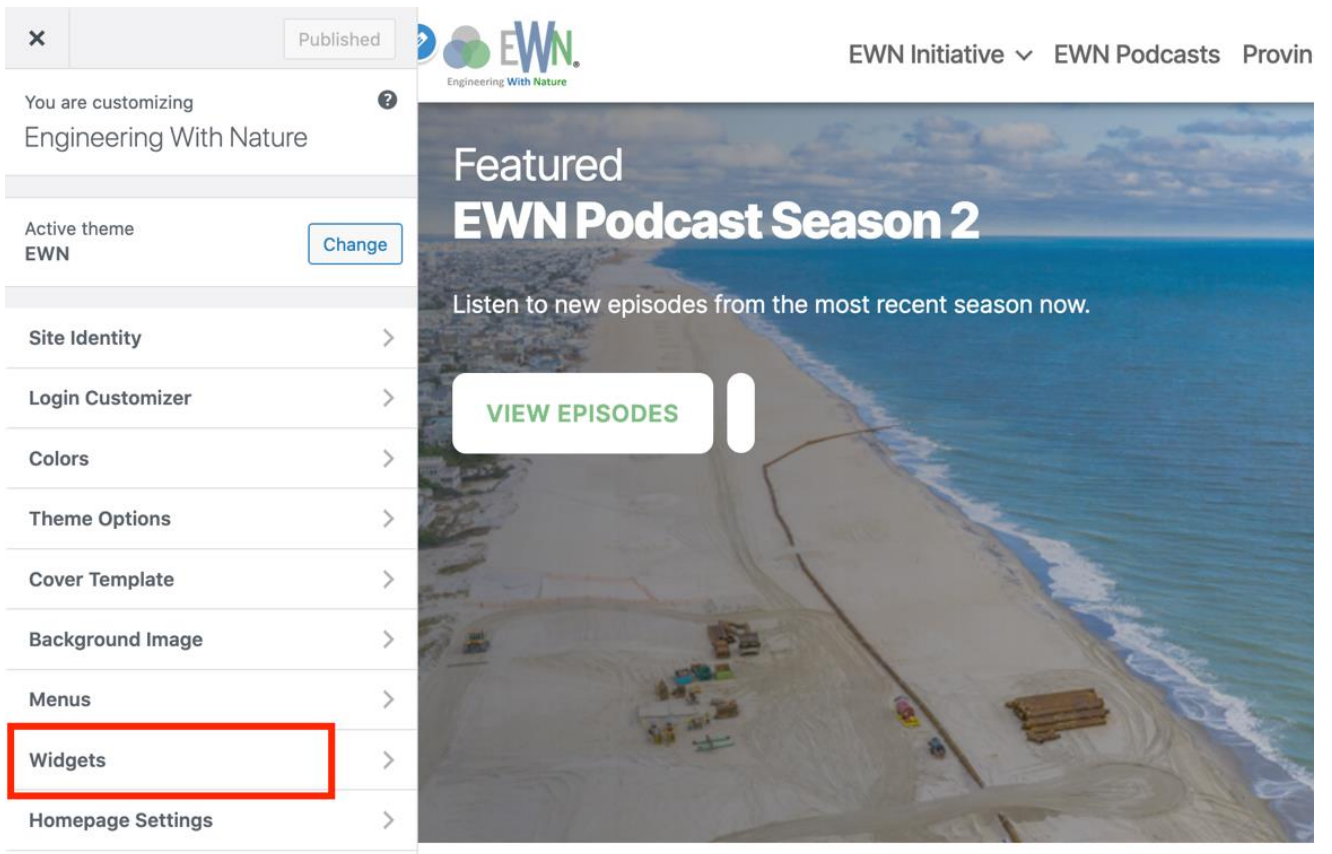


This will display a list of widget areas that are available. Selecting Home Page Widgets (Top) will target the widget area directly below the featured post. After selecting a widget area, all widgets that are currently active in that area are displayed. To add a new widget, click the +Add a Widget button. This opens up a second side bar from which a widget can be selected (Figure 22).

Figure 22. Widget selection.
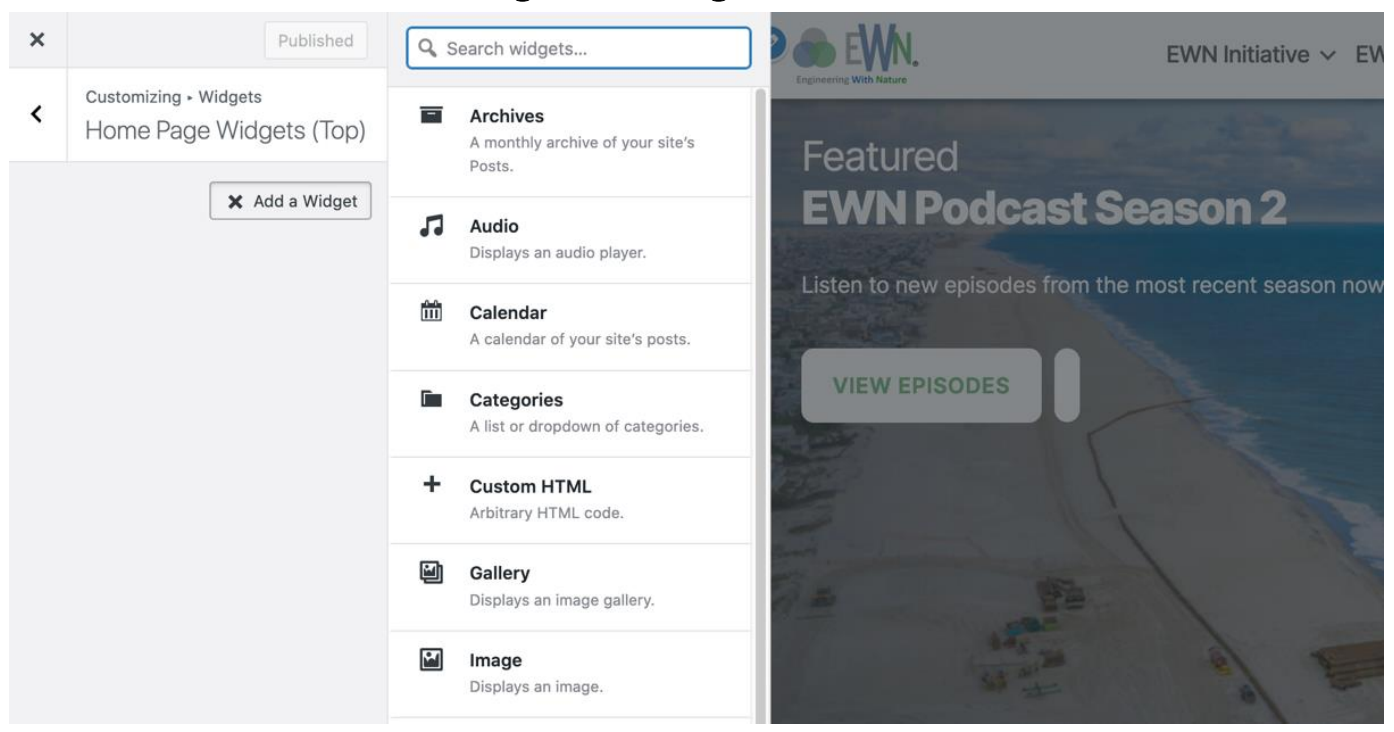

After selecting a widget, the widget can be customized-adding a gallery of images for example (Figure 23-Figure 27).

Figure 23. Gallery widget setup- name the gallery.

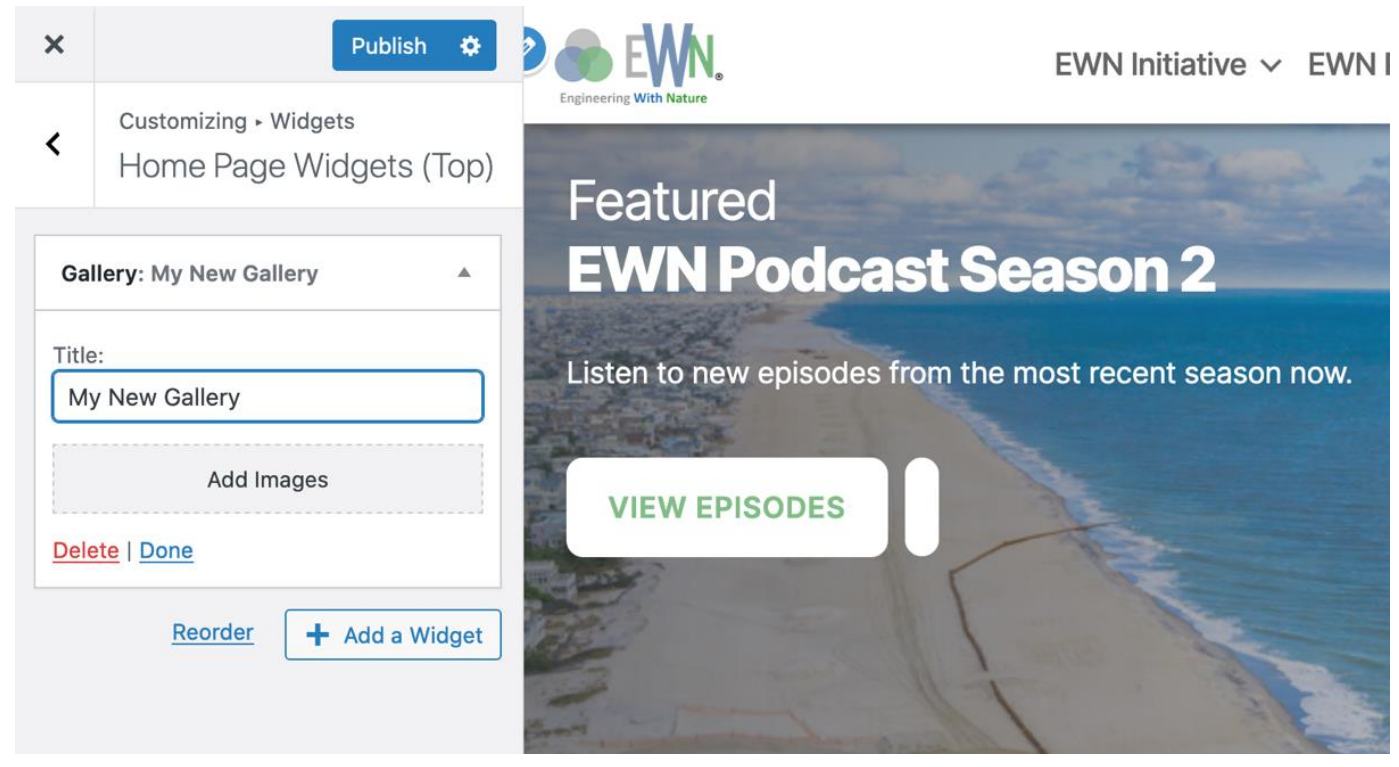


Figure 24. Gallery widget setup-select images.

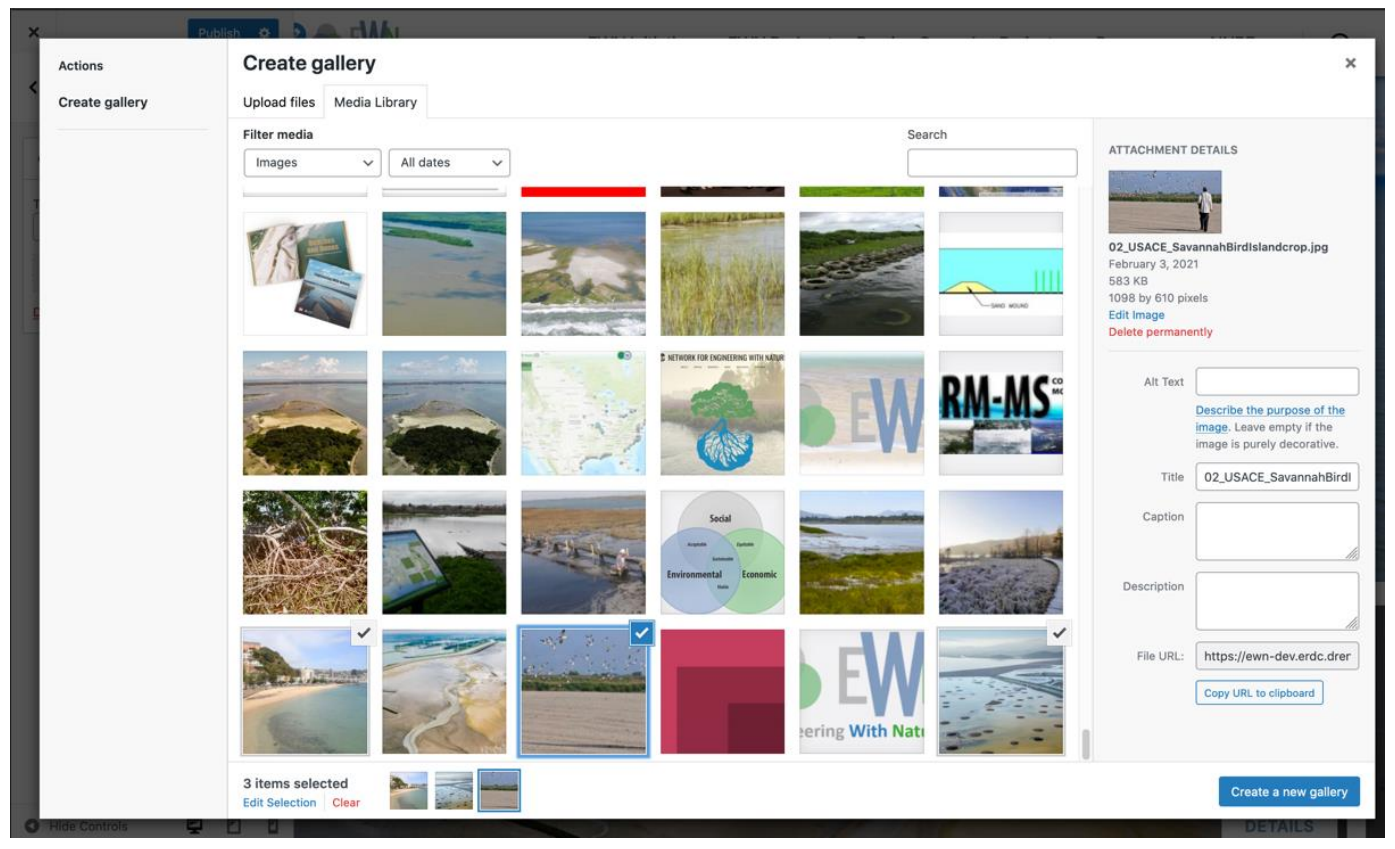

Figure 25. Gallery widget setup-reorder images.

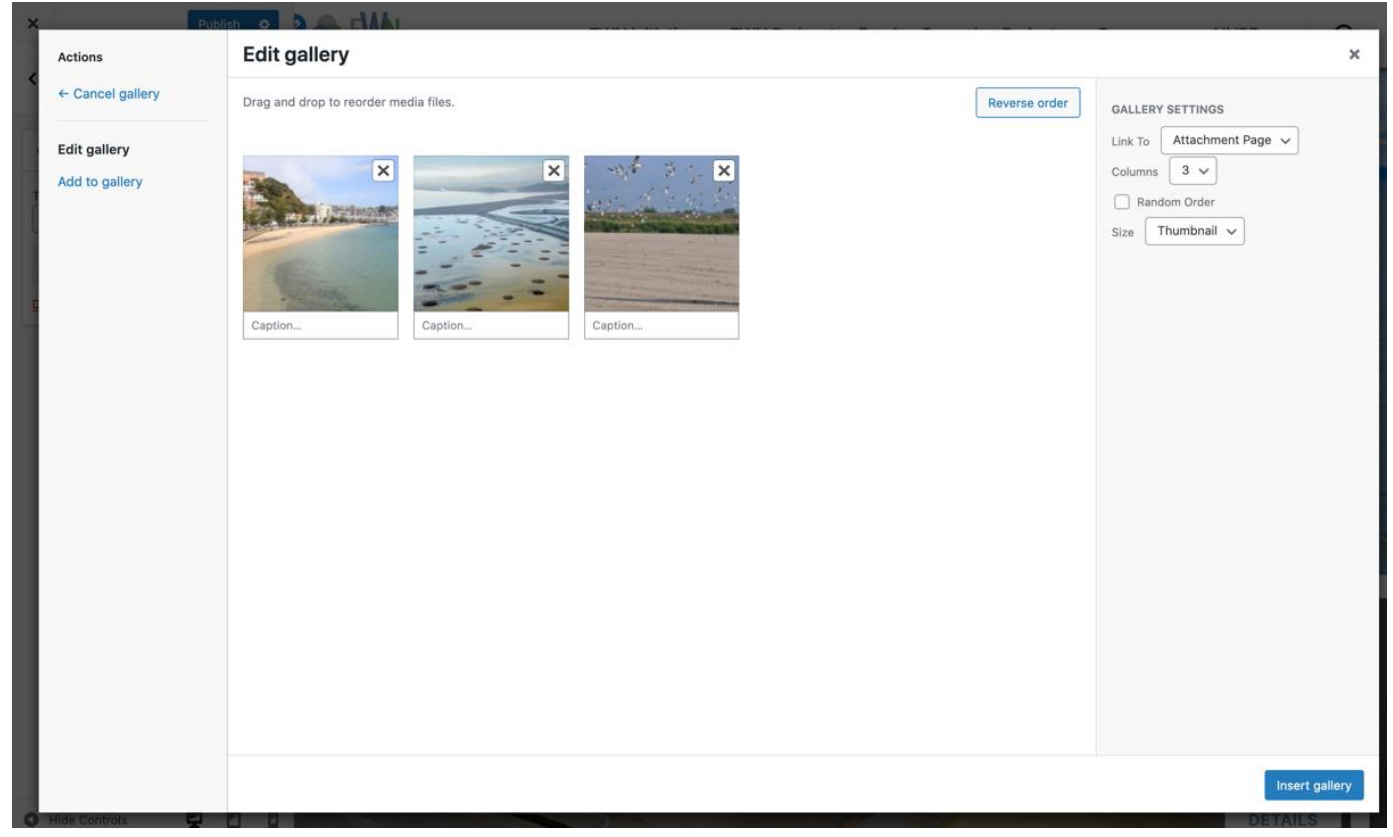


Figure 26. Publish gallery.

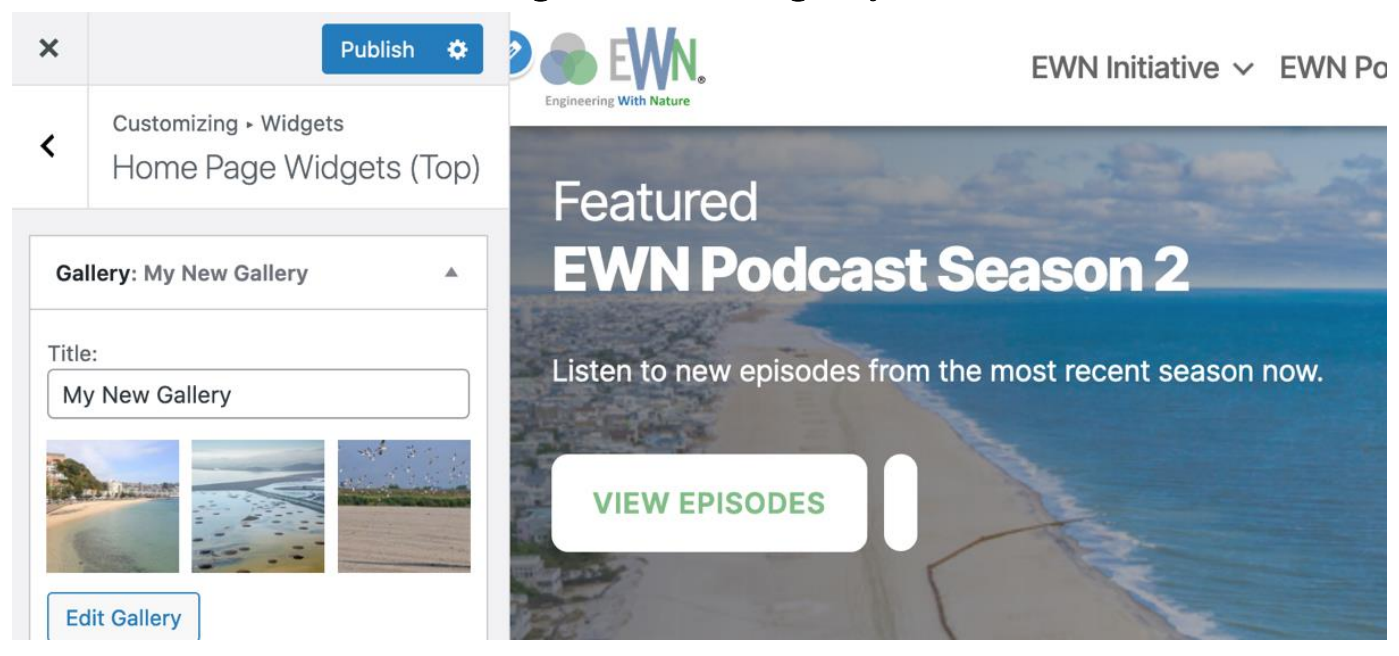

Figure 27. New gallery widget on home page.
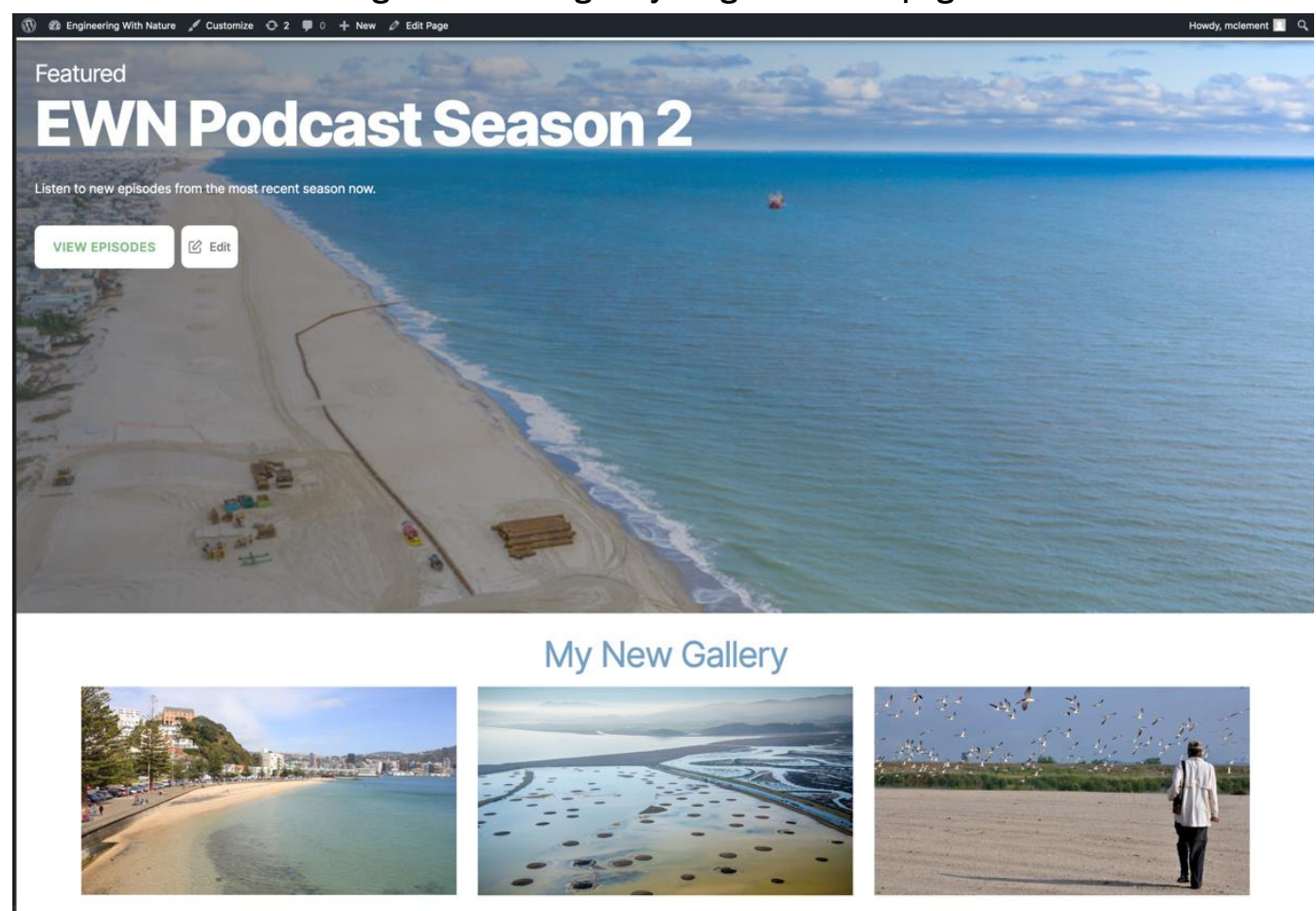

My New Gallery
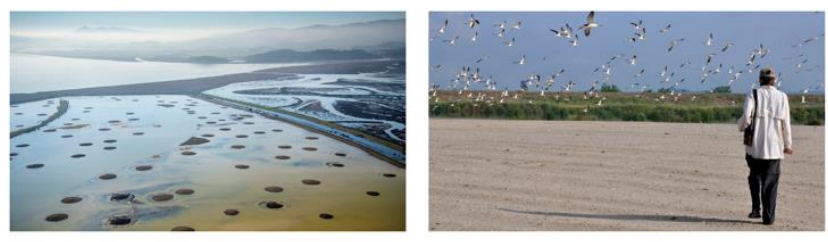

The gallery widget now displays below the featured post. Multiple widgets may be added to a single widget area.

\subsection{Home page blocks}

Below the top widget area, all posts that have been categorized as Home Page Blocks are displayed. To add a post as a home page block, the edi- 
tor must check Home Page Blocks as the selected category when creating or editing the post. This will result in it automatically being displayed on the home page (Figure 28).

Figure 28. Home page blocks.
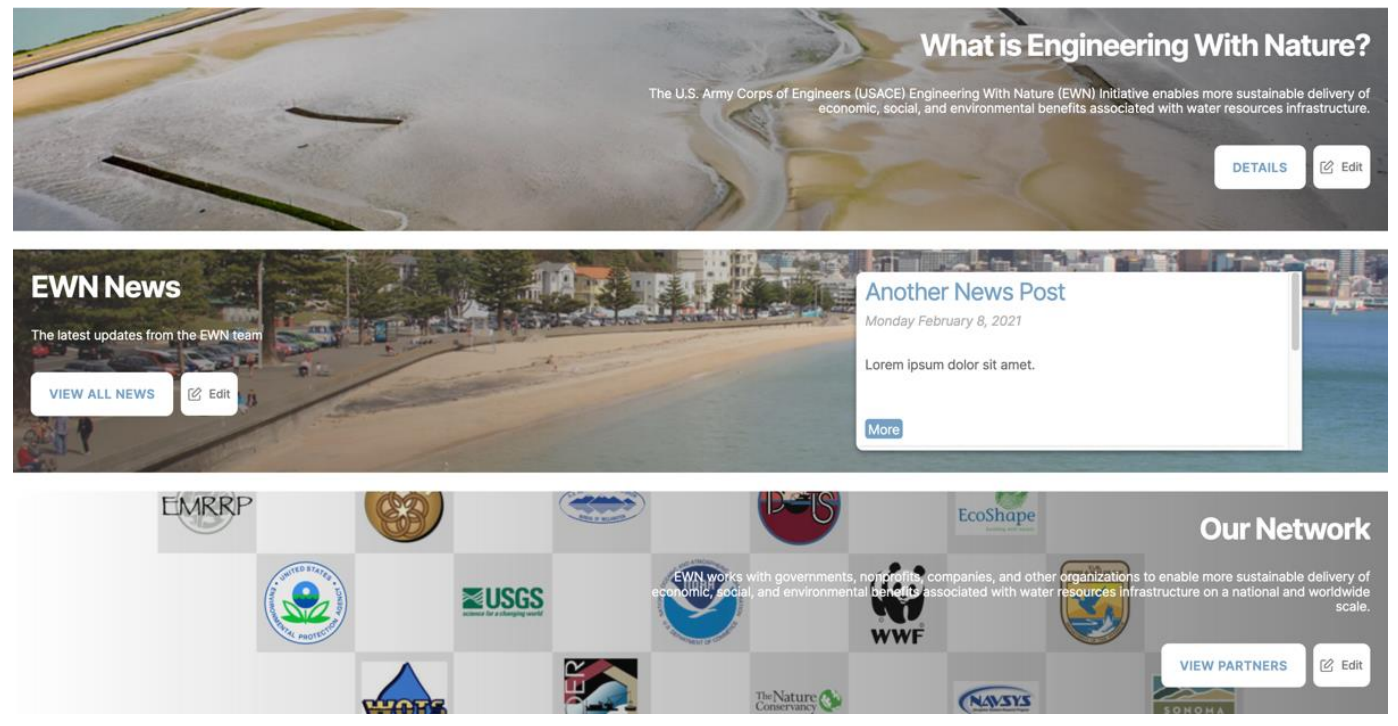

Home page blocks are used to highlight important content. Just like with the main featured post, home page blocks are displayed with their featured image, title, and excerpt text.

When an administrator or other privileged user is logged in, they will see an Edit button alongside the home page block's main button. Clicking that edit button will take the user to the post's edit page where they can make changes to the post content, update the featured image, or uncheck the Home Page Blocks category to remove it from the home page.

\subsection{Footer}

The footer is a collection of relevant links found at the bottom of the website. To customize the footer requires editing some custom HTML. To edit the footer's HTML, log in and click the Customize button in the administrative toolbar at the top of the page. This will open a sidebar that contains several options.

Select the Widgets option, and then select Footer \#1. This will reveal a custom HTML widget. Clicking on the custom HTML widget will expand a text field that contains the HTML content of the footer (Figure 29). 
Figure 29. Footer HTML widget.
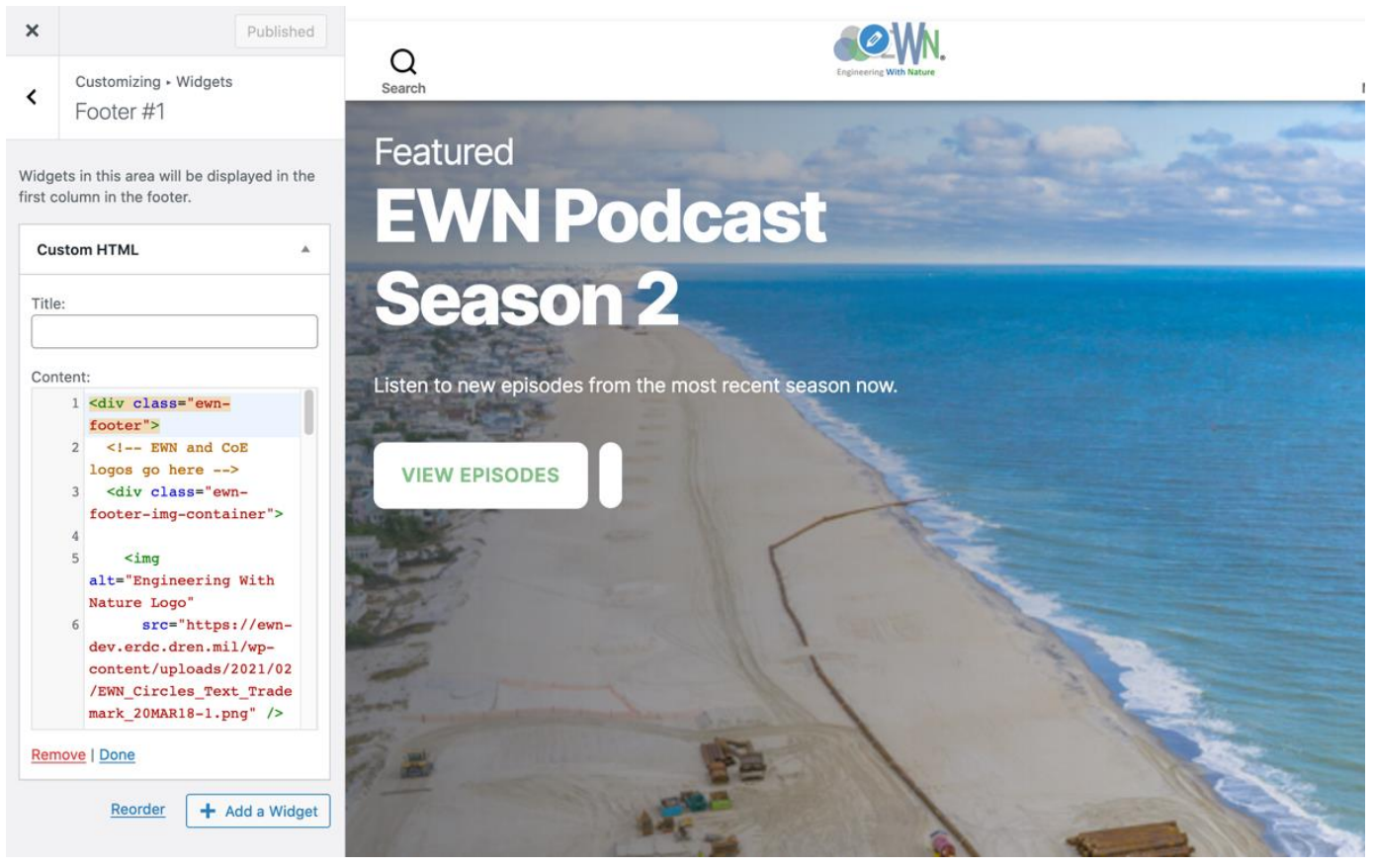

It is recommended that users do not edit this HTML directly but, instead, edit the text in an external text-editor program.

(Note: NEVER use Microsoft Word to edit HTML. It may insert hidden characters that can break the HTML. Instead, use a plain text editor such as Notepad (Windows) or TextEdit (Mac).

To do this, copy all the HTML from the widget, and paste it into a separate text file on the computer (Figure 30). Make the necessary changes, and then copy the text from the file back into the widget area on the site. 
Figure 30. Editing footer HTML.

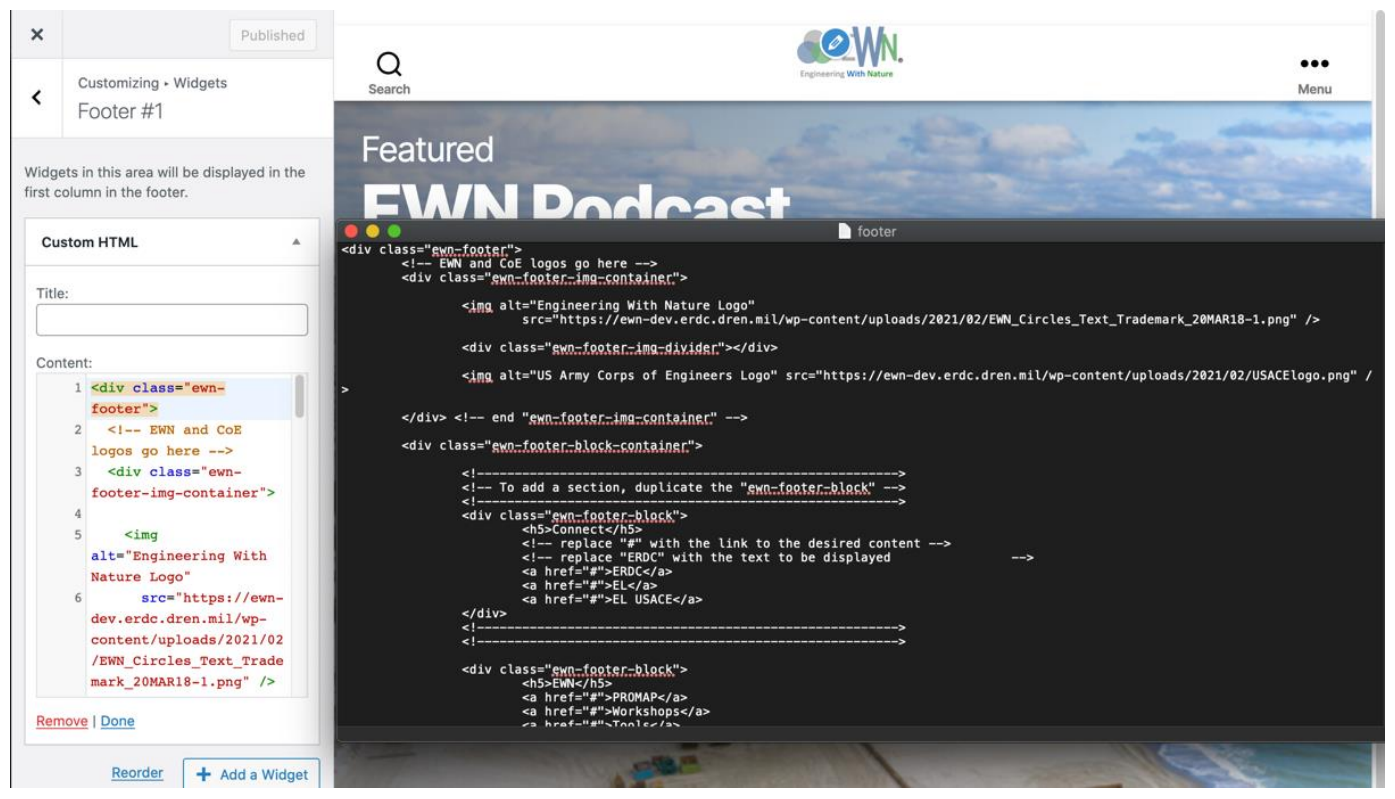

Once changes are complete, click the big, blue Publish button at the top of the sidebar. 


\section{Podcasts}

This section gives detailed steps on adding podcast episodes to the site.

\subsection{Create a podcast post}

The first step when adding a podcast to the site is to create a new post and categorize it as a podcast.

First, $\log$ in by going to https://ewn.erdc.dren.milwp-login.php and create a new post (for more detail on creating a post, see Section 3.2).

Once the post has been created, categorize it as a podcast by selecting Podcast from the categories section as well as the specific season category for this specific episode (see 1 in Figure 31). Setting the category for a podcast is necessary to ensure it displays on the Podcasts page.

Figure 31. Categorize podcast.

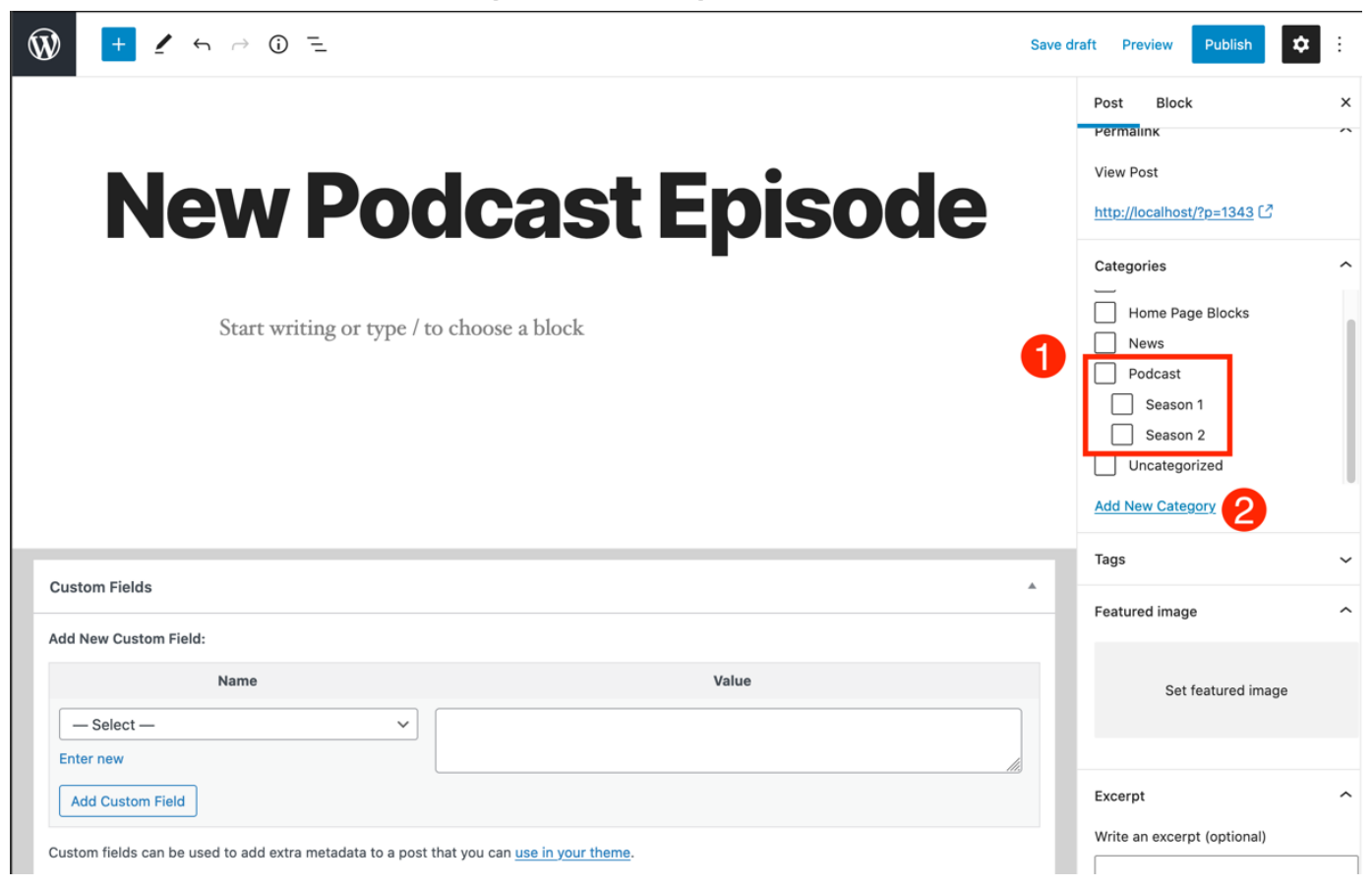

If a podcast's season isn't listed, it can be added by creating a category for it. Click Add New Category (see 2 in Figure 31), name the season, and set the parent category as Podcast (Figure 32). 
Figure 32. Add podcast season category.

\section{New Category Name}

Season 3
Parent Category
$\checkmark$ - Parent Category -
Featured - Podcasts
Home Page Blocks
News
Podcast
Season 1
Season 2
Uncategorized

\subsection{Embed podcast player}

To add the podcast audio to the post, it is necessary to generate the embeddable Apple Podcast link to the episode and add it to the post. To do so, navigate to https://tools.applemediaservices.com/apple-podcasts. Once there, you will be met with a page featuring a large search bar. Type "Engineering With Nature" into the search bar and press the return/enter key on your keyboard.

After searching for the EWN podcast, locate it in the search results and click on it. This will take you to the podcast screen.

On the podcast screen is a list of episodes. Click on an episode from the list to select it. If the desired episode is not displayed, click the Show More Episodes button at the bottom center of the screen.

On the episode screen, scroll down to the Podcast Player section and click Copy Embed.

Once the embed has been copied, go back to the podcast post on the EWN website and add a custom HTML block (for more info on adding blocks see Section 3.1, Figure 4 and Figure 5), pasting the embed code inside (Figure 33 and Figure 34). 
Figure 35. Set podcast template.

$\checkmark$ Default template

EWN Page Template

Home Page Template

Podcast Episode Template

Podcast Season Template

Cover Template

Full Width Template

Default template

\subsection{Set podcast featured image and excerpt}

Podcasts feature a large image at the top of the post along with a text excerpt (Figure 36). To set these items, head to the right-hand sidebar of the post edit screen:

Figure 36. Podcast featured image and excerpt.

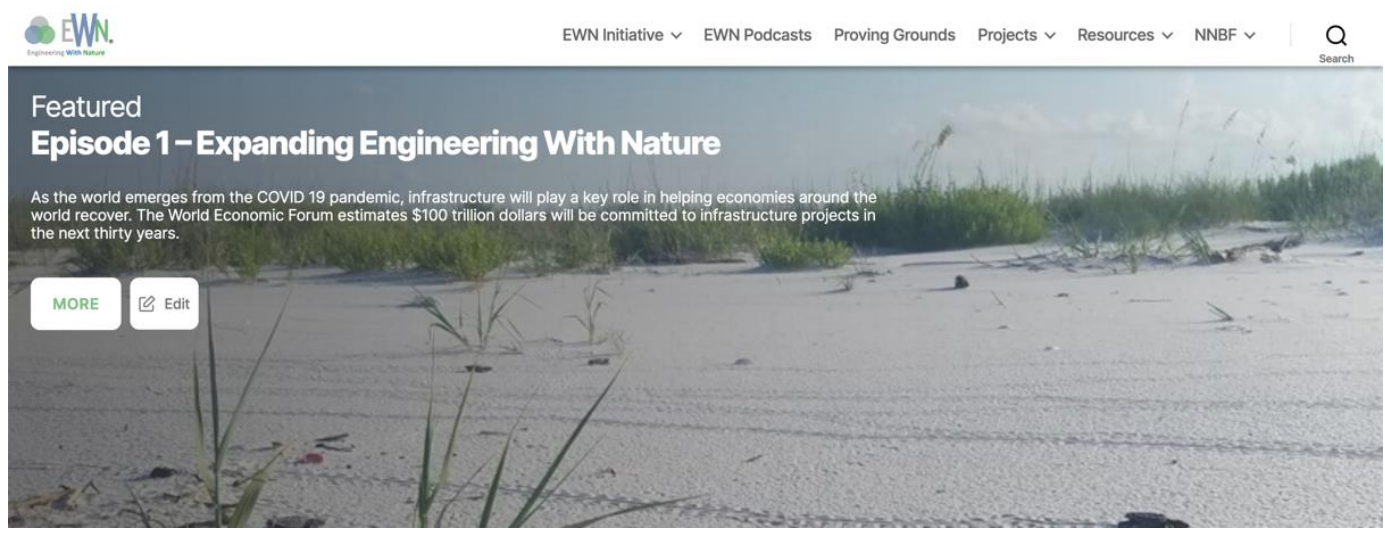

- Setting Featured Image: locate the Featured Image section in the post edit sidebar. Click Set featured image and choose an existing photo or upload one.

- Setting the Excerpt: locate the Excerpt section in the post edit sidebar and type or paste the desired excerpt text into the textbox.

Save or publish the post. The featured image and excerpt should now display at the top of the podcast. 
Note: If an excerpt is not specified, the first few lines of text from the podcast post will automatically be used.

\subsection{Add additional content}

Now that the podcast has the audio player embedded, has been categorized, and the template selected, all that is left is to add any additional text or media needed in the post. Do this by adding text or image blocks (for more info on adding blocks see Section 3.1, Figure 4 and Figure 5) and then clicking Publish when finished.

If the post should not be immediately published, click Save Draft and revisit it at a later time by going to the Posts -> Drafts section of the admin interface (https://ewn.erdc.dren.milwp-admin/edit.php?post_status=draft\&post_type=post).

\subsection{View podcasts}

Once the podcast is published, navigate to the podcasts page by clicking EWN Podcasts from the navigation bar on the site home page. The new episode will automatically display on this page below a heading that denotes the podcast season (Figure 37).

Figure 37. Podcast listing.

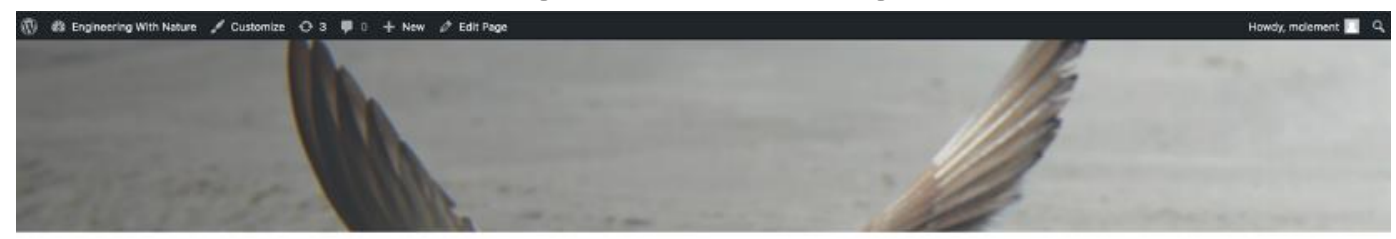

\section{Episodes}

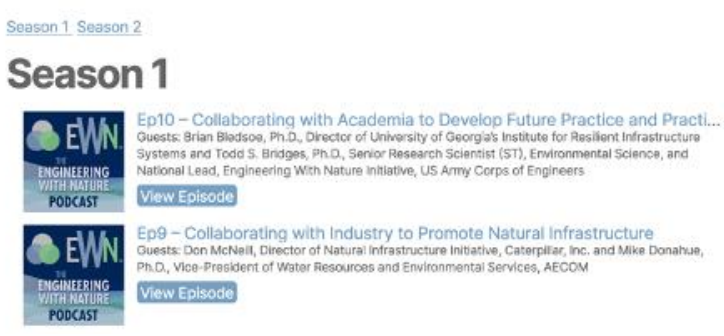

\section{7 “Listen on Apple Podcasts" link}

The podcasts page features a large badge that links to the Apple Podcast page, where users can opt to listen via the Apple Podcasts app as well as 
view episodes directly. This link is a Custom HTML Widget, which can be modified by logging in as a privileged user at https://ewn.erdc.dren.milwp-admin, then selecting Customize from the main toolbar at the top of the page, then clicking Widgets, and finally clicking Podcasts Page Widget (for more information on accessing widgets, see Section 4.3). This will reveal a custom HTML widget. This widget holds an embedded link to the EWN Podcast on Apple Podcasts. This embed is generated by navigating to the EWN Apple Podcasts page (https://tools.applemediaservices.com/podcast/1528233207? country=us) and scrolling down to the section labeled Badges and Lockups. Click Copy Embed.

Once the embed has been copied, return to the Podcasts Page Widget, and click on the Custom HTML widget to expand the text field. When the text field is expanded, the podcast embed can be pasted in the Content field (Figure 38). To save, click the big, blue Publish button in the top right of the sidebar.

Figure 38. Updating the Apple podcast embed HTML.

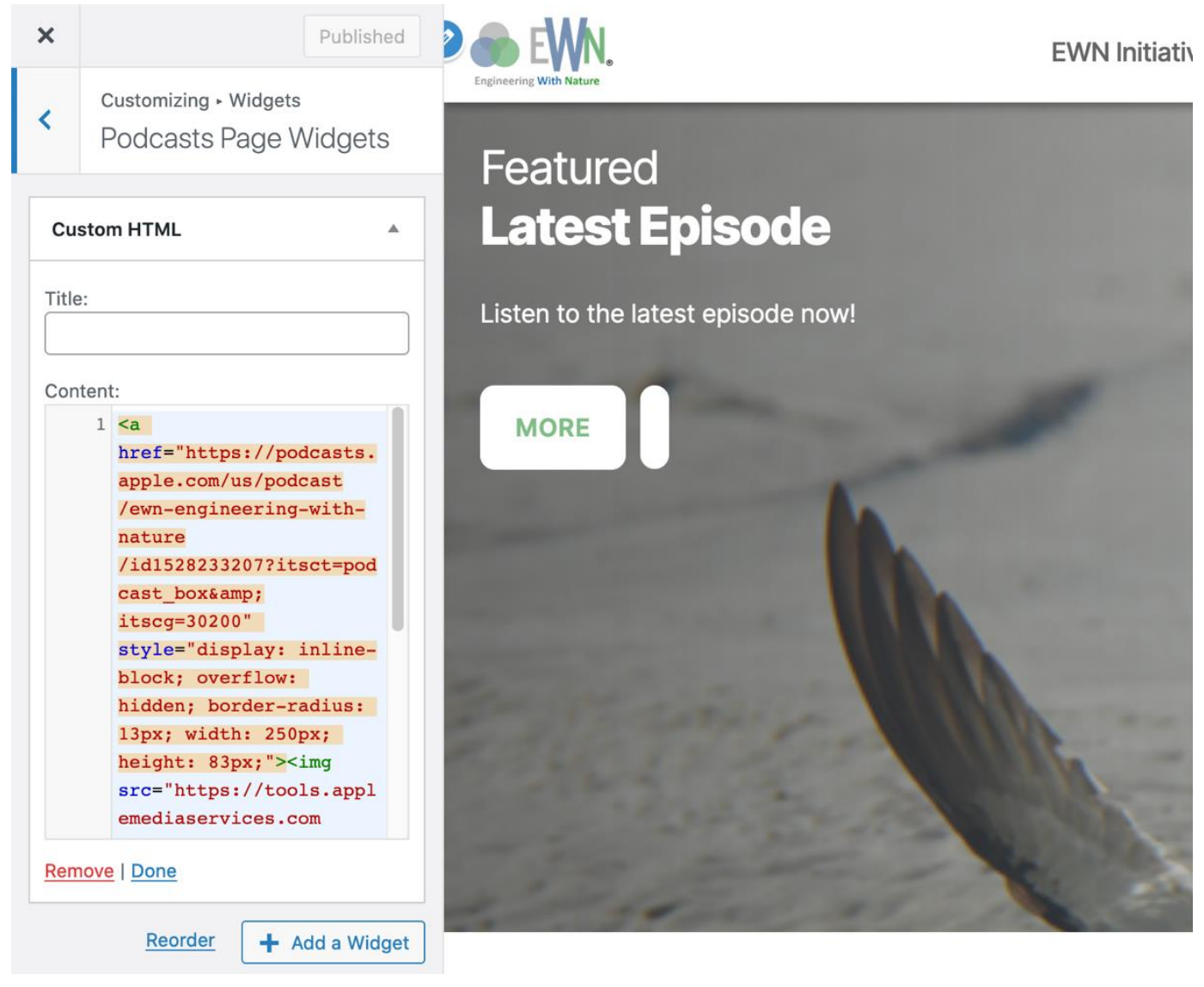

Note: Updating this embed will only be necessary if the link breaks. 


\section{Additional Customization}

This section covers miscellaneous customization processes that are used in various places across the site.

\subsection{Setting custom button text on home page blocks and podcasts}

Home page blocks (see Section 4.4) and podcasts (see Section 5) both feature a large "call-to-action" button (Figure 39).

Figure 39. Call to action button.

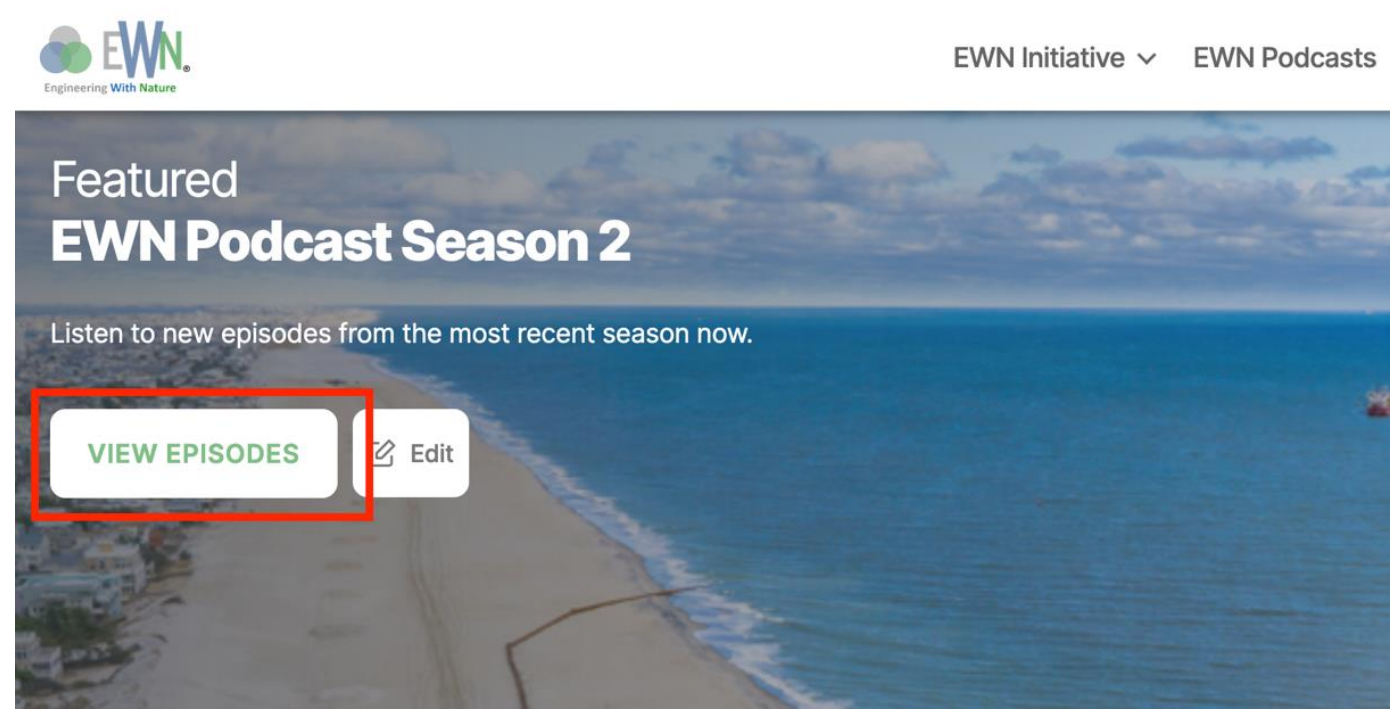

By default, any post that is categorized as a home page block or podcast features a button that says "More" and links to the post directly. There are some cases where different text or a different destination URL may be desirable. To do this, $\log$ in as a user with editing privileges and locate the post you wish to edit via the admin interface (Admin Screen -> Posts in the left-hand sidebar).

Once the post has been located, begin editing it. At the bottom of the edit screen is a section labeled Custom Fields. This section features a dropdown and text field labeled Name and Value (Figure 40). 
Figure 40. Customize text and URL of call-to-action button.

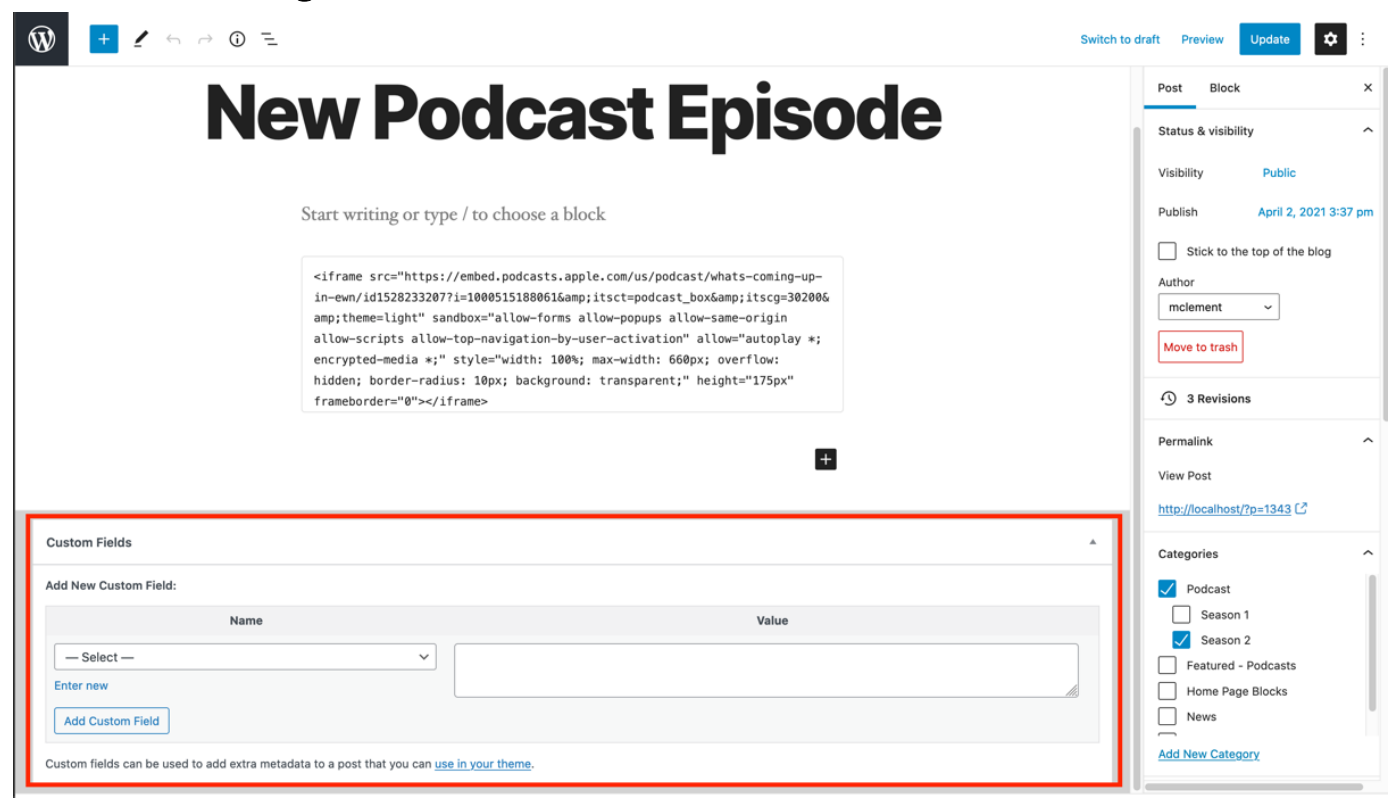

- To Set Custom Button Text: Select link_text from the Name dropdown, then type the custom text in the Value text field. Once the text has been entered, click the Add Custom Field button in the bottom left.

- To Set Custom Button URL: Select secondary_url from the Name dropdown, then type the desired destination URL into the Value text field. Once the text has been entered, click the Add Custom Field button in the bottom left.

After making these changes, save or publish the post.

\subsection{Adding news posts}

The home page features an "EWN News" section that displays the most recent news posts. This section is a standard post but has been set to have a custom button that links to a page of all news posts, as well as displaying the custom news post collection on the home page (Figure 41). 
Figure 41. News section on home page.

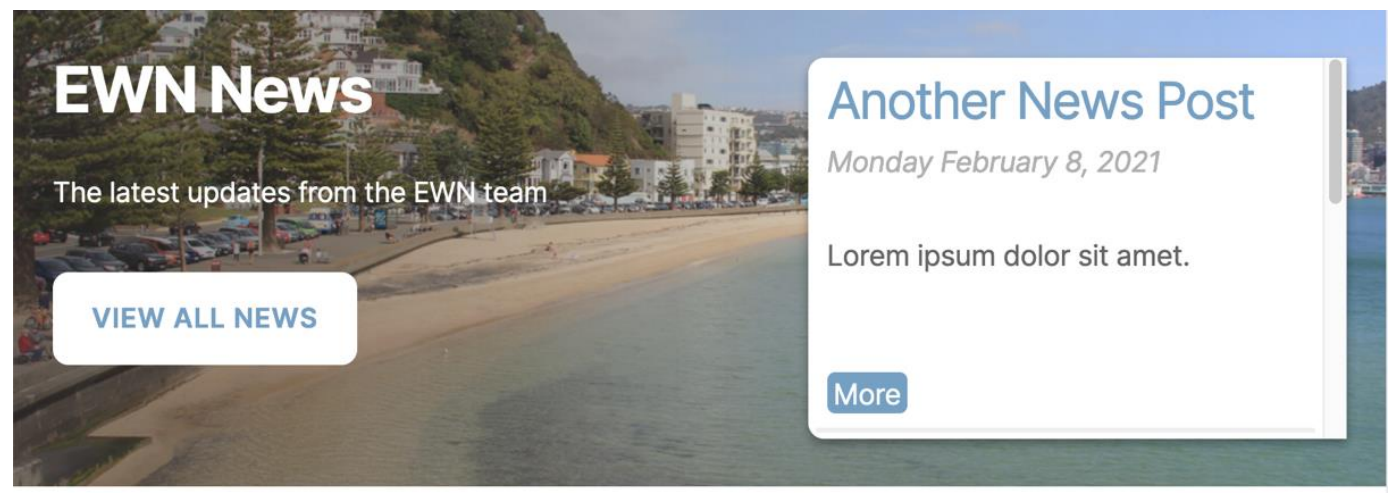

To display news posts in this section, a post must be created (see Section 3.2) and categorized as News by clicking the News category in the righthand sidebar of the post editor (Figure 42). This will automatically cause the news post to display in this section on the home page.

Figure 42. Categorize a post as news.

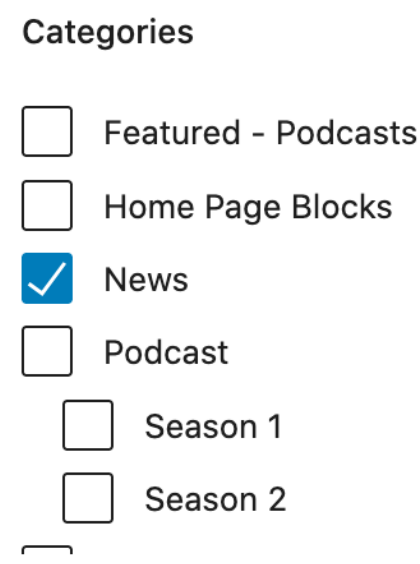

Add New Category

Clicking the View All News button on this home page section will navigate to a page that displays all posts that have been categorized with the category News. This is handled dynamically, and all that needs to be done to add posts there is to categorize posts as News.

Note: The home page block post for EWN News uses custom fields to display the latest news posts in its sidebar. The custom fields for this post should NOT be modified, with the exception of the link_text custom field if a different button label is desired (see Section 6.1 for more on custom button text). 


\subsection{Adding searchable tables}

In some cases, it is useful to have a table of searchable and sortable entries, such as large collections of publications or other records (Figure 43). Tables such as these are used in multiple places across the site, and more tables can be easily added.

Figure 43. Table example: “Workshops \& Presentations.”

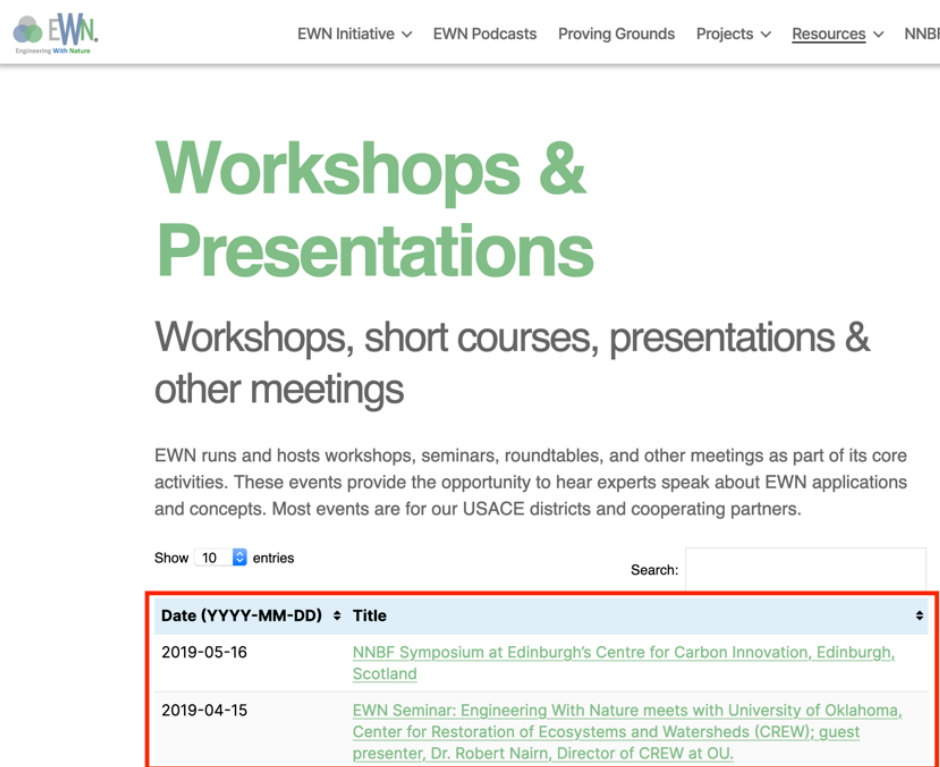

To add a table of data, log into the admin interface by going to https://ewn.erdc.dren.milwp-admin and clicking on TablePress in the sidebar. From here, a list of all existing tables is visible (Figure 44).

Figure 44. All tables.

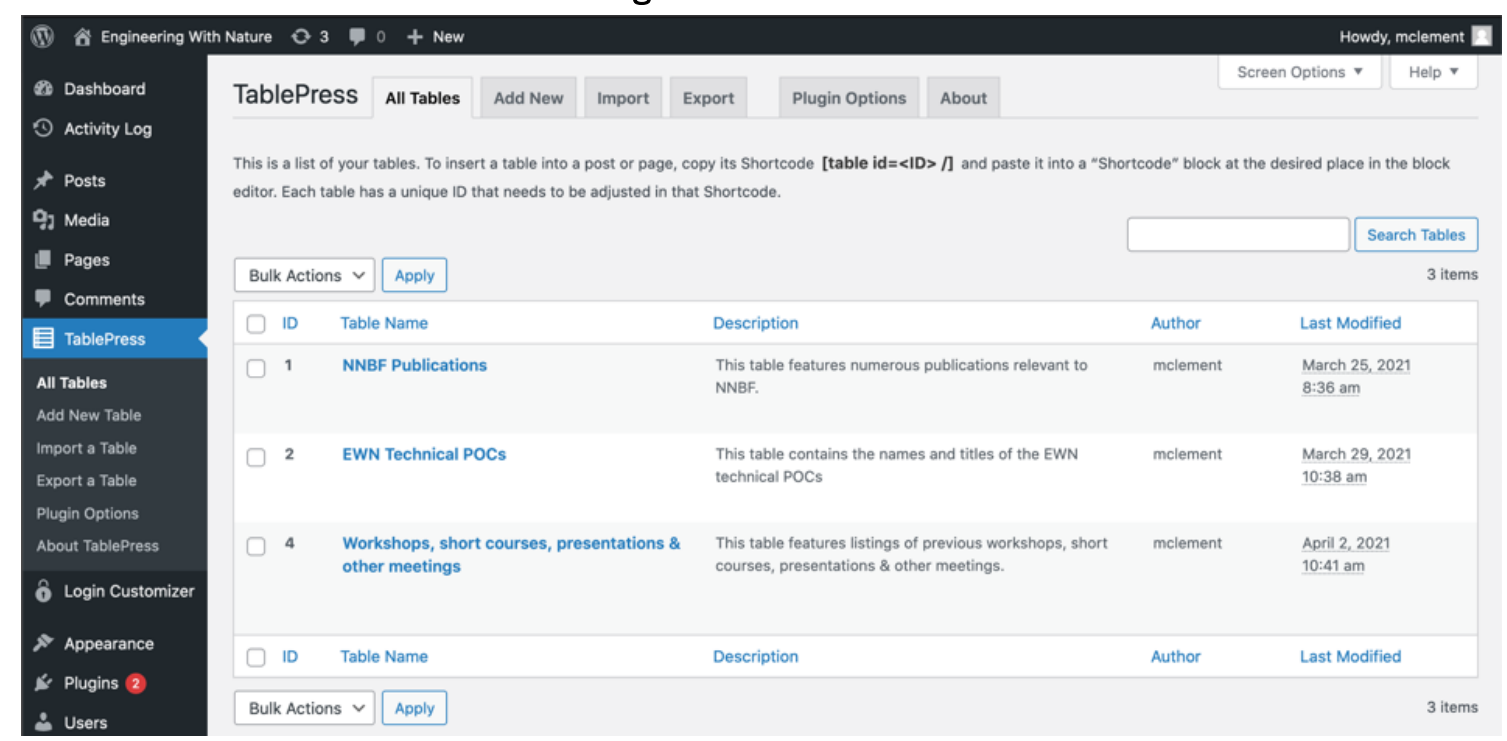


Clicking on a table's name will allow the user to edit the contents of the table. To create a new table, click Add New in the tab list at the top of the screen. This will take the user to a screen where they can name their new table, add a description, and create the empty table with the desired number of rows and columns. All of this information can be edited later. Click Add Table at the bottom of the screen to generate the new table (Figure 45).

Figure 45. Create new table.

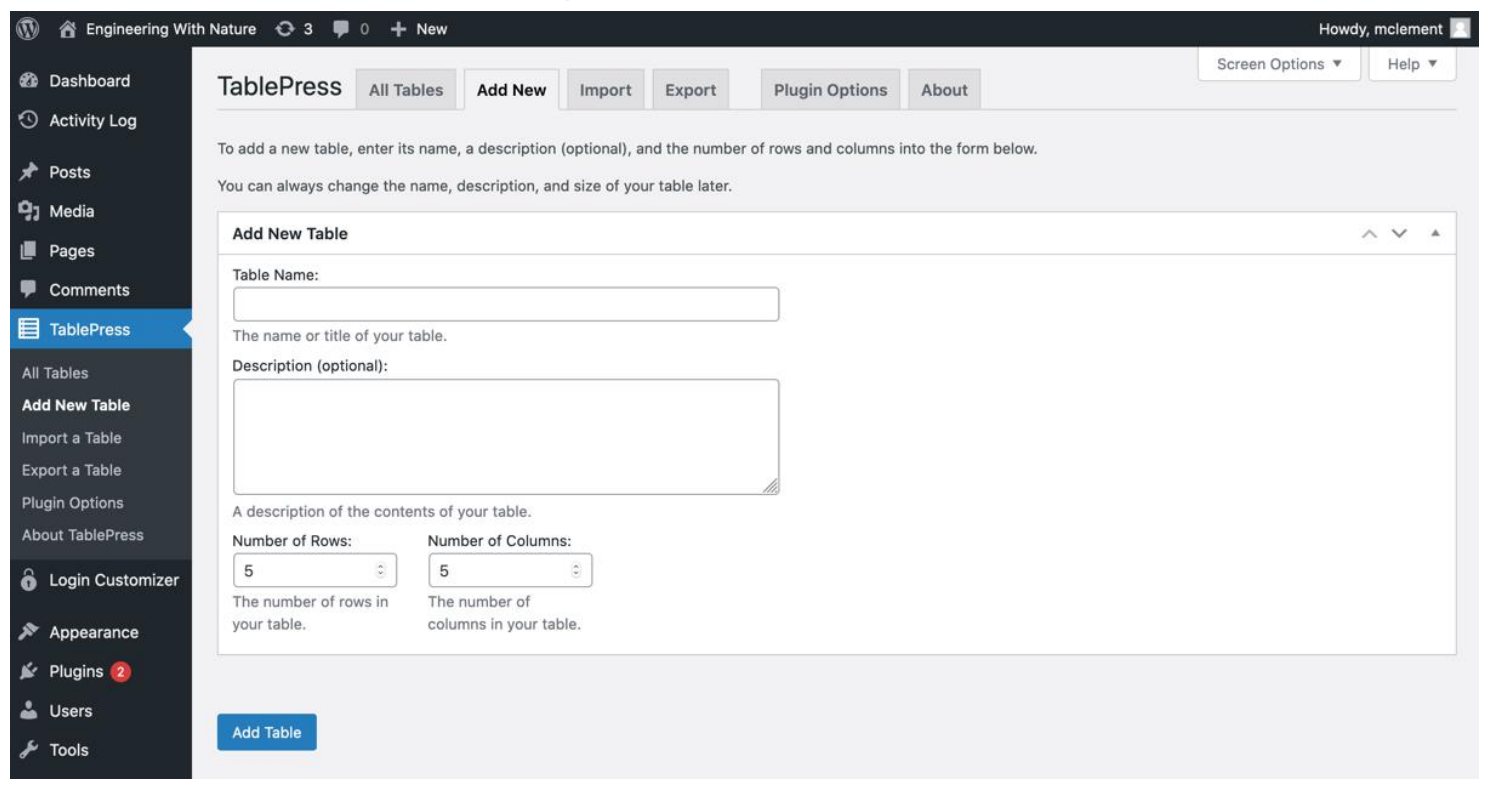

After creating the new table, the user is taken to a screen where they can input data and configure more advanced table settings (Figure 46). 
Figure 46. Edit a table.

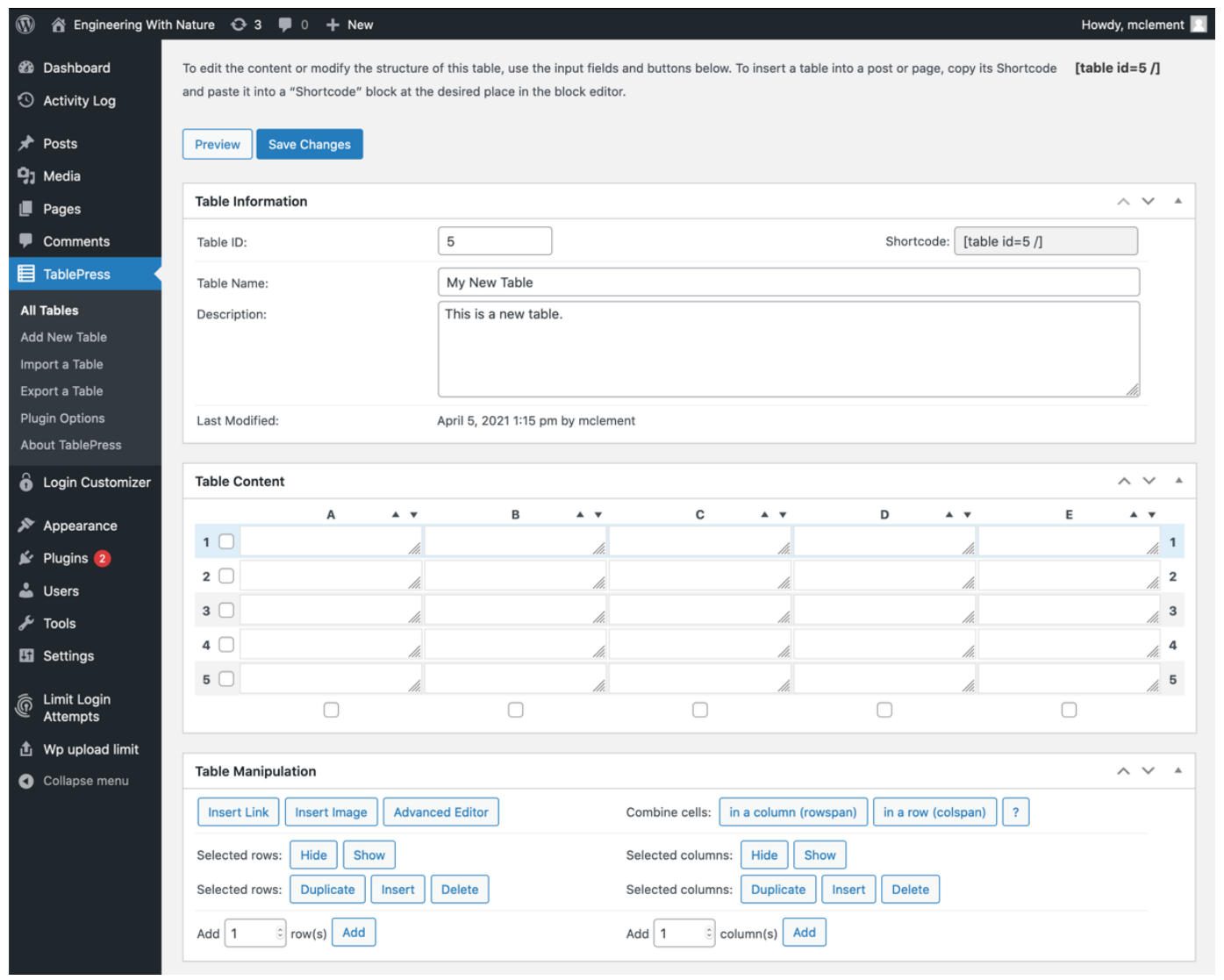

To add data to the table, simply fill in cells with the desired content. By default, the first row of the table acts as the header, so any data entered in those cells will be treated as column titles. This can be disabled by unchecking the Table Head Row setting on this screen.

When the table has been filled out, click Save Changes (located at the top AND bottom of the edit screen). When the table is saved, copy the Shortcode to embed the table into a post or page. A shortcode is a special reference that will point to this table, and it takes the form

\section{[table id $=x]$}

The variable " $\mathbf{x}$ " is the specific ID of the table. This shortcode is displayed at the top of the table edit screen and can be copied and pasted directly into a post to embed the table (Figure 47). 
Figure 47. Embed table shortcode in a post or page.

\begin{tabular}{|c|c|c|}
\hline \multicolumn{2}{|c|}{ Table Information } & $\wedge \vee$ \\
\hline Table ID: & Shortcode & [table id $=4 /$ ] \\
\hline Table Name: & \multicolumn{2}{|c|}{ Workshops, short courses, presentations \& other meet } \\
\hline Description: & \multicolumn{2}{|c|}{$\begin{array}{l}\text { This table features listings of previous workshops, short } \\
\text { courses, presentations \& other meetings. }\end{array}$} \\
\hline Last Modified: & \multicolumn{2}{|l|}{ April $2,202110: 41$ am by mclement } \\
\hline
\end{tabular}

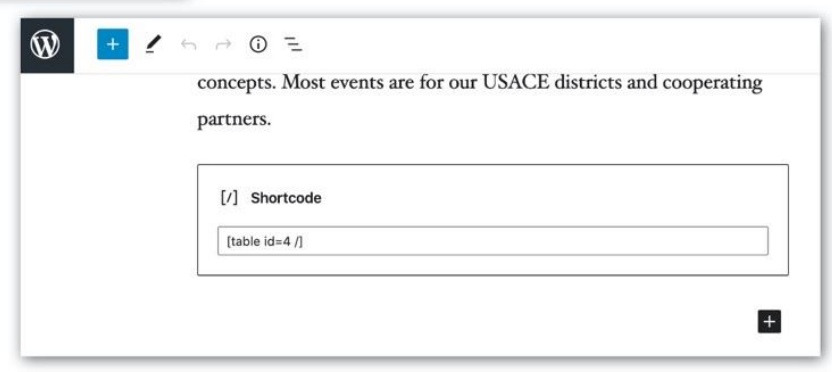

After pasting the shortcode into a post or page, save the post or page and exit the editor interface to view the page. The shortcode will automatically expand into the specified table (Figure 43).

\subsection{Adding custom forms}

This section covers how to create a custom form, useful for event registrations or collecting other information, such as user inquiries or book orders (see, for example, Figure 48). 
Figure 48. Example: Atlas Order Form.

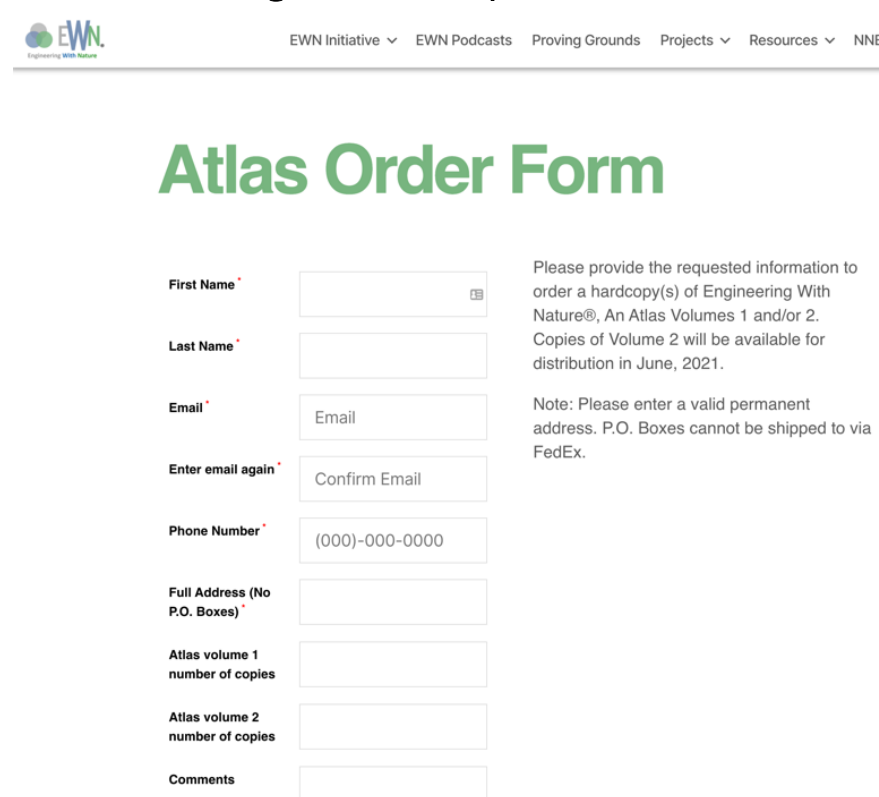

To create a form, sign in as an administrative user and click on the Registration Magic option in the sidebar (Figure 49).

Figure 49. Registration Magic tool.

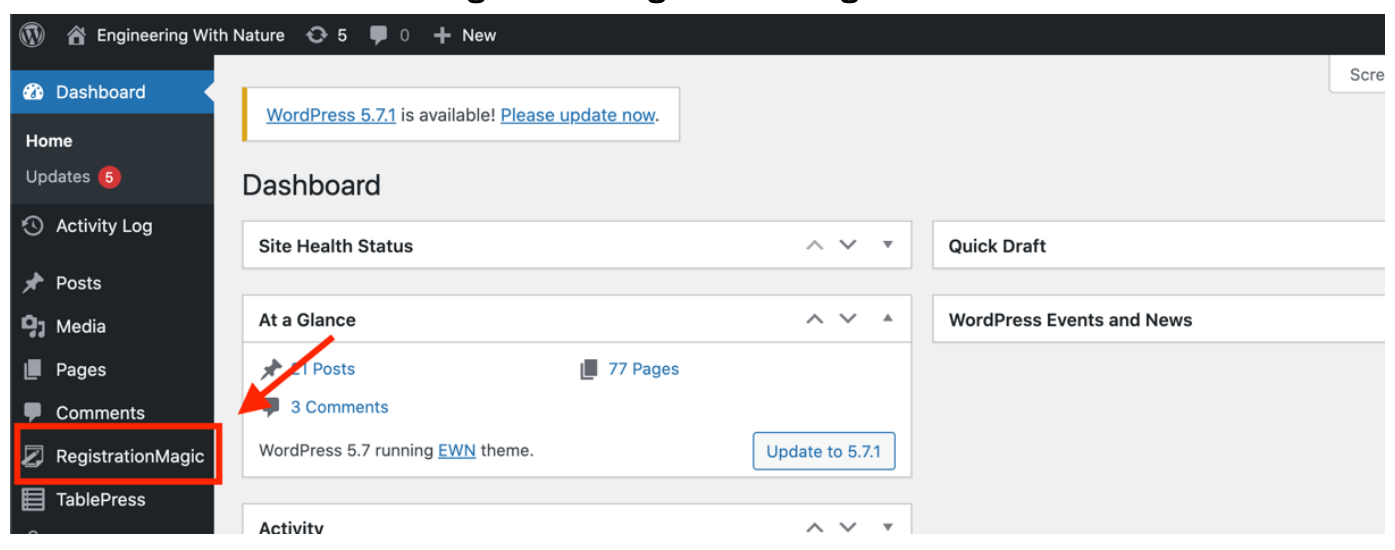

From there, select New Form to create a new form (Figure 50). 
Figure 50. Create a new form.

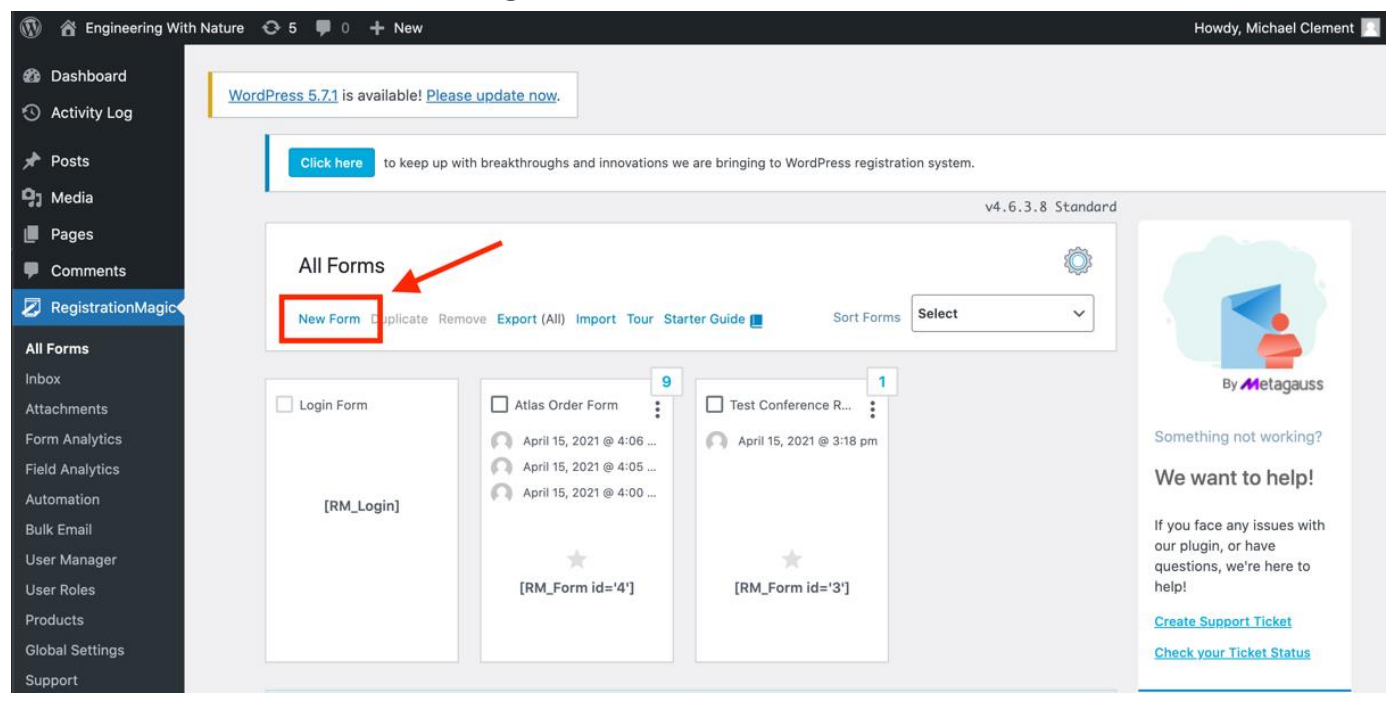

A popup will appear asking for a form name. Name the form and check the box that says, "Turn off user registration with this form" (Figure 51).

Figure 51. Name a new form.

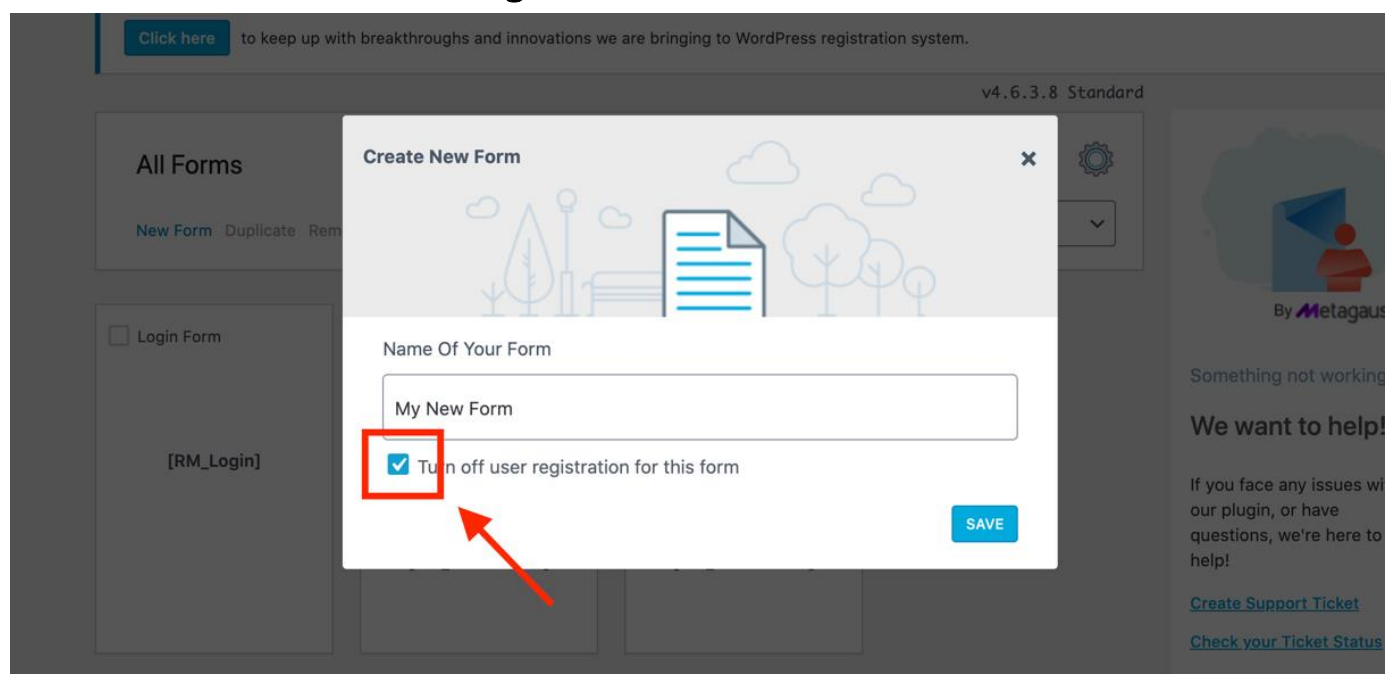

Once the form is named, click Save. Then, hover over the newly added form and click Fields to configure the information you want to collect from users (Figure 52). 
Figure 52. Configure form fields.

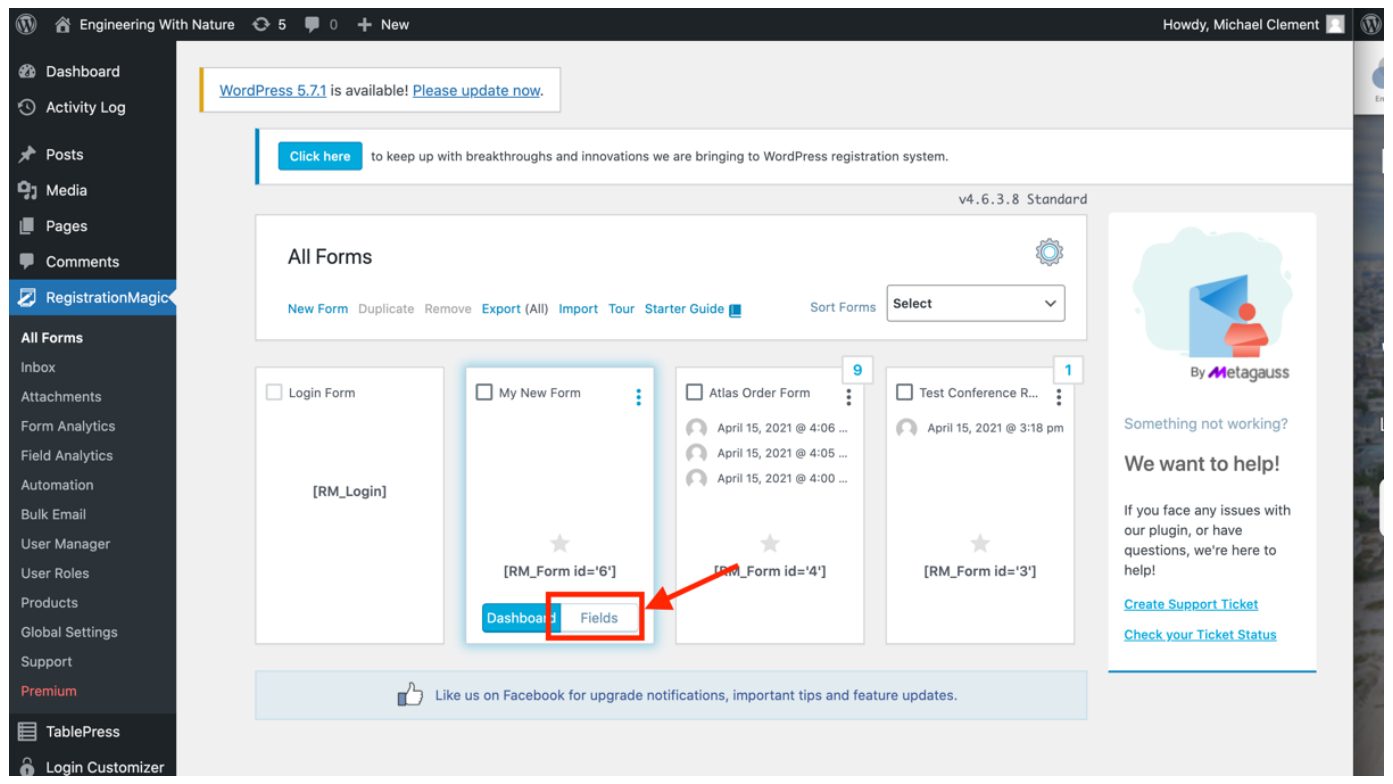

After clicking the Fields button, you will be taken to a screen where you can add various fields to the form, such as name, email, phone number, and more. To add fields, click the Add Field button in the upper left of the screen (Figure 53).

Figure 53. Adding fields to a form.

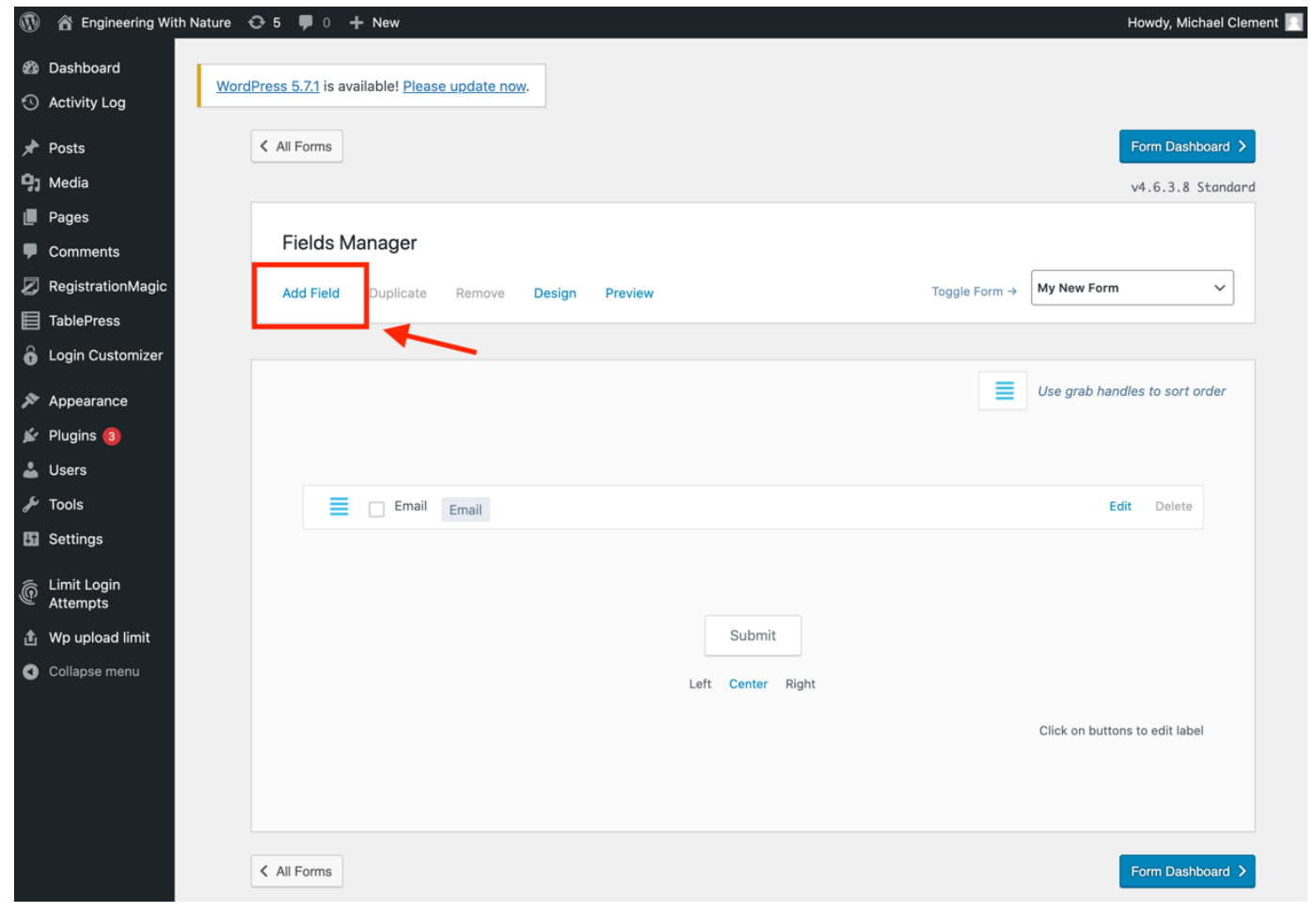


Clicking this button will open a pop-up with a list of form fields to choose from. Click on the desired field name, and it will open a configuration screen. Take note of the Advanced Settings button at the bottom of the configuration screen (Figure 54).

Figure 54. Form field customization.

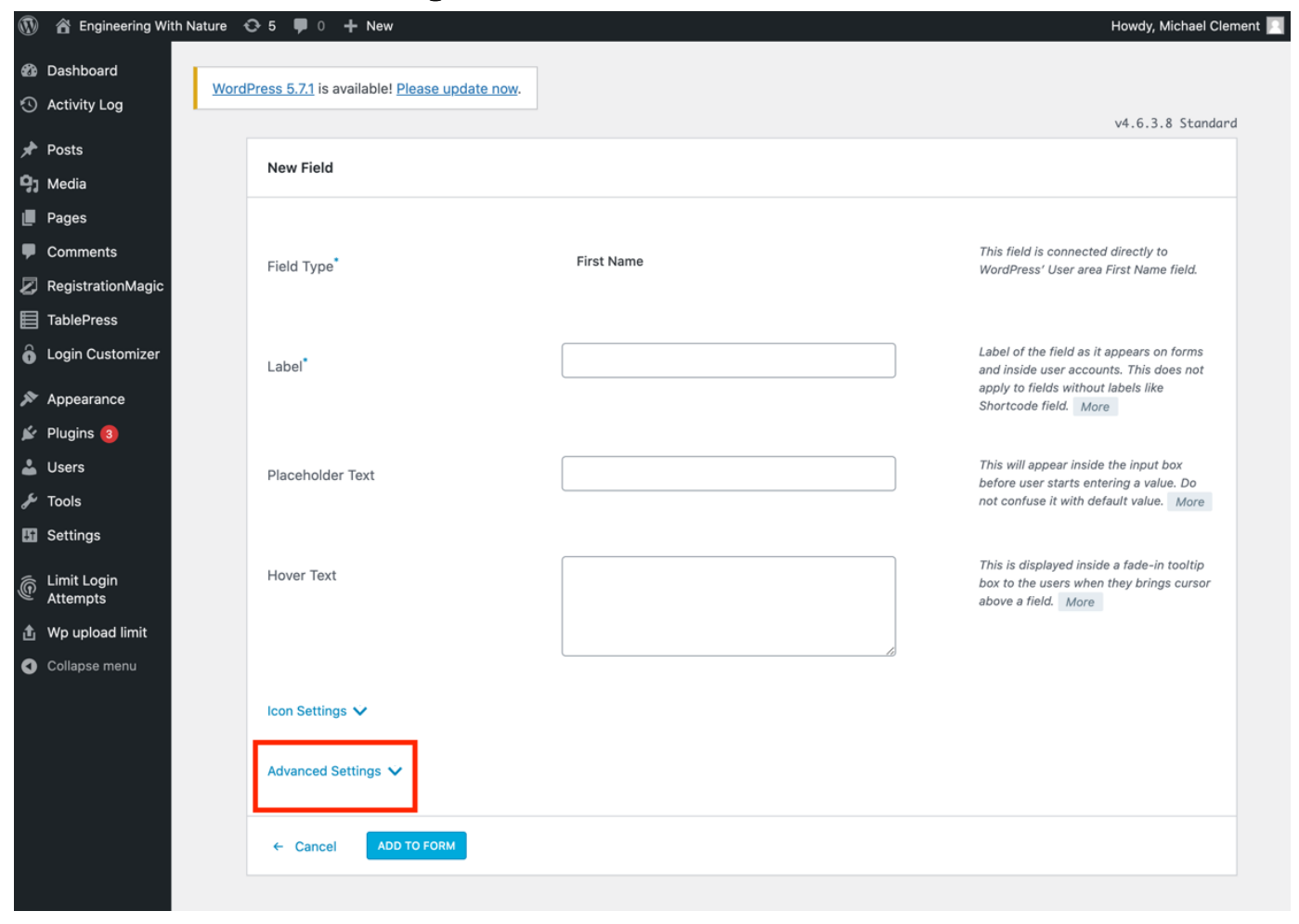

On this configuration screen, configure the field as necessary (i.e., provide a custom label or some placeholder text). If the field is a required field, click Advanced Settings and then click the checkbox labeled Required Field. Once the field is configured, click Add To Form at the bottom of the configuration screen.

At this point, the new field will display in the fields manager. Once all fields are added, click the blue Form Dashboard button in the top right of the screen (Figure 55). 
Figure 55. View form dashboard.

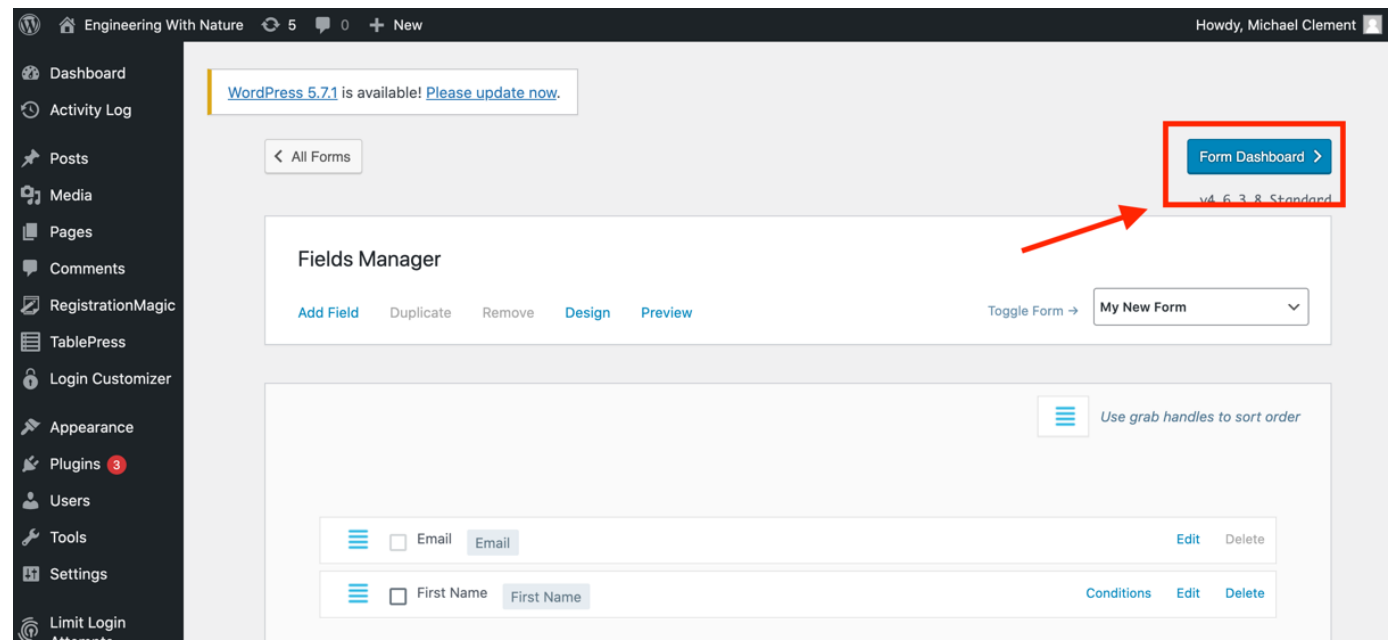

The form dashboard screen can also be accessed by clicking Registration Magic in the sidebar and clicking Dashboard when hovering on the desired form. The form dashboard page houses all the information relating to the form, including all submissions and the Shortcode used to embed the form into a post or page (Figure 56). A shortcode is a special reference that will point to this table, and it takes the form:

\section{[RM_Form id='x']}

The variable " $\mathbf{x}$ " is the specific ID of the form.

Figure 56. Form dashboard.

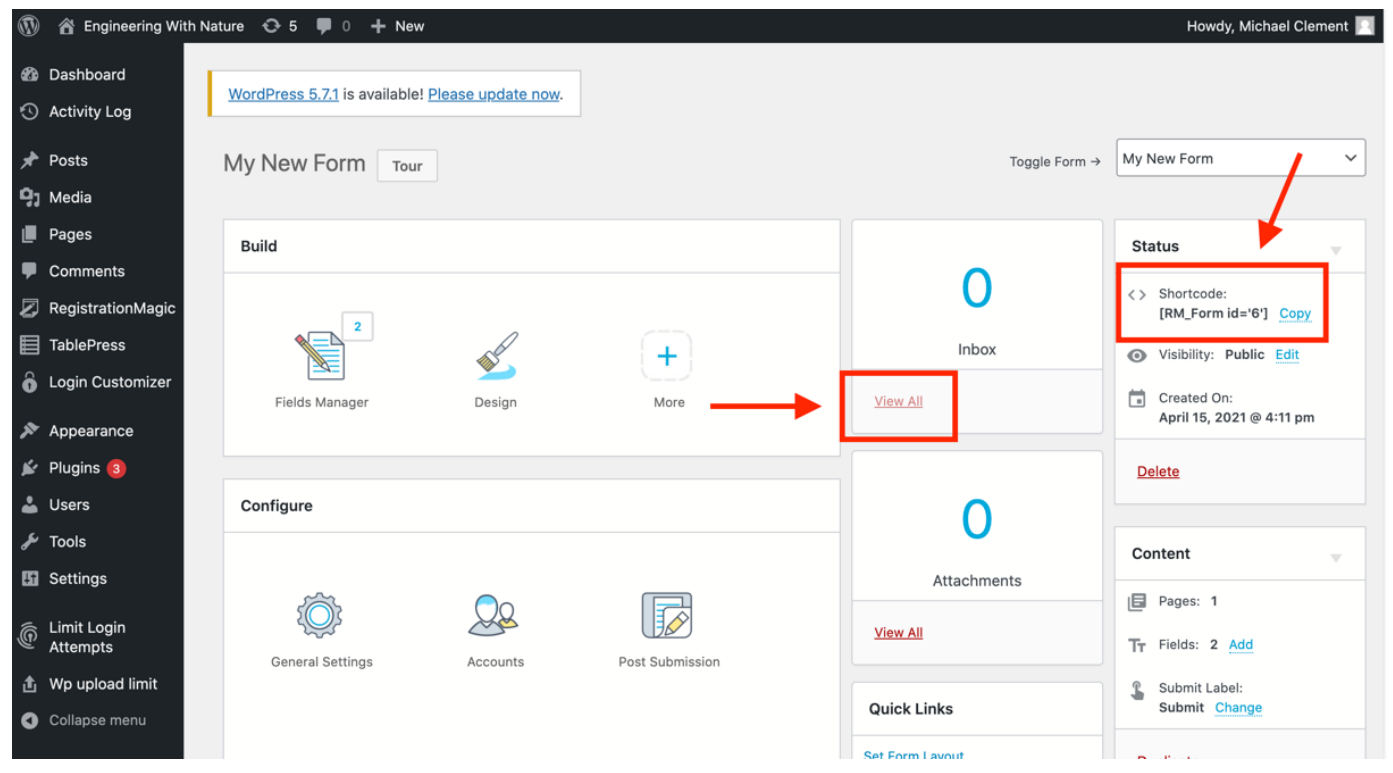


The View All button will display all submissions a form has received. This is where you go to collect the information users have submitted. The shortcode for the form is located in the upper right of the dashboard (as seen in Figure 56).

To place the form on a page so users can submit it, copy the shortcode from the form's dashboard and paste it into a new or existing page (Figure 57) (for more on creating pages, see Section 3.1).

Figure 57. Add form shortcode to page.

(1)

$+1 \leftrightarrow \rightarrow \oplus \equiv$

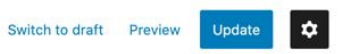

Atlas Order Form

\begin{tabular}{|c|c|c|}
\hline बा $: \vdots \hat{\imath}$ & $\equiv$ & B $1 \leftrightarrow$ \\
\hline [RM_Form id & & \\
\hline
\end{tabular}

Please provide the requested

information to order a hardcopy(s) of

Engineering With Nature ${ }^{\circledR}$, An Atlas

Volumes I and/or 2. Copies of Volume

2 will be available for distribution in

June, 2021.

Note: Please enter a valid permanent

address. P.O. Boxes cannot be shipped

Switch to draft Preview Update

Page Block

Start with the building block of all Start with the
narrative.

Typography

Font size

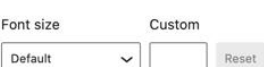

Color settings

Text settings

Drop cap

Toggle to show a large initial letter.

Advanced

\subsection{Adding slideshows}

To add an animated slideshow to a page or post, use the MetaSlider plugin (found in the plugins section of the admin dashboard) to create a blank slideshow (Figure 58). 
Figure 58. Create new slideshow.

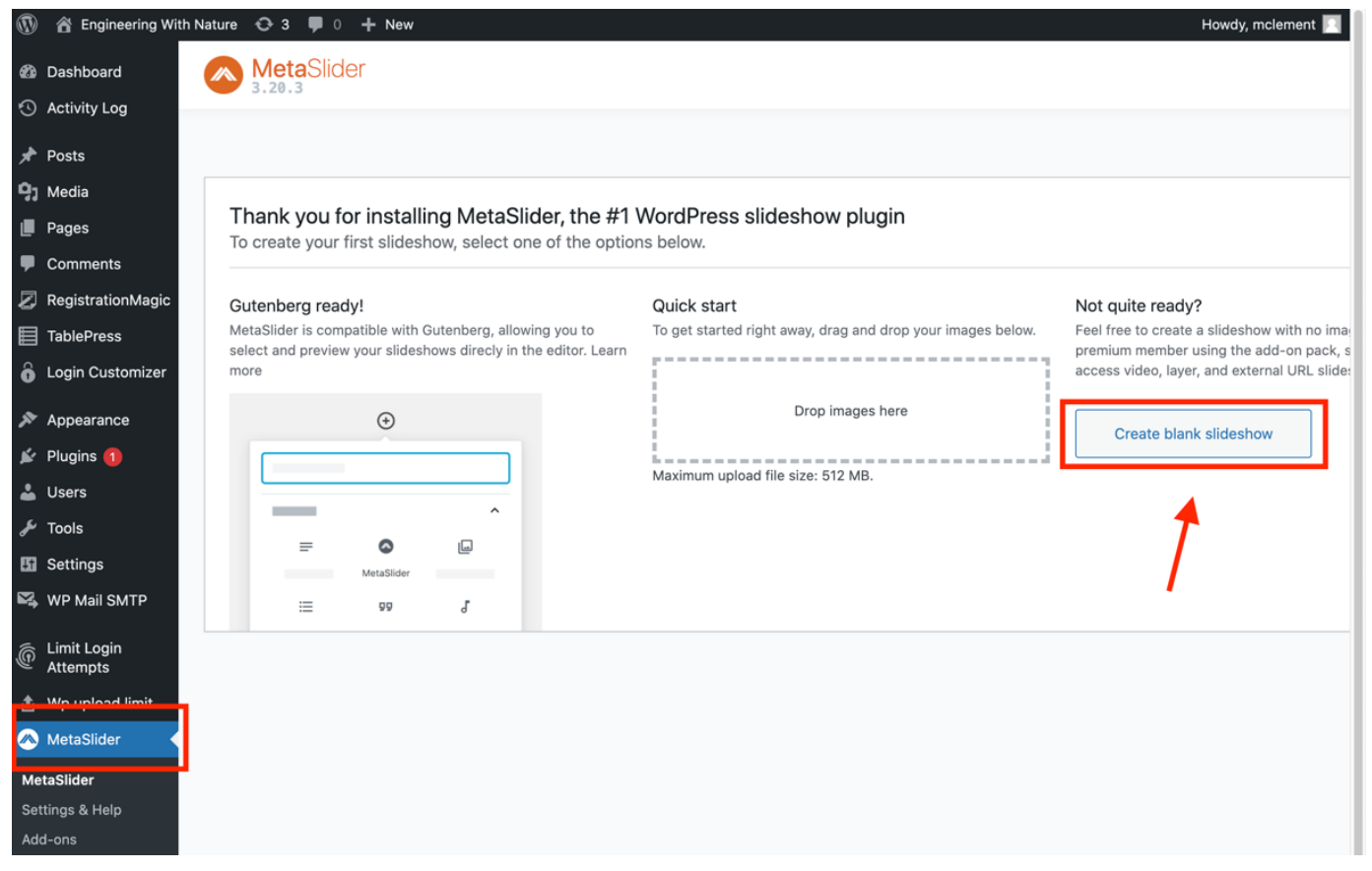

Next, click Add Slides (Figure 59).

Figure 59. Add to slideshow.

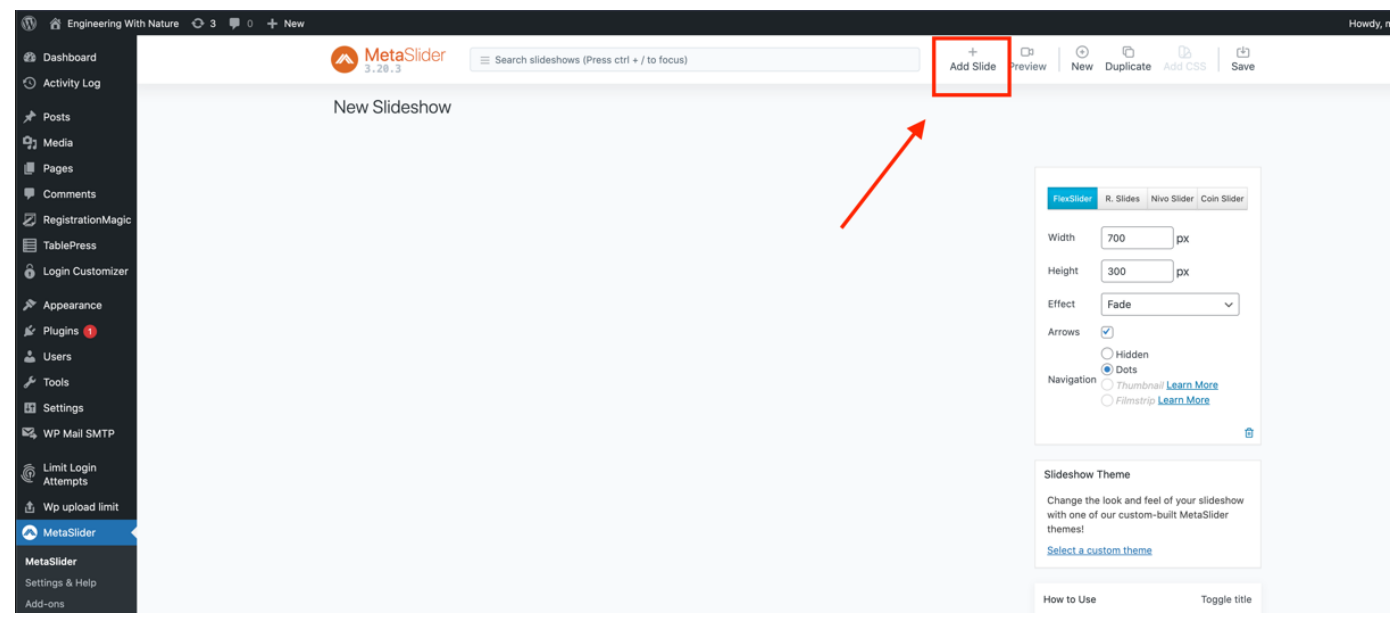

From there, either drag in new media files from the computer or select images from the media library, then click Add to slideshow (Figure 60). 
Figure 60. Add slides to slideshow.

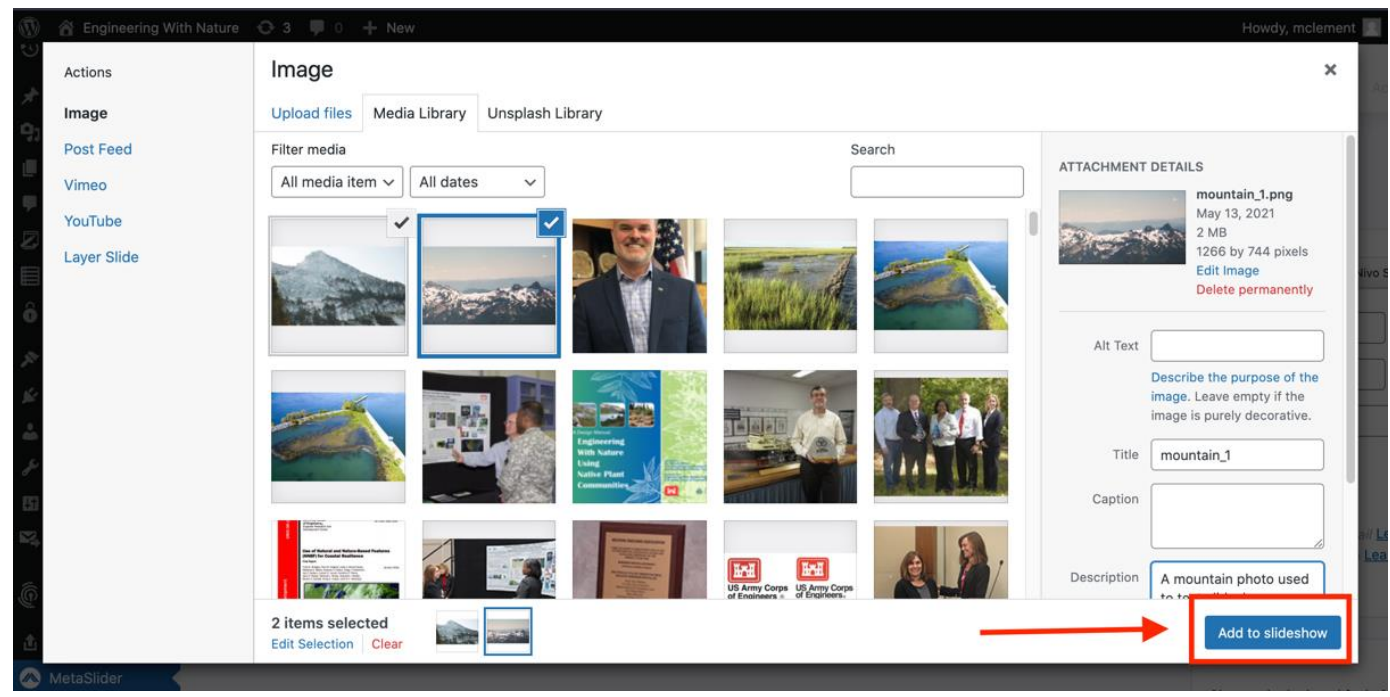

After selecting the images, make any edits to their captions and information and click the save button (Figure 61).

Figure 61. Save slideshow.

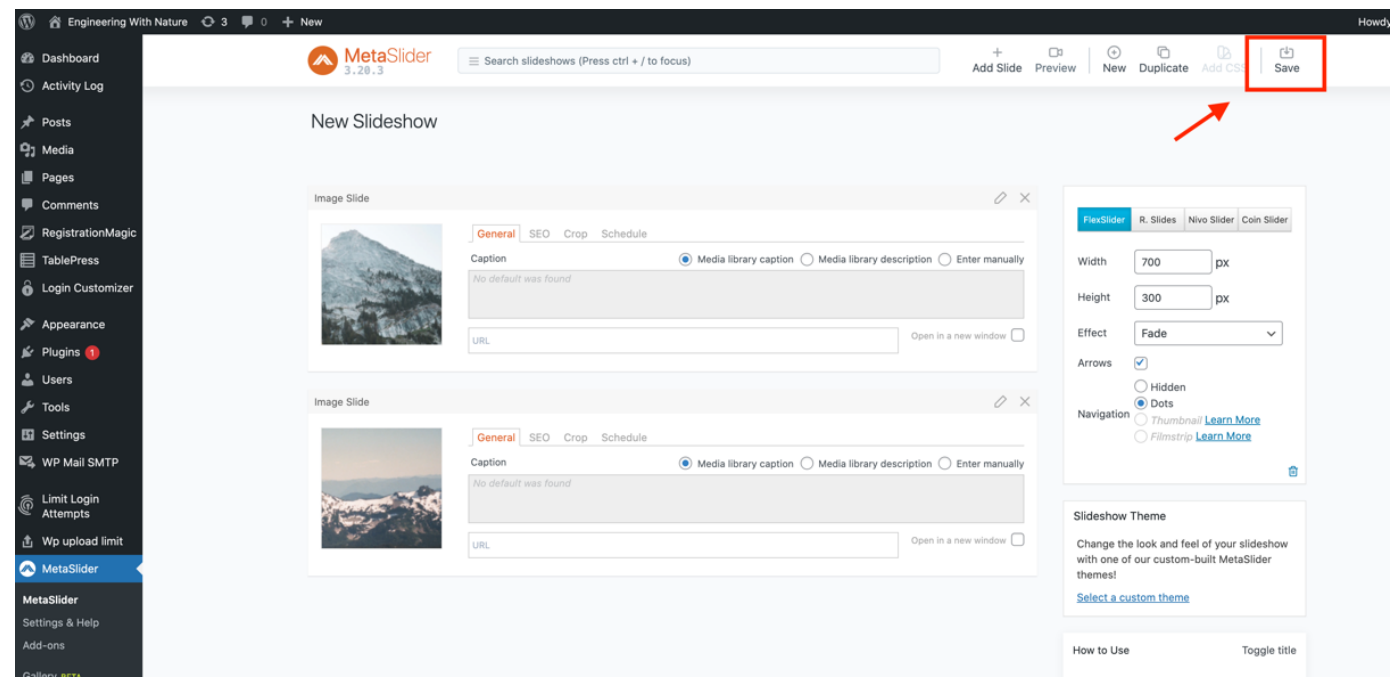

Once the slideshow is configured, paste the shortcode into the desired page or post (Figure 62). This will result in the slideshow appearing in the content of the post (Figure 63). 
Figure 62. Copy slideshow shortcode.

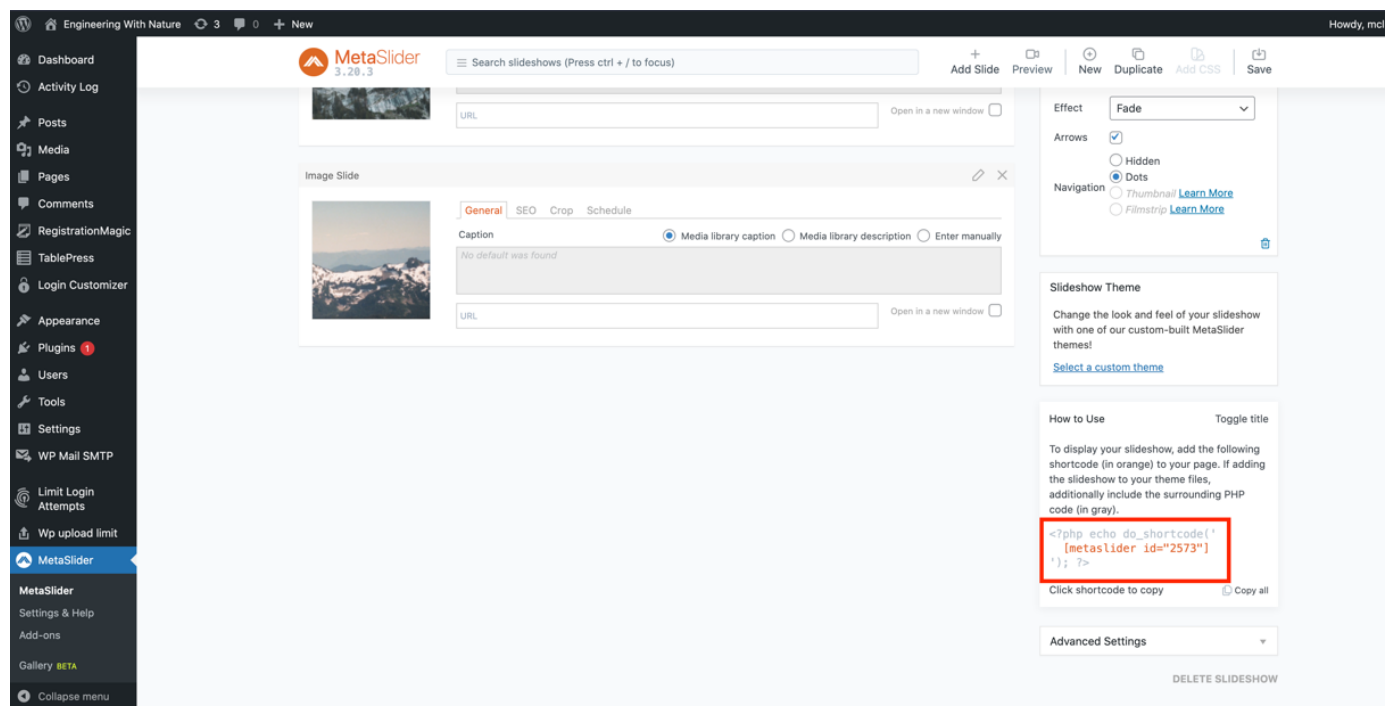

Figure 63. Slideshow in a post.

EWN. EWN Initiative $\vee$ EWN Podcasts Proving Grounds Projects $\vee$ Resources $\vee$ NNBF $\vee Q$

\section{Slideshow Test}

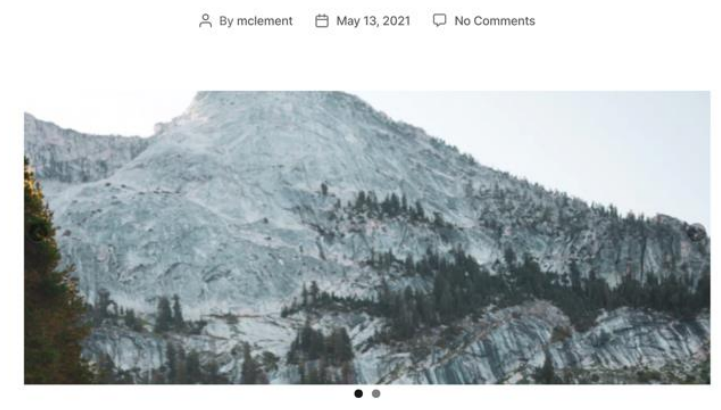

\subsection{Configuring SMTP for email notifications (WP Mail SMTP plugin)}

To configure Secure Mail Transfer Protocol (SMTP) settings (which should only have to be done once), navigate to the WP Mail SMTP plugin in the admin interface and scroll down to the Mailer section. From there, select Other SMTP and then fill in the details as pictured in Figure 64 below. 
Figure 64. Configure SMTP mail settings.

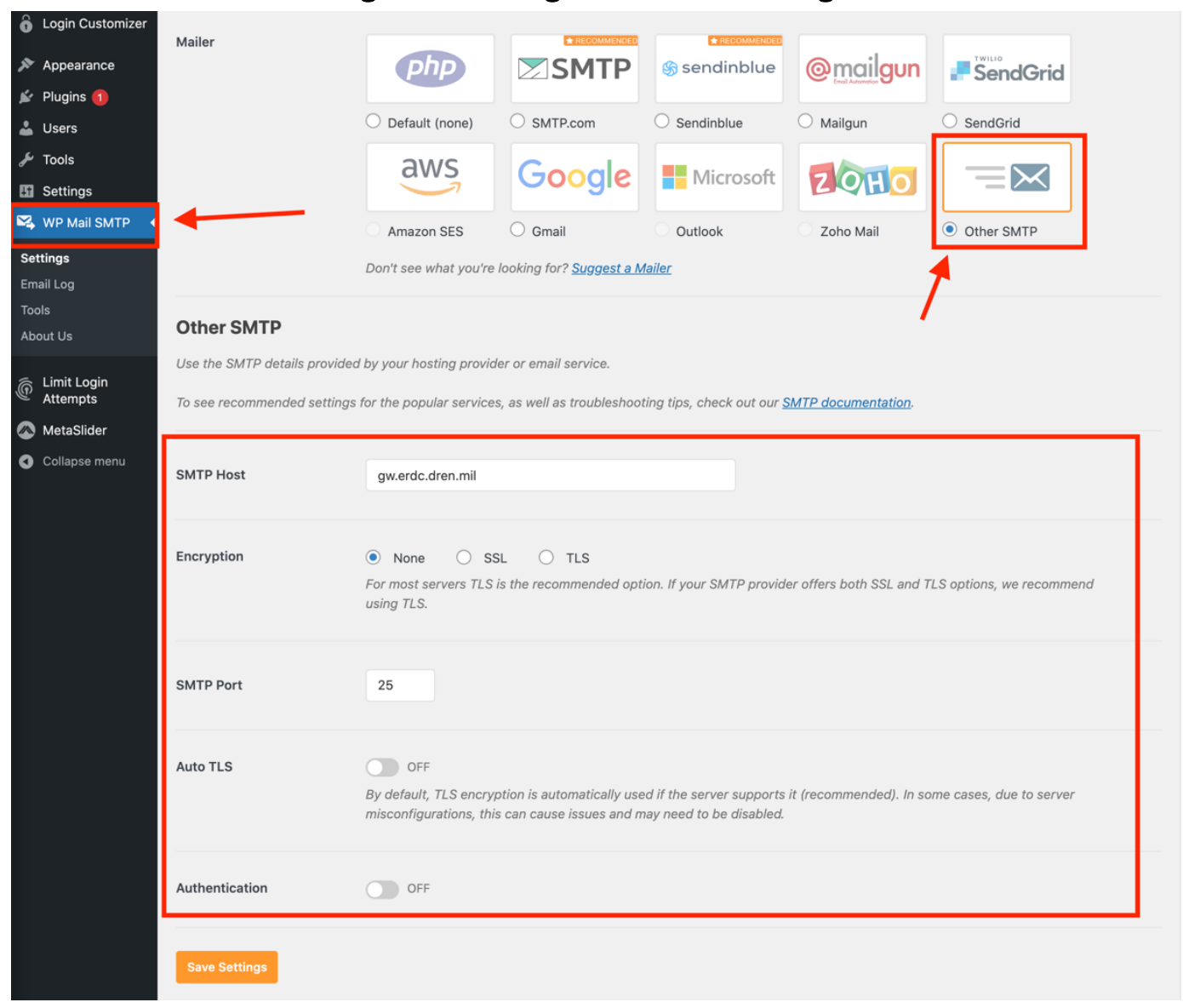

Once these settings are configured, plugins and behaviors that rely on SMTP (such as inquiry form submissions) will automatically use SMTP to send emails. 


\section{Moderation}

This section will cover the moderation tools that are included in the EWN WordPress site.

\subsection{Reviewing pending posts and pages}

When a post or page is created, it can be saved as a draft and marked with the Pending Review checkbox (Figure 65).

Figure 65. Mark post or page as pending review.

(1)

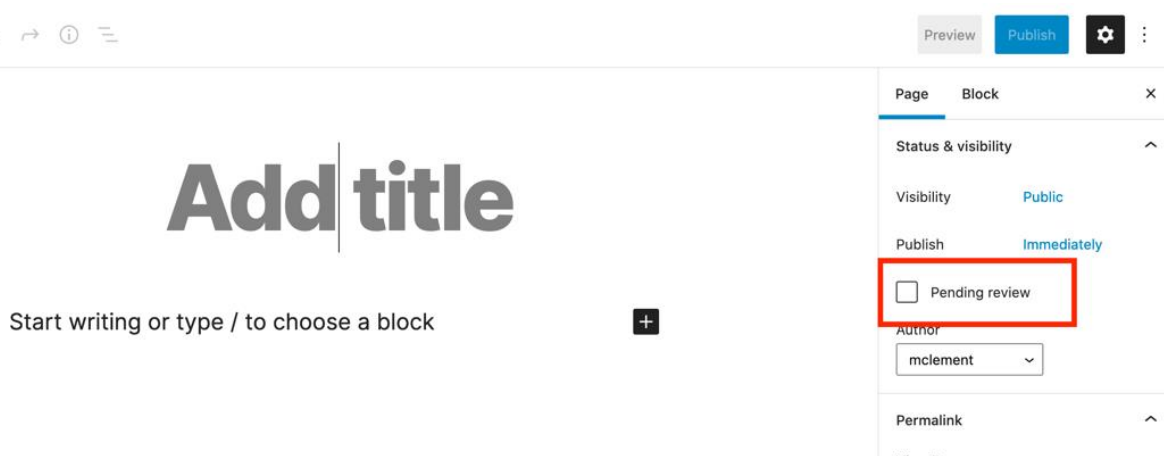

When this box is checked, the post or page will display in the admin interface under the Pending filter (Figure 66).

Figure 66. View pending posts.

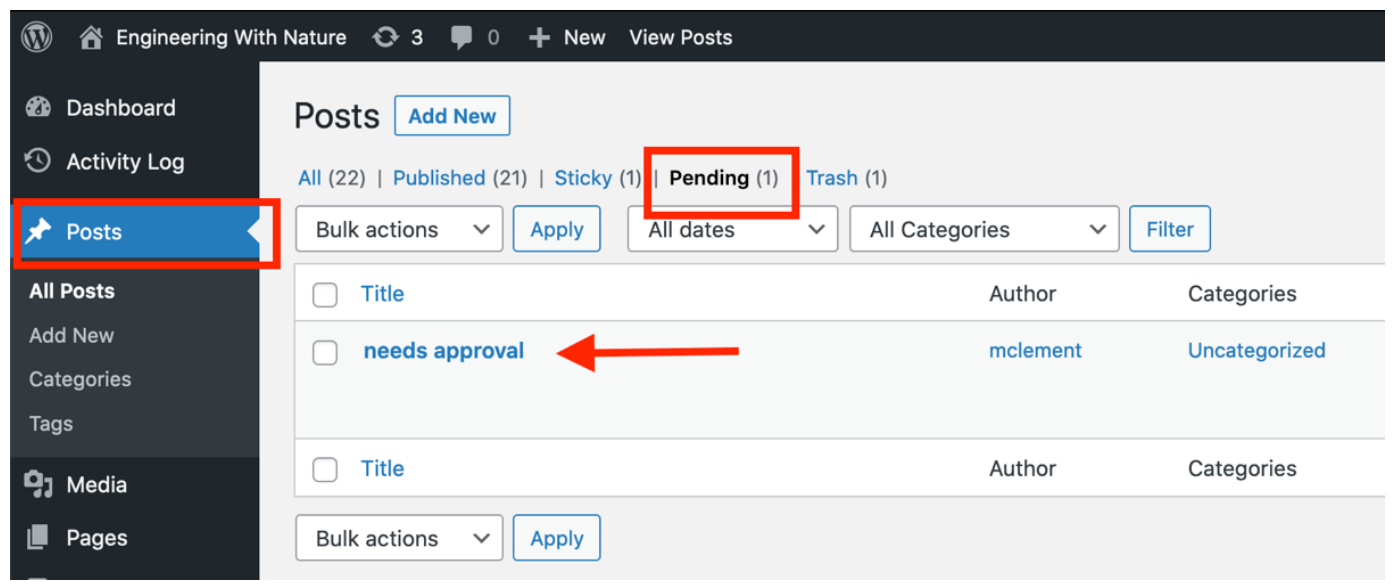

From this screen, select the post or page and, after making the appropriate edits and reviews, uncheck the Pending Review checkbox and publish, or simply publish the post or page by clicking the big, blue Publish button in the top right of the editor. This will move it from Pending to Published. 


\subsection{User activity logs}

User activity logs are available in the admin interface and allow administrators to view when changes are made to the site and who made the changes. This is helpful for identifying parties responsible for edits and for documenting any unapproved postings or changes that might have been made by a malicious actor. On this page, activity is displayed along with the content that was affected, the username that made the change, the user's IP address, and other relevant information (Figure 67).

Figure 67. Activity log.

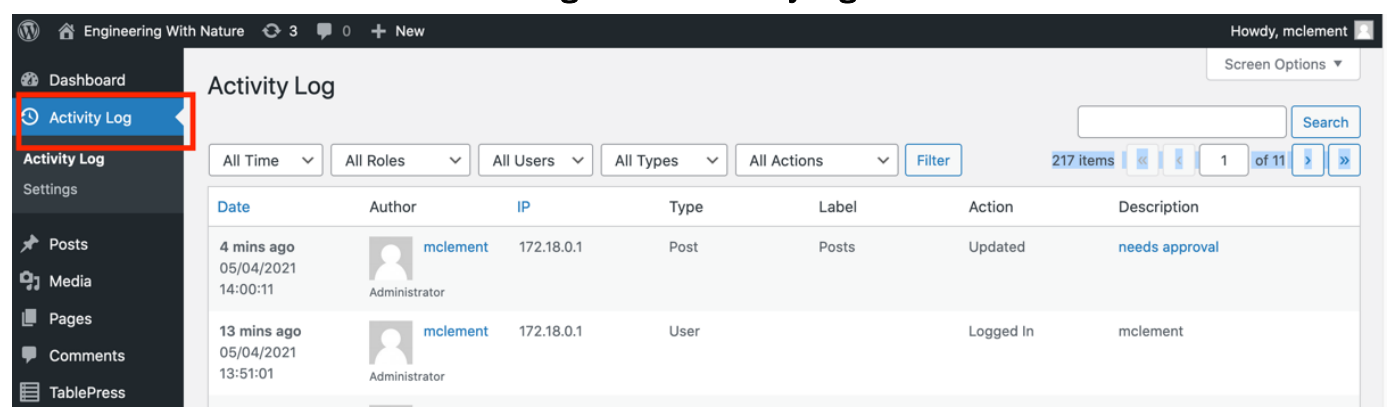

\subsection{Comment moderation}

Comments can be left on the site by visitors who have provided a name and email address. If a user posts a comment for the first time, it is not automatically posted to the site but, first, must be approved in the admin interface. To view all comments, $\log$ in as a privileged user and go to the Comments section (Figure 68).

Figure 68. All comments.

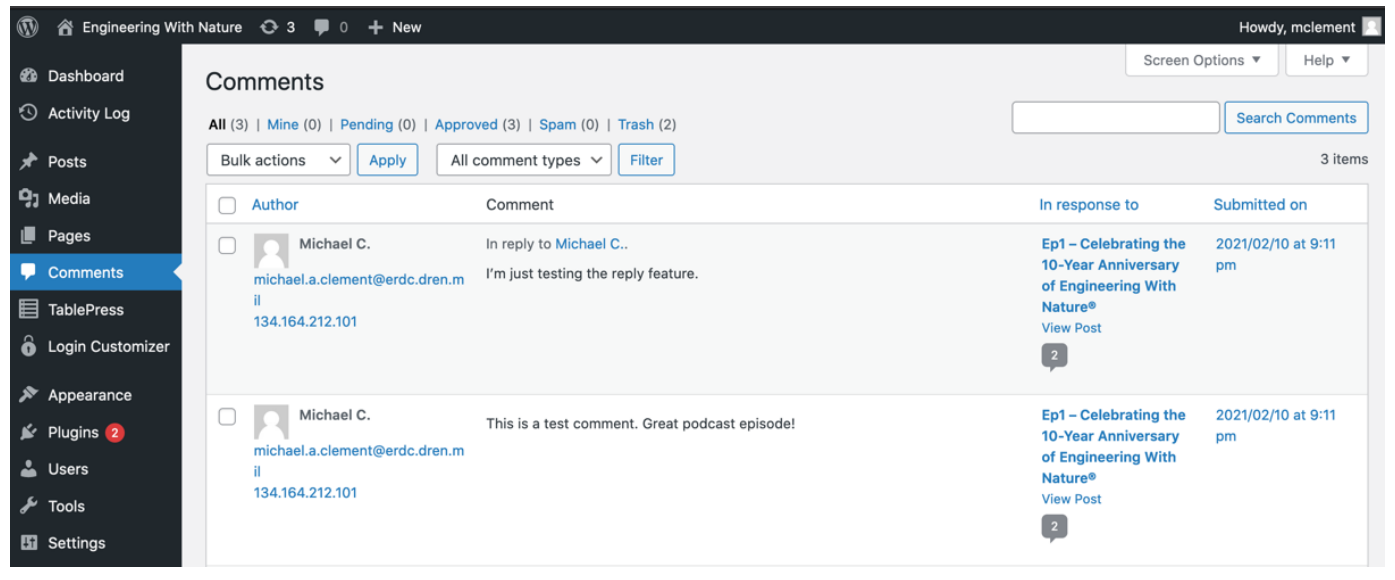


From this screen, comments can be deleted, approved, or marked as spam. After a commenter has received approval for their first comment, their future comments will automatically post without need for approval. However, this can be changed by adjusting the comment settings. To adjust the comment settings, click on Settings -> Discussion in the administrative sidebar (Figure 69).

Figure 69. Comment settings.

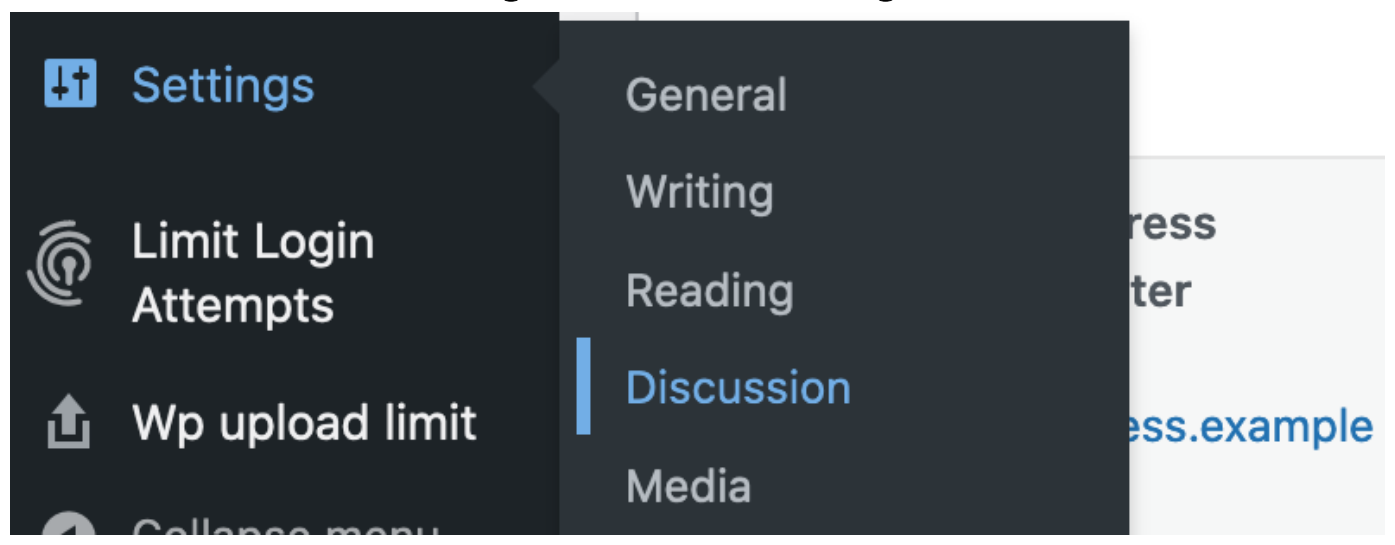

On this screen, additional comment safeguards can be put in place, including a word blacklist for disallowed words and phrases. If a comment contains words or phrases that are blacklisted, it can be automatically put in the trash. This is helpful for preventing spam comments that may be posted to the site. To add to the blacklist, go to the comment settings (Settings -> Discussion) and scroll down to Disallowed Comment Keys. In this text field, enter words or phrases (one per line) that are blacklisted (Figure 70). When finished, click the blue Save Changes button at the bottom of the screen.

Figure 70. Comment moderation blacklist.
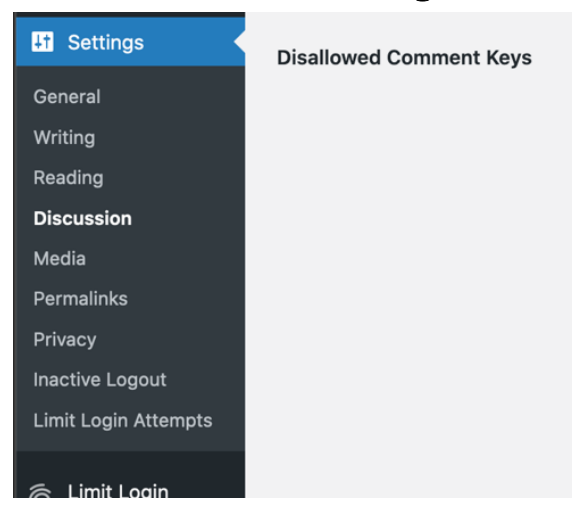

When a comment contains any of these words in its content, author name, URL, email, IP address, or browser's user agent string, it will be put in the Trash. One word or IP address per line. It will match inside words, so "press" will match "WordPress". 


\subsection{User accounts}

In order to make posts, pages, and moderate or update content, users need to have an account. Accounts have varying levels of privilege, which restricts account holder actions in specific ways. There are five different roles a user account may have-from least to most privilege, they are

1. Subscriber-This user is only permitted to change settings and information that pertains to their user profile.

2. Contributor-This user can write posts and edit or delete posts that belong to them but cannot publish a post.

3. Author-This user can write, edit, delete, and publish their own posts.

4. Editor-This user can write, edit, delete, and publish posts belonging to them or any other user.

5. Administrator-This user can manage all administrative settings and features on the site and create or manage all content. This includes creating other user accounts and managing their roles.

To create a user account, $\log$ in as an administrator at https://ewn.erdc.dren.milwp-admin. From the admin interface, click on Users in the left-hand sidebar. From there, new users can be added by clicking Add New at the top of the page. This opens a form that requires a username and email address. The form generates a secure password for the user account, which must be given to the user to enable them to log in.

Existing users may be edited by selecting their usernames from the table of users (Figure 71). 
Figure 71 . View all users.

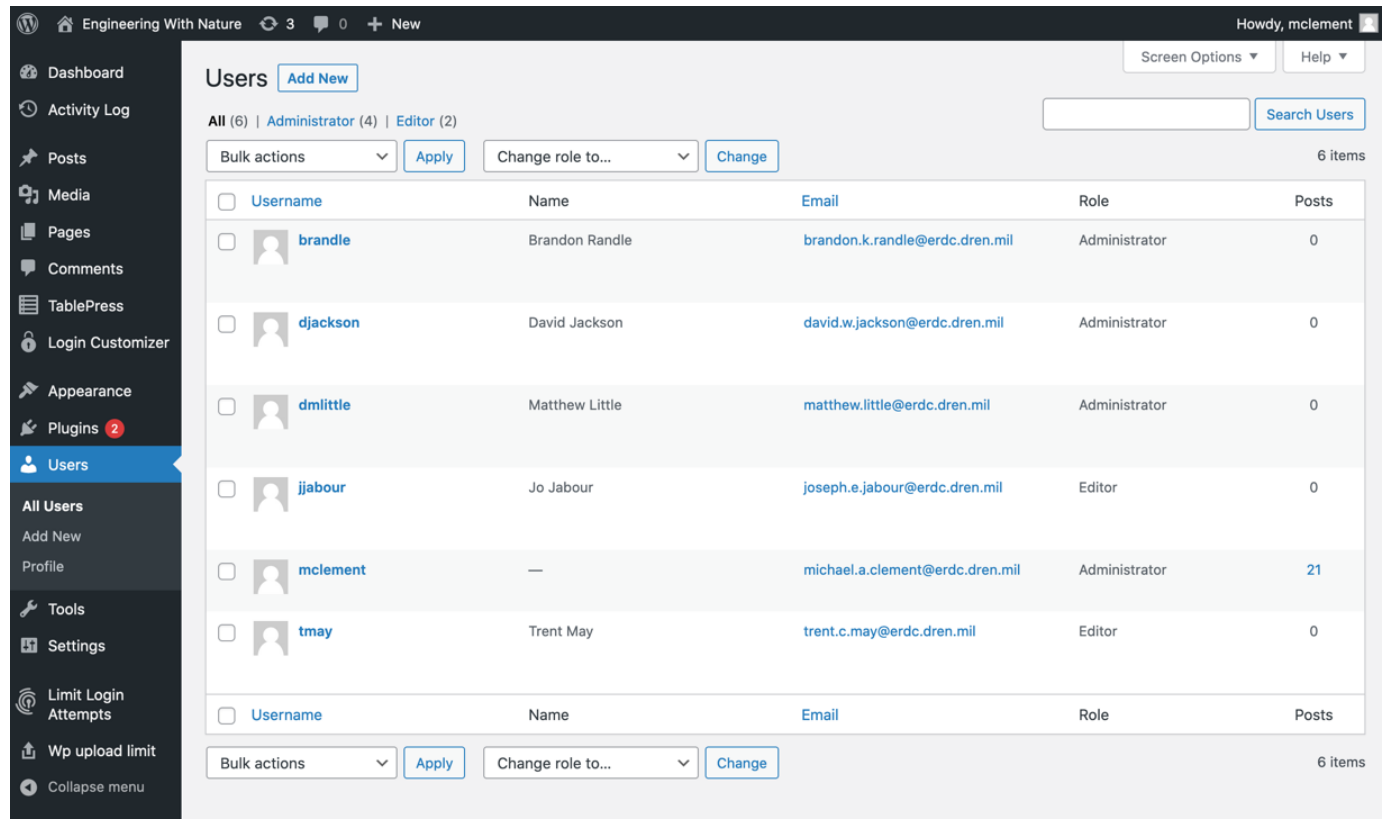

To change a user's role, click on their account and scroll down to Role.

From the dropdown, select the desired level of privilege based on the descriptions above. When a role has been selected, click Update User at the bottom of the page to save the changes. 


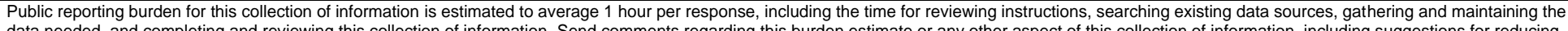

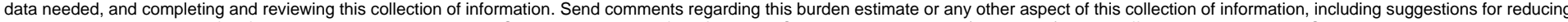

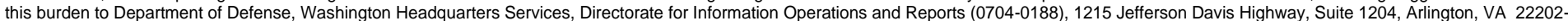

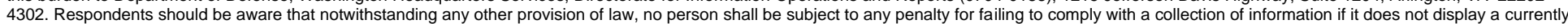
valid OMB control number. PLEASE DO NOT RETURN YOUR FORM TO THE ABOVE ADDRESS.

\begin{tabular}{l|l} 
valid OMB control number. PLEASE DO NOT RETURN YOUR FORM TO THE ABOVE ADDRESS. \\
\hline 1. REPORT DATE (DD-MM-YYYY)
\end{tabular}

\begin{tabular}{|c|c} 
O3--2022 & Final Report \\
\hline
\end{tabular}

\section{TITLE AND SUBTITLE}

Engineering With Nature Website User Guide

\section{DATES COVERED (From - To)}

5a. CONTRACT NUMBER

\section{5b. GRANT NUMBER}

\section{5c. PROGRAM ELEMENT}

\section{AUTHOR(S)}

Michael A. Clement

\section{5d. PROJECT NUMBER}

495371

5e. TASK NUMBER

5f. WORK UNIT NUMBER

8. PERFORMING ORGANIZATION REPORT NUMBER

7. PERFORMING ORGANIZATION NAME(S) AND ADDRESS
U.S. Army Engineer Research and Development Center (ERDC)

ERDC/ITL SR-22-2

Information Technology Laboratory (ITL)

Waterways Experiment Station, 3909 Halls Ferry Road

Vicksburg, MS 39180-6199

\section{SPONSORING / MONITORING AGENCY NAME(S) AND ADDRESS(ES)}

ERDC Environmental Laboratory

3909 Halls Ferry Road

Building 3270

Vicksburg MS 39180

11. SPONSOR/MONITOR'S REPORT NUMBER(S)

\section{DISTRIBUTION / AVAILABILITY STATEMENT}

Approved for public release; distribution is unlimited.

\section{SUPPLEMENTARY NOTES}

Civil Direct Funding Account Code U4376841

\section{ABSTRACT}

The Engineering With Nature (EWN) program is a high-profile effort that aims to deliver cost-effective, broadly beneficial solutions to natural re-source and sustainability challenges across the nation. A portion of this is accomplished through the use of the EWN website, which features news, podcasts, articles, and more. The content on the EWN website serves to educate and inform hundreds of visitors monthly. This content is generated and managed by EWN team members with web development experience, as it requires manually editing the website HTML and staging changes on a development server. With the EWN website 2.0, a new web-site framework (WordPress) has been implemented that will save content managers time and effort by providing a front-end user interface (UI) to enable the uploading, staging, and approval of new content for the website, along with a visual refresh to herald the impending release of season 2 of the EWN Podcast. This document's purpose is to demonstrate the functionality of the new EWN website and provide instructional material for those managing content via the new EWN website.

\section{SUBJECT TERMS}

Sustainable engineering-Research; Engineer Research and Development Center (U.S.)--Web sites; WordPress (Electronic resource)

\begin{tabular}{|c|c|c|}
\hline \multicolumn{3}{|c|}{ 16. SECURITY CLASSIFICATION OF: } \\
\hline $\begin{array}{l}\text { a. REPORT } \\
\text { Unclassified }\end{array}$ & $\begin{array}{l}\text { b. ABSTRACT } \\
\text { Unclassified }\end{array}$ & $\begin{array}{l}\text { c. THIS PAGE } \\
\text { Unclassified }\end{array}$ \\
\hline
\end{tabular}

NSN 7540-01-280-5500

17. LIMITATION
OF ABSTRACT
SAR

8. NUMBER OF PAGES

60 19a. NAME OF RESPONSIBLE PERSON

19b. TELEPHONE NUMBER (include area code) 